\title{
MÉTODOS PARA AVALIAÇÃO DO POTENCIAL FISIOLÓGICO DE SEMENTES DE MELÃO
}

SALVADOR BARROS TORRES

Tese apresentada à Escola Superior de Agricultura "Luiz de Queiroz", Universidade de São Paulo, para obtenção do título de Doutor em Agronomia, Área de Concentração: Fitotecnia.

\author{
P I R A C I C A B A \\ Estado de São Paulo - Brasil \\ Janeiro - 2002
}




\title{
MÉTODOS PARA AVALIAÇÃO DO POTENCIAL FISIOLÓGICO DE SEMENTES DE MELÃO
}

\section{SALVADOR BARROS TORRES}

Engenheiro Agrônomo

Orientador: Prof. Dr. JULIO MARCOS FILHO

\begin{abstract}
Tese apresentada à Escola Superior de Agricultura "Luiz de Queiroz", Universidade de São Paulo, para obtenção do título de Doutor em Agronomia, Área de Concentração: Fitotecnia.
\end{abstract}

\author{
PIRACICABA \\ Estado de São Paulo - Brasil \\ Janeiro - 2002
}




\section{Dados Internacionais de Catalogação na Publicação (CIP)}

DIVISÃO DE BIBLIOTECA E DOCUMENTAÇÃO - ESALQ/USP

\section{Torres, Sa lva dor Barros}

Métodos para a valiação do potencial fisiológico de sementes de melão / Salvador Barros torres. - - Piracicaba, 2002.

103 p.: il.

Tese (doutora do) - - Esc ola Superior de Agric ultura Luiz de Queiroz, 2002.

Bibliografia.

1. Condutivida de elétrica 2. Germinação de sementes 3. Melão 4. Potássio 5. Sementes I. Título

CDD 365.61

"Permitida a cópia total ou parcial deste documento, desde que citada a fonte - $\mathrm{O}$ autor" 


\section{A Deus,}

aos meus antepassados,

a minha avó, Inês Severiana (in memoriam),

aos meus pais, Francisco e Bertina,

aos meus irmãos, Nega, Rafa e Torres,

aos meus cunhados, Elvson e Quitéria,

aos meus queridos sobrinhos, Karine e Léo,

e a todos aqueles que são vítimas de injustiças e, que

por falta de oportunidade, permanecem na ignorância,

DEDICO. 


\section{AGRADECIMENTOS}

Ao Prof. Dr. Julio Marcos Filho, pela orientação e confiança em mim depositada.

À Escola Superior de Agricultura "Luiz de Queiroz" - USP e àEmpresa de Pesquisa Agropecuária do Rio Grande do Norte (EMPARN), pela oportunidade de realização do curso.

Aos Professores Sílvio Moure Cicero e Walter Rodrigues da Silva, pela atenção e ensinamentos durante o curso.

Ao Dr. José Flamarion de Oliveira, pela atenção e apoio durante o curso.

Às Engenheiras Agrônomas Ana D. C. L. Novembre, Evelyn F. A. Koch e Helena M. C. P. Chamma, pela colaboração e amizade.

Às funcionárias do Depto. de Produção Vegetal Ilze Helena C.G. das Neves e Luciane Aparecida Lopes e, Maria Gorete Medeiros dos Santos (Embrapa-Sede), pelo auxílio durante o curso.

Ao CNPq e àEmbrapa, pela concessão da bolsa de estudos.

À Empresa SAKATA S.A., pelo fornecimento das sementes.

Aos funcionários da Biblioteca Central da USP/ESALQ, em especial à bibliotecária Eliana Maria Garcia, pela valiosa correção das referências bibliográficas.

Aos companheiros do curso de Pós-Graduação pelos anos de convivência. 


\section{SUMÁRIO}

LISTA DE FIGURAS

Página

2.1 Avaliação do vigor de sementes ............................................. 3

2.1.1 Deterioração controlada ..................................................... 5

2.1.2 Envelhecimento acelerado ….................................................

2.1.3 Condutividade elétrica ....................................................... 10

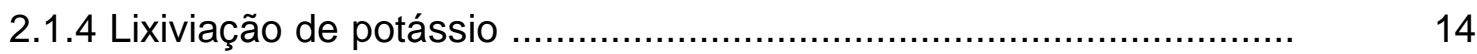

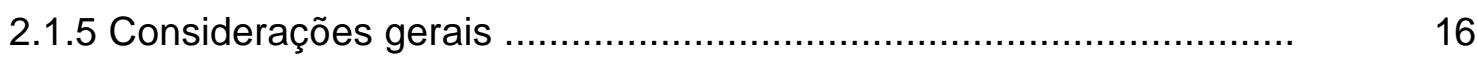

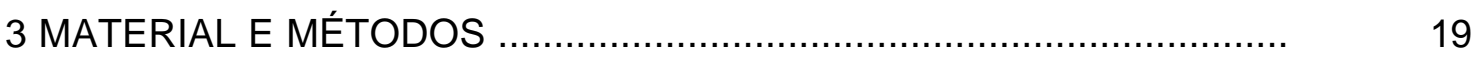

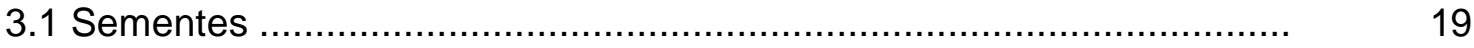

3.2 Estudo dos testes de deterioração controlada, envelhecimento acelerado, condutividade elétrica e lixiviação de potássio (Etapa 1)

3.2.1 Determinação do grau de umidade............................................ 20

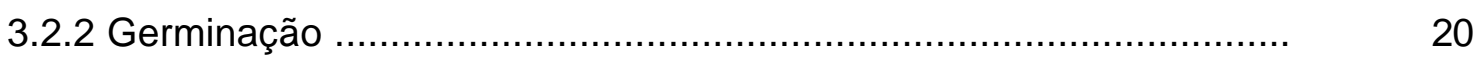

3.2.3 Primeira contagem de germinação .............................................. 20

3.2.4 Deterioração controlada ........................................................ 20

3.2.5 Envelhecimento acelerado (procedimento tradicional) ..................... 21

3.2.6 Envelhecimento acelerado (solução saturada de sal ) .................... 22 


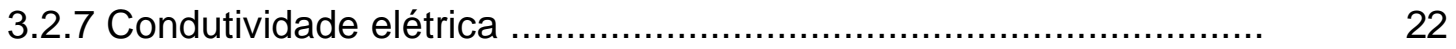

3.2.8 Lixiviação de potássio ..............................................................

3.2.9 Método Agroflora para avaliação do vigor em melão ...................... 24

3.2.10 Emergência de plântulas em casa de vegetação ......................... 27

3.3 Comparação entre testes para avaliação do potencial fisiológico de sementes de melão (Etapa 2) ......................................................... 28

3.3.1 Determinação do grau de umidade ............................................. 28

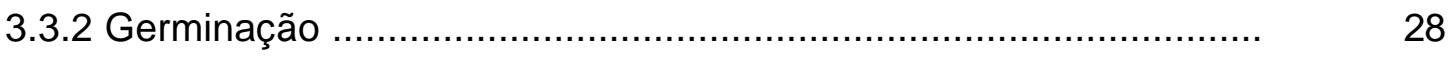

3.3.3 Primeira contagem de germinação ........................................... 28

3.3.4 Deterioração controlada .......................................................... 28

3.3.5 Envelhecimento acelerado (procedimento tradicional).................... 28

3.3.6 Envelhecimento acelerado (solução saturada de sal) .................... 28

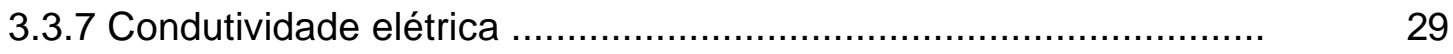

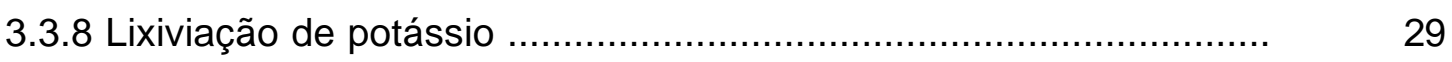

3.3.9 Método Agroflora para avaliação do vigor em melão ...................... 29

3.3.10 Emergência de plântulas em casa de vegetação ......................... 29

3.4 Procedimento estatístico ………................................................. 29

4 RESULTADOS E DISCUSSÃO ……………………....................

4.1 Estudo dos testes de deterioração controlada, envelhecimento acelerado, condutividade elétrica e lixiviação de potássio (Etapa 1) ...... 33

4.1.1 Avaliação inicial da qualidade dos lotes .......................................

4.1.2 Deterioração controlada ......................................................... 38

4.1.3 Envelhecimento acelerado (procedimento tradicional) ................... 44

4.1.4 Envelhecimento acelerado (solução saturada de sal) ..................... 51

4.1.4 Condutividade elétrica ............................................................ 5

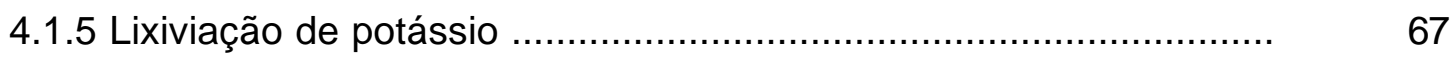

4.2 Comparação entre os testes para avaliação do potencial fisiológico de sementes de melão (Etapa 2) ……………………………….....

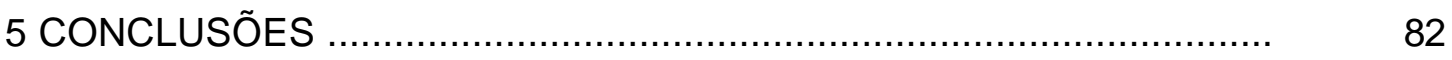

REFERÊNCIAS BIBLIOGRÁFICAS ..................................................... 


\section{LISTA DE FIGURAS}

Página

1 Critérios de avaliação de plântulas de melão pelo Método Agroflora: $\mathrm{N}_{\mathrm{A}}$ (Normal); $\mathrm{F}_{\mathrm{A}}$ (Fraca); $\mathrm{F}_{\mathrm{B}}$ (Fraca/cotilédones presos pelo tegumento); $F_{C}$ (Fraca/dano $\leq 50 \%$ ); $A_{A}$ (Anormal/dano $\geq$ $50 \%$ ) e $A_{B}$ (Anormal/“cotilédone cego”)

2 Desenvolvimento de microrganismos em amostras de sementes de melão submetidas aos testes de Envelhecimento Acelerado Tradicional (EAT) e Envelhecimento Acelerado com Solução Salina (EASS), 96 horas 


\section{LISTA DE TABELAS}

Página

1 Análise da variância, para cada híbrido, dos dados de germinação, primeira contagem de germinação, Método Agroflora e emergência de plântulas, na Etapa 1

2 Análise da variância dos dados de envelhecimento acelerado (procedimento tradicional e com solução salina) e deterioração controlada, para cada híbrido, preliminarmente, na Etapa 1

3 Análise da variância dos dados de envelhecimento acelerado (procedimento tradicional e com solução salina) e deterioração controlada, após identificação das melhores combinações, para cada híbrido, na Etapa 1

4 Análise da variância dos dados de condutividade elétrica e lixiviação de potássio, para cada híbrido, na Etapa 1

5 Análise da variância, para cada híbrido, dos dados de germinação, primeira contagem de germinação, Método Agroflora, emergência de plântulas, deterioração controlada, envelhecimento acelerado, condutividade elétrica e lixiviação de potássio, para cada híbrido, na Etapa 2 ...................................... 
6 Qualidade inicial de dez lotes de sementes de melão, híbridos AF-646 e AF-682

7 Dados médios obtidos para o teste de deterioração controlada de dez lotes de sementes de melão, híbridos AF-646 e AF-682 .........

8 Dados médios referentes ao grau de umidade após o teste de deterioração controlada de dez lotes de sementes de melão, híbridos AF-646 e AF-682

9 Dados médios obtidos para o teste de deterioração controlada de dez lotes de sementes de melão, híbridos AF-646 e AF-682 .........

10 Dados médios referentes ao grau de umidade após o teste de deterioração controlada de dez lotes de sementes de melão, híbridos AF-646 e AF-682

11 Dados médios obtidos para o teste de envelhecimento acelerado (procedimento tradicional) de dez lotes de sementes de melão, híbridos AF-646 e AF-682

12 Dados médios do grau de umidade obtidos após os períodos de envelhecimento acelerado (procedimento tradicional) de dez lotes de sementes de melão, híbridos AF-646 e AF-682

13 Dados médios obtidos para o teste de envelhecimento acelerado (procedimento tradicional) de dez lotes de sementes de melão, híbridos AF-646 e AF-682 
14 Dados médios do grau de umidade obtidos após os períodos de envelhecimento acelerado (procedimento tradicional) de dez lotes de sementes de melão, híbridos AF-646 e AF-682

15 Dados médios obtidos para o teste de envelhecimento acelerado, com solução salina, de dez lotes de sementes de melão, híbridos AF-646 e AF-682

16 Dados médios do grau de umidade obtidos após os períodos de envelhecimento acelerado, com solução salina, de dez lotes de sementes de melão, híbridos AF-646 e AF-682

17 Dados médios obtidos para o teste de envelhecimento acelerado, com solução salina, de dez lotes de sementes de melão, híbridos AF-646 e AF-682

18 Dados médios do grau de umidade obtidos após os períodos de envelhecimento acelerado, com solução salina, de dez lotes de sementes de melão, híbridos AF-646 e AF-682

19 Dados médios de condutividade elétrica $\mu \mathrm{mho} / \mathrm{cm} / \mathrm{g}$ ) utilizando as combinações 25 sementes $/ 50 \mathrm{~mL}$ e 50 sementes $/ 50 \mathrm{~mL}$, a $20^{\circ} \mathrm{C}$, respectivamente, de dez lotes de sementes de melão, híbridos AF-646 e AF-682, em cada período de embebição

20 Dados médios de condutividade elétrica $\mu \mathrm{mho} / \mathrm{cm} / \mathrm{g}$ ) utilizando as combinações 25 sementes $/ 75 \mathrm{~mL}$ e 50 sementes $/ 75 \mathrm{~mL}$, a $20^{\circ} \mathrm{C}$, respectivamente, de dez lotes de sementes de melão, híbridos AF-646 e AF-682, em cada período de embebição . 
21 Dados médios de condutividade elétrica $\mu \mathrm{mho} / \mathrm{cm} / \mathrm{g}$ ) utilizando as combinações 25 sementes $/ 50 \mathrm{~mL}$ e 50 sementes $/ 50 \mathrm{~mL}$, a $25^{\circ} \mathrm{C}$, respectivamente, de dez lotes de sementes de melão, híbridos AF-646 e AF-682, em cada período de embebição ..........

22 Dados médios de condutividade elétrica $\mu \mathrm{mho} / \mathrm{cm} / \mathrm{g}$ ) utilizando as combinações 25 sementes $/ 75 \mathrm{~mL}$ e 50 sementes $/ 75 \mathrm{~mL}$, a $25^{\circ} \mathrm{C}$, respectivamente, de dez lotes de sementes de melão, híbridos AF-646 e AF-682, em cada período de embebição

62

23 Dados médios de condutividade elétrica $\mu \mathrm{mho} / \mathrm{cm} / \mathrm{g}$ ) utilizando as combinações 25 sementes $/ 50 \mathrm{~mL}$ e 50 sementes $/ 50 \mathrm{~mL}$, a $30^{\circ} \mathrm{C}$, respectivamente, de dez lotes de sementes de melão, híbridos AF-646 e AF-682, em cada período de embebição ...........

24 Dados médios de condutividade elétrica $\mu \mathrm{mho} / \mathrm{cm} / \mathrm{g}$ ) utilizando as combinações 25 sementes $/ 75 \mathrm{~mL}$ e 50 sementes $/ 75 \mathrm{~mL}$, a $30^{\circ} \mathrm{C}$, respectivamente, de dez lotes de sementes de melão, híbridos AF-646 e AF-682, em cada período de embebição ...........

25 Dados médios de lixiviação de potássio ( $\mathrm{ppm} / \mathrm{g}$ ) utilizando as combinações 25 sementes $/ 50 \mathrm{~mL}$ e 50 sementes $/ 75 \mathrm{~mL}$, a $25^{\circ} \mathrm{C}$, respectivamente, de dez lotes de sementes de melão, híbridos AF-646 e AF-682, em cada período de embebição

26 Dados médios de lixiviação de potássio $(\mathrm{ppm} / \mathrm{g})$ utilizando as combinações 25 sementes $/ 50 \mathrm{~mL}$ e 50 sementes $/ 75 \mathrm{~mL}$, a $30^{\circ} \mathrm{C}$, respectivamente, de dez lotes de sementes de melão, híbridos AF-646 e AF-682, em cada período de embebição 
27 Dados médios do grau de umidade, primeira contagem de germinação, Método Agroflora, emergência de plântulas de dez lotes de sementes de melão, híbridos AF-646 e AF-682 .............. 73

28 Dados médios obtidos para os testes de deterioração controlada (DC) e de envelhecimento acelerado IEA (procedimento tradicional e com solução salina)\} de dez lotes de sementes de melão, híbridos AF-646 e AF-682

29 Dados médios do grau de umidade obtidos após os períodos de deterioração controlada (DC) e de envelhecimento acelerado \{EA (procedimento tradicional e com solução salina)\} de dez lotes de sementes de melão, híbridos AF-646 e AF-682

30 Dados médios obtidos para os testes de condutividade elétrica (após 8 e 24 horas de embebição) e de lixiviação de potássio (após 2 horas de embebição), de dez lotes de sementes de melão, híbridos AF-646 e AF-682 


\title{
MÉTODOS PARA AVALIAÇÃO DO POTENCIAL FISIOLÓGICO DE SEMENTES DE MELÃO
}

\author{
Autor: SALVADOR BARROS TORRES \\ Orientador: Prof. Dr. JULIO MARCOS FILHO
}

\section{RESUMO}

A pesquisa teve como objetivo estudar procedimentos para a condução dos testes de deterioração controlada, envelhecimento acelerado, condutividade elétrica e lixiviação de potássio, procurando-se verificar sua eficiência para identificação de diferentes níveis de vigor de lotes de sementes de melão (Cucumis melo L.). Para tanto, o estudo foi conduzido em duas etapas, utilizando-se cinco lotes de sementes dos híbridos AF-646 e AF-682. $\mathrm{Na}$ primeira foram realizados os testes de germinação, primeira contagem de germinação, Método Agroflora, emergência de plântulas em casa de vegetação e estudos específicos para os testes de deterioração controlada (graus de umidade de $18 \%, 21 \%$ e $24 \%$, a $45^{\circ} \mathrm{C}$, durante 24 e 48 horas), de envelhecimento acelerado, com e sem solução salina (períodos 48, 72 e 96 horas, a $38^{\circ} \mathrm{C}$ ou $41^{\circ} \mathrm{C}$ ), de condutividade elétrica (temperaturas de $20^{\circ} \mathrm{C}, 25^{\circ} \mathrm{C}$ e $30^{\circ} \mathrm{C}$, volumes de 50 e $75 \mathrm{~mL}$ de água, 25 e 50 sementes e períodos de 1, 2, $4,8,12,16,20$ e 24 horas) e de lixiviação de potássio (25 e 50 sementes, 50 e $75 \mathrm{~mL}$ de água, a $25^{\circ} \mathrm{C}$ e $30^{\circ} \mathrm{C}$, durante 30,60 , e 90 minutos, $2 \mathrm{~h}, 2 \mathrm{~h}$ e 30 minutos, 3 , 4 e 5 horas). Os procedimentos considerados mais promissores para cada teste, nesta primeira fase, foram comparados na segunda etapa, que 
também incluiu os testes de germinação, primeira contagem de germinação, Método Agroflora e emergência de plântulas em casa de vegetação. Diante dos resultados obtidos, concluiu-se que os testes de deterioração controlada $\left(24 \% / 45^{\circ} \mathrm{C} / 24 \mathrm{~h}\right)$ e de envelhecimento acelerado (procedimento tradicional e com solução salina), utilizando a combinação $41^{\circ} \mathrm{C} / 72 \mathrm{~h}$, apresentam sensibilidade suficiente para avaliação do potencial fisiológico de sementes de melão. O teste de condutividade elétrica não constitui em opção eficiente para avaliação do vigor das sementes, enquanto o teste de lixiviação de potássio necessita de estudos adicionais para adequar sua metodologia e viabilizar a sua utilização para sementes de melão, considerando-se, inclusive, os prováveis efeitos do genótipo. 


\title{
METHODS FOR THE PHYSIOLOGICAL POTENTIAL EVALUATION IN MELON SEEDS
}

\author{
Author: SALVADOR BARROS TORRES \\ Adviser: Prof. Dr. JULIO MARCOS FILHO
}

\section{SUMMARY}

This research was conducted to study and select procedures for the controlled deterioration, accelerate aging, electrical conductivity and potassium lixiviation tests, to verify their sensitivity to identify different vigor levels of melon (Cucumis melo L.) seed lots. Five seed lots each from the hybrids AF-646 and AF-682 were used. In the first experimental stage, the following tests were performed: germination, germination first count, Agroflora Method and seedling emergence. Specific studies were also conducted to the following tests: controlled deterioration (seed moisture content of $18 \%, 21 \%$ and $24 \%$, at $45^{\circ} \mathrm{C}$, for 24 and 48 hours), traditional accelerated aging, saturated salt accelerated aging (for 48,72 and 96 hours, at $38^{\circ} \mathrm{C}$ or $41^{\circ} \mathrm{C}$ ), electrical conductivity ( 25 or 50 seeds imbibed in $50 \mathrm{~mL}$ or $75 \mathrm{~mL}$ water, $20^{\circ} \mathrm{C}, 25^{\circ} \mathrm{C}$ and $30^{\circ} \mathrm{C}$, for $1,2,4,8,12$, 16 and 20 hours) and potassium leachate (25 or 50 seeds, imbibed in $50 \mathrm{~mL}$ and $75 \mathrm{~mL}$, at $25^{\circ} \mathrm{C}$ and $30^{\circ} \mathrm{C}$, for $30,60,90,120,150,180,240$ and 300 minutes).

The procedures considered the most promising for each test in the first stage were compared, in the second stage. The later stage also included 
germination, germination first count, Agroflora Method and seedling emergence tests. From the results, it was concluded that controlled deterioration $\left(24 \% / 45^{\circ} \mathrm{C} / 24 \mathrm{~h}\right)$ and accelerate aging (traditional procedure and salt saturated) tests, using the $41^{\circ} \mathrm{C} / 72 \mathrm{~h}$ combination, showed to be sufficiently sensitive for the evaluation of the physiological potential of melon seeds. The electrical conductivity test does not constitute an efficient option for the vigor evaluation, while the potassium lixiviation test needs further studies in order to adjust its methodology and enable its use for melon seeds, also considering the probable genotype effects. 


\section{INTRODUÇÃO}

A avaliação do potencial fisiológico de sementes é componente fundamental de programas de controle de qualidade de sementes, pois constitui referência para adoção de práticas de manejo destinadas à garantia de nível satisfatório de desempenho das sementes. O teste padrão de germinação, conduzido em laboratório geralmente superestima o potencial fisiológico de lotes de sementes; é, portanto, cada vez maior a necessidade do aprimoramento dos testes destinados à avaliação do vigor de sementes, principalmente, no que diz respeito à obtenção de informações consistentes e, de preferência, em período relativamente curto.

Para algumas culturas, existem testes considerados praticamente padronizados para avaliar o vigor das sementes, como por exemplo, o de envelhecimento acelerado para as de soja e o de condutividade elétrica para as de ervilha. Por outro lado, poucos estudos têm sido conduzidos sobre o uso de testes de vigor para avaliação do potencial fisiológico de sementes de hortaliças; nesse sentido, McDonald (1998) afirmou que testes de vigor devem

ser desenvolvidos para sementes dessas espécies, com a finalidade de detectar as mudanças na qualidade das sementes ao longo do processo produtivo, ressaltando que o valor comercial das sementes vem aumentando e, assim, o desenvolvimento de novos testes, o aprimoramento dos disponíveis e sua padronização devem ocorrer o mais rápido possível. Segundo Marcos Filho, 1999a), as informações sobre o vigor são ainda mais importantes para sementes de valor comercial elevado, como as hortaliças. Estas, em função de seu tamanho e, também, por apresentarem menores quantidades de reservas 
armazenadas, são sensíveis às alterações provocadas pela deterioração após a maturidade fisiológica. Por esse motivo, são habitualmente armazenadas em embalagens herméticas ou em ambientes especiais, sob temperatura e/ou umidade relativa reduzidas.

Dentre as espécies da família Cucurbitaceae, o melão (Cucumis melo L.) vem sendo produzido em volumes significativos, principalmente na região Nordeste do Brasil, contribuindo com aproximadamente 95\% da produção total do País; o estado do Rio Grande do Norte é o maior produtor, representando $66 \%$ de todo o melão produzido na região (FNP Consultoria \& Comércio, 2001). As sementes, por apresentarem alto valor comercial, merecem atenção especial quanto ao potencial fisiológico. Entretanto, para esta espécie, verifica-se a quase inexistência de pesquisas direcionadas à comparação de testes de vigor, sobretudo em nossas condições.

Desta forma, o presente trabalho teve como objetivo estudar a metodologia dos testes de deterioração controlada, envelhecimento acelerado, condutividade elétrica e lixiviação de potássio, procurando-se verificar sua sensibilidade para identificar diferenças entre níveis de vigor de lotes de sementes de melão. Além disso, verificou-se a consistência das informações fornecidas por esses testes, buscando indicar opções para utilização em programas de controle de qualidade adotados por instituições produtoras de sementes dessa espécie. 


\section{REVISÃO DE LITERATURA}

\subsection{Avaliação do vigor de sementes}

Os testes de vigor têm constituído ferramentas de uso cada vez mais rotineiro pela indústria de sementes, visando a determinação do potencial fisiológico. As empresas produtoras e as instituições oficiais têm incluído esses testes em programas internos de controle de qualidade e/ou para garantia da qualidade de sementes destinadas à comercialização. Segundo Marcos Filho (1999a), os objetivos básicos dos testes de vigor são: avaliar ou detectar diferenças significativas na qualidade de lotes com germinação semelhante, complementando as informações fornecidas pelo teste de germinação; distinguir, com segurança, lotes de alto dos de baixo vigor; separar (ou classificar) lotes em diferentes níveis de vigor, de maneira proporcional à emergência das plântulas em campo, resistência ao transporte e potencial de armazenamento. Freqüentemente, observa-se que lotes de sementes apresentando germinação semelhante exibem comportamentos distintos em campo e/ou armazenamento.

Essas diferenças no comportamento de lotes com germinação semelhante podem ser explicadas pelo fato de que as primeiras alterações nos processos bioquímicos associados à deterioração ocorrem, geralmente, antes que sejam verificados declínios na capacidade germinativa (Delouche \& Baskin, 1973). Por isso, o uso dos testes de vigor é de grande utilidade no monitoramento da qualidade das sementes, a partir da maturidade (Dias \& Marcos Filho, 1995). 
A Association of Official Seed Analysts - AOSA (1983) ressalta que o principal desafio das pesquisas sobre testes de vigor está na identificação de parâmetros adequados, comuns à deterioração das sementes, de forma que, quanto mais próximo da maturidade fisiológica ou mais distante da perda da capacidade de germinação estiver o parâmetro avaliado, mais promissor será o teste, fornecendo, assim, informações complementares àquelas obtidas pelo teste de germinação.

Portanto, além da necessidade de padronização da metodologia e de interpretação dos resultados, para possibilitar a comparação entre resultados obtidos por diferentes analistas e laboratórios, os testes de vigor devem preencher outras características, como: relação com a emergência de plântulas em campo, rapidez, objetividade, simplicidade, baixo custo e reprodutibilidade (Delouche, 1976; AOSA, 1983; TeKrony, 1983).

Diante destas considerações, de acordo com Perry (1981) e McDonald (1998), a importância da padronização dos testes de vigor torna-se fundamental, à medida que as técnicas de manejo cultural tornam-se mais sofisticadas, evidenciando a necessidade de se utilizarem sementes de qualidade diferenciada. Nesse sentido, Hampton \& Coolbear (1990) afirmaram que os testes de vigor são cada vez mais relevantes para muitas espécies de hortaliças, viabilizando a prática da semeadura de precisão, a eliminação do desbaste e a obtenção de uniformidade de desenvolvimento e maturação de plantas. Para tanto, as sementes devem exibir potencial fisiológico elevado, o que exige o uso rotineiro de testes de vigor em programas de controle de qualidade.

Até o momento, a International Seed Testing Association - ISTA considera como praticamente padronizado o teste de condutividade elétrica para ervilha, enquanto que a AOSA tem a mesma postura diante do teste de envelhecimento acelerado para sementes de soja (Hampton \& TeKrony, 1995).

Segundo Marcos Filho (1999a), as informações sobre o vigor são ainda mais importantes para sementes de maior valor comercial, como as de hortaliças. Como o cultivo dessas espécies é efetuado de maneira intensiva, deve ser estabelecido com sementes de qualidade superior, germinando rápida e 
uniformemente. Isso permite, para espécies em que a produção comercial envolve o transplante de mudas, a utilização de plantas com tamanho e qualidade uniformes, com reflexos no desenvolvimento das plantas e, possivelmente, na produção final.

O vigor da semente é função de um conjunto de características que determinam o potencial para emergência rápida e uniforme de plântulas normais, sob ampla diversidade de condições de ambiente (AOSA, 1983). Em função disso, o uso de um único teste de vigor (fisiológico, bioquímico ou de resistência a estresse), pode gerar informações incompletas, tanto para uma única espécie como para avaliar o potencial de desempenho das sementes sob diferentes condições ambientais (Hampton \& Coolbear, 1990). Portanto, segundo Marcos Filho (1999a), a tendência predominante é a combinação de resultados de diferentes testes, levando-se sempre em consideração a finalidade do uso dos resultados e as suas limitações.

A seguir, será efetuada abordagem sobre testes de deterioração controlada, envelhecimento acelerado, condutividade elétrica e lixiviação de potássio, procurando enfatizar sua importância para hortaliças e as principais variáveis que podem afetar seus resultados.

\subsubsection{Deterioração controlada}

O teste de deterioração controlada foi inicialmente desenvolvido para a avaliação do vigor de lotes de sementes de hortaliças, como cenoura, cebola, alface e brássicas (Matthews, 1980; Powell \& Matthews, 1981), procurando obter informações referentes ao potencial de armazenamento (Matthews \& Powell, 1987).

Este teste tem sua fundamentação baseada no conhecimento de que as sementes deterioram mais rapidamente quando armazenadas em condições de umidade relativa do ar e temperatura elevadas (Powell, 1995). A comparação da resposta de vários lotes seria possível através de um controle preciso da temperatura e do teor de água das sementes, de modo que o estresse seria 
imposto de maneira uniforme a todas as sementes da amostra avaliada. A mesma autora ponderou que, no teste de envelhecimento acelerado, as diferenças na velocidade e intensidade de absorção de água, quando as sementes são expostas a atmosfera muito úmida, podem originar variações acentuadas no grau de umidade das amostras ao final do período de envelhecimento, especialmente para sementes relativamente pequenas, o que não ocorre no teste de deterioração controlada.

Neste teste, a deterioração é provocada através do ajuste do grau de umidade das sementes para, no mínimo, 15,5\%, previamente à instalação do teste. As sementes umedecidas são acondicionadas em recipientes herméticos e mantidas em banho-maria, a temperatura constante ( 40 a $45^{\circ} \mathrm{C}$ ), durante período pré-estabelecido; em seguida, são colocadas para germinar. A porcentagem de plântulas normais é considerada proporcional ao vigor das sementes.

No teste de deterioração controlada, o efeito do teor de água sobre a deterioração das sementes é direto, ao contrário do que se verifica no teste de envelhecimento acelerado (Marcos Filho et al., 2001). Portanto, o teste de deterioração controlada é conduzido com amostras que possuem o mesmo teor de água, resultando na exposição das sementes a condições uniformes e, consequentemente, padronização mais efetiva, principalmente em espécies que produzem sementes de menor tamanho, como as hortaliças.

A literatura contém informações sobre o uso do teste de deterioração controlada para várias espécies de hortaliças. As pesquisas recomendam, por exemplo, as seguintes combinações grau de umidade/temperatura/período de exposição para condução do teste: alface, couve-flor e couve de bruxelas, 20\%/45 $\mathrm{C} / 24 \mathrm{~h}$ (ISTA, 1995); berinjela, $24 \% / 41^{\circ} \mathrm{C} / 48 \mathrm{~h}$ (Bhéring et al., 2001b); beterraba e cenoura, $24 \% / 45^{\circ} \mathrm{C} / 24 \mathrm{~h}$ (ISTA, 1995); brócolis, $22 \% / 40^{\circ} \mathrm{C} / 24 \mathrm{~h}$ (Mendonça et al., 2000); ervilha, 20\%/45 C/24h (Bustamante et al., 1984; Powell et al., 1997; Larsen et al., 1998); maxixe, 19\%/45은 $24 \mathrm{~h}$ (Torres et al., 1999);

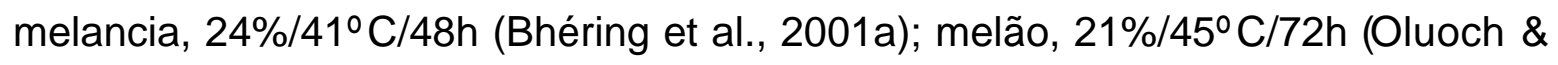
Welbaum, 1996); nabo, 20\%/45든 $24 \mathrm{~h}$ (Zhang \& Hampton, 1999); pepino,

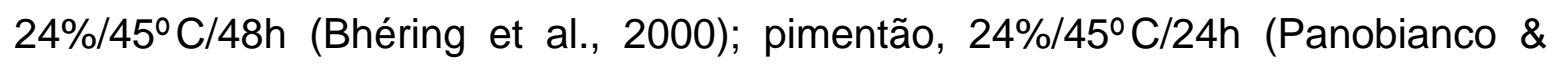


Marcos Filho, 1998); repolho, 24\%/45ㄷㄴㄷㅐ (Strydom \& Van de Venter, 1998); tomate, 24\%/45을 $24 \mathrm{~h}$ (Alsadon et al., 1995; Panobianco \& Marcos Filho, 2001).

Um dos principais cuidados com relação ao teste de deterioração controlada é o ajuste do grau de umidade das sementes. Essa etapa é tida como crítica na condução do teste e isso pode acelerar a deterioração das sementes, principalmente se a hidratação for muito rápida e, a temperatura, inadequada. Nesse sentido, Rosseto et al. (1995) recomendam que o processo seja lento e, para isso, o melhor meio de embebição controlada seria a utilização do umedecimento das sementes através do método da atmosfera úmida, a $20^{\circ} \mathrm{C}$.

Mesmo assim, observa-se, que o teste de deterioração controlada é relativamente simples, não exige conhecimentos sofisticados, investimentos significativos e não apresenta dificuldades acentuadas para padronização. Entretanto, verifica-se, através da literatura consultada que este teste, mesmo sendo dirigido para a avaliação do potencial fisiológico de sementes de hortaliças, pouco foi estudado para sementes de melão. Portanto, pesquisas destinadas à avaliação do vigor de sementes dessa importante hortaliça fruto, para as nossas condições, são indispensáveis.

\subsubsection{Envelhecimento acelerado}

O teste de envelhecimento acelerado é reconhecido como um dos mais populares para avaliação do vigor de sementes de várias espécies, sendo capaz de proporcionar informações com alto grau de consistência (TeKrony, 1995). Tem como princípio a aceleração artificial da taxa de deterioração das sementes através de sua exposição a níveis elevados de temperatura e umidade relativa do ar, considerados os fatores ambientais preponderantes na intensidade $e$ velocidade de deterioração (Marcos Filho, 1999b). Nessa situação, sementes de baixa qualidade deterioram-se mais rapidamente do que as mais vigorosas, apresentando queda diferenciada da viabilidade.

Para Delouche \& Baskin (1973), a seqüência hipotética do processo de deterioração da semente envolve a degradação das membranas celulares, a 
redução das atividades respiratórias e biossintéticas, a menor velocidade na germinação, a redução do potencial de conservação durante o armazenamento, a menor taxa de crescimento e desenvolvimento, a menor uniformidade, a maior sensibilidade às adversidades do ambiente, a redução da emergência das plântulas em campo, o aumento da ocorrência das plântulas anormais e, finalmente, a perda do poder germinativo. Consequentemente, 0 teste de envelhecimento acelerado poderia ser considerado como um dos mais sensíveis para a avaliação do vigor, dentre os disponíveis (Marcos Filho, 1999b), pois se relaciona ao potencial de conservação das sementes.

Recentemente, alguns trabalhos, referentes ao assunto foram conduzidos com sementes de hortaliças. Assim, Piana et al. (1995) concluíram que, dentre os testes estudados, o envelhecimento acelerado foi um dos que mais se associou à emergência de plântulas de cebola em campo e àobtenção de mudas vigorosas, além de identificar os lotes com diferentes níveis de vigor. Em sementes de cenoura, Martins et al. (1996), constataram que o teste se relacionou com a emergência das plântulas em campo. Informações semelhantes também foram obtidas por Trigo \& Trigo (1995a, b, c.), com sementes de pepino, cenoura e melancia, respectivamente.

Dentre os fatores que afetam o comportamento das sementes submetidas ao teste, a interação temperatura/período de exposição é um dos mais estudados. Na literatura pesquisada, alguns autores se dedicaram ao estudo dessa interação, indicando, para sementes de melancia, $45^{\circ} \mathrm{C} / 144 \mathrm{~h}$ (Delouche \& Baskin, 1973) e $41^{\circ} \mathrm{C} / 48 \mathrm{~h}$ (Bhéring et al., 2001a); tomate, $42^{\circ} \mathrm{C} / 72 \mathrm{~h}$ (Nascimento et al., 1993); alface, $41^{\circ} \mathrm{C} / 72 \mathrm{~h}$ (TeKrony, 1995); cebola, 41ํㅡ $\mathrm{C} / 72 \mathrm{~h}$ (Idiarte, 1995; TeKrony, 1995); pimentão, 41ํㅡ/72h (TeKrony, 1995; Panobianco \& Marcos Filho, 1998); brócolis, $45^{\circ} \mathrm{C} / 48 \mathrm{~h}$ (Tebaldi et al., 1999); berinjela, $41^{\circ} \mathrm{C} / 48 \mathrm{~h}$ (Bhéring et al., 2001b); melão, $42^{\circ} \mathrm{C} / 48 \mathrm{~h}$ (Cano-Ríos et al., 2000); cenoura, 42ํㅡ $\mathrm{C} / 24 \mathrm{~h}$ (Barbedo et al., 2000), $41^{\circ} \mathrm{C} / 48 \mathrm{~h}$ (Rodo et al., 2001). 
No teste de envelhecimento acelerado, as diferenças na absorção de água pelas sementes, expostas a atmosfera úmida, podem originar, entretanto, variações acentuadas no grau de umidade. Segunconduzidas com espécies de sementes pequenas, como as de hortaliças, têm revelado resultados pouco consistentes devido à variação muito acentuada do grau de umidade das amostras, após o envelhecimento. Nesse sentido, vem sendo estudadas alternativas para a condução do envelhecimento acelerado com sementes dessas espécies, como a substituição da água por soluções saturada de sais (SSAA "Saturated Salt Accelerated Aging"). Dependendo da solução utilizada, são obtidos níveis específicos de umidade relativa do ar, permitindo reduzir a taxa de absorção de água, a velocidade e a intensidade de deterioração das sementes. Baseados nesses fatos, Jianhua \& McDonald (1997), trabalhando com sementes de Impatiens wallerana Hook, utilizaram soluções saturadas de sais, que produziram diferentes umidades relativas no interior dos compartimentos individuais ( $\mathrm{KCl}-87 \% \mathrm{UR}, \mathrm{NaCl}-76 \% \mathrm{UR}$ e $\mathrm{NaBr}-55 \% \mathrm{UR}$ ), identificando a eficiência desse método para reardar a absorção de água das sementes pequenas, durante o envelhecimento acelerado, sem prejudicar a eficiência do teste. Também foi constatada maior eficiência do teste de envelhecimento acelerado com uso de soluções saturadas de sal na classificação de lotes de sementes pimentão (Panobianco \& Marcos Filho, 1998), cenoura (Rodo et al., 2000), pepino (Bhéring et al, 2000), milho doce (Bennett et al., 2001) e tomate (Panobianco \& Marcos Filho, 2001). Por outro lado, Ribeiro \& Carvalho (2001), comparando a eficiência dos sistemas de envelhecimento acelerado com e sem soluções salinas para sementes de cenoura (Daucus carota L.), alface (Lactuca sativa L.) e brócolis (Brassica oleracea variedade Itálica Plenk), concluíram que o controle da umidade relativa do ar no interior dos compartimentos (gerbox), através do uso de soluções saturadas de $\mathrm{NaCl}$ e $\mathrm{KCl}$ não forneceu bons resultados; segundo os autores, o emprego de água pura parece se constituir em procedimento mais confiável para as espécies estudadas. 
Observa-se que, embora o teste de envelhecimento acelerado venha sendo amplamente estudado visando a sua padronização para muitas espécies, as informações são escassas para as nossas condições e também para as sementes de cultivares de melão.

\subsubsection{Condutividade elétrica}

Este teste avalia indiretamente o grau de estruturação das membranas celulares, em decorrência da deterioração das sementes, através da determinação da quantidade de íons lixiviados em uma solução de embebição. As sementes são embebidas em determinado volume de água destilada, sob temperatura controlada, durante período pré-estabelecido. As sementes de menor potencial fisiológico liberam maior quantidade de lixiviados, como conseqüência da menor estruturação e seletividade das membranas; a avaliação se dirige àconcentração de íons na solução de embebição.

Várias pesquisas têm demonstrado que 0 decréscimo do potencial fisiológico e da germinação das sementes têm relação direta com o aumento da lixiviação de solutos, como conseqüência da perda da integridade das membranas. Dentre os trabalhos envolvendo espécies de sementes de hortaliças, destacam-se os realizados por Loomis \& Smith (1980) com repolho; Gorecki et al. (1985) e Powell et al. (1997), com ervilha; Krishnasamy \& Ramarajpalaniappan (1989), Rodo et al. (1998a), Sá (1999) e Panobianco (2000), com tomate; Trawatha et al (1990), Demir \& Ellis (1992), Durán et al. (1997), Panobianco \& Marcos Filho (1998) e Torres \& Minami (2000), com pimentão; Deswal \& Sheoran (1993), com grão de bico; Guimarães et al. (1993), com alface; Andrade et al. (1995), com cenoura; Piana et al. (1995), com cebola; Dias et al. (1996), com couve-flor, cebola e cenoura; Torres et al. (1998), com maxixe e Mello et al. (1999), com brócolis. 
$\mathrm{Na}$ fase inicial do processo de embebição, a capacidade da semente reorganizar o sistema de membranas celulares e reparar danos físicos e/ou biológicos, que podem ter ocorrido durante o processo de produção, irá influenciar a quantidade e natureza de lixiviados liberados para o meio externo (Simon \& Raja Harun, 1972; Bewley \& Black, 1994; Vieira \& Krzyzanowski, 1999). Assim, quanto maior a velocidade de restabelecimento da integridade das membranas, menor será a quantidade de lixiviados liberados para o meio externo e, consequentemente, maior o vigor da semente. $O$ valor da condutividade elétricada solução de embebição das sementes varia em quantidade e tipo de lixiviados, tais como açúcares, aminoácidos, ácidos graxos, enzimas e íons inorgânicos, como $\mathrm{K}+, \mathrm{Ca}+, \mathrm{Mg}+$ + e Na +(Short \& Lacy, 1976; Marcos Filho et al., 1982; AOSA, 1983; Givelberg et al., 1984; Doijode, 1988; Woodstock, 1988; Cortes \& Spaeth, 1994 ; Taylor et al., 1995).

O teste de condutividade elétrica, inicialmente desenvolvido para sementes de ervilha (Matthews \& Bradnock, 1967), tem sido usado intensivamente para avaliar o vigor de sementes dessa espécie, em várias partes do mundo (Hampton \& Tekrony, 1995).

Em termos de padronização, o teste é considerado promissor e interessante. Entretanto, estudos conduzidos pelo Comitê de Vigor da ISTA constataram variações nos resultados entre laboratórios, devido a problemas de metodologia (Perry, 1981). De fato, estudos têm demonstrado que vários fatores podem afetar os resultados desse teste, entre os quais destacam-se: o genótipo dentro de uma mesma espécie e/ou cultivar (Short \& Lacy, 1976; Schmidt \& Tracy, 1989; Vieira et al., 1996; Panobianco \& Vieira, 1996; Vieira et al., 1998 e Panobianco et al., 1999); o estádio de desenvolvimento no momento da colheita (Powell, 1986); as mudanças na estrutura e composição da semente durante o desenvolvimento (Styer \& Cantliffe, 1983) e a desestruturação das membranas (Givelberg et al., 1984; Powell, 1986). Acrescidos a esses fatores, tem-se ainda: a) tamanho da amostra (Tao, 1978; Loeffler, 1981; Deswal \& Sheoran, 1993); b) 
massa da semente (Hepburn et al., 1984; Siddique \& Goodwin, 1985); c) temperatura de embebição (Leopold, 1980; Murphy \& Noland, 1982; Givelberg et al., 1984); d) período de embebição (Loeffler et al., 1988; Schmidt \& Tracy, 1989; Wang et al., 1994); e) volume de água utilizado (Tao, 1978; Loeffler et al., 1988; Hampton et al., 1994; f) teor de água inicial das sementes (Tao, 1978; McDonald \& Wilson, 1979; Loeffler et al., 1988; Hampton et al., 1992; Hampton et al., 1994; g) presença de sementes danificadas fisicamente (Tao, 1978); h) integridade do tegumento (Samad \& Pearce, 1978; Duke \& Kakefuda, 1981) e sua permeabilidade (Powell \& Matthews, 1979); i) cor da semente (Short \& Lacy, 1976); j) tamanho do recipiente de embebição (Loeffler et al., 1988); I) qualidade da água (Tao, 1978; Loeffler et al., 1988); m) número de sementes constituintes da amostra avaliada (Hampton et al., 1994); n) equipamento usado para a leitura da condutividade (Hepburn et al., 1984); o) expressão dos resultados (Mullet \& Wilkinson, 1979; Siddique \& Goodwin, 1985) e p) composição (teor de lignina) do tegumento (Panobianco et al., 1999).

Outro aspecto a ser levado em consideração é a temperatura durante a embebição. Esta afeta diretamente a velocidade de embebição e a lixiviação de eletrólitos do interior das células para o meio externo (Leopold, 1980; Murphy \& Noland, 1982). O efeito da temperatura sobre a lixiviação se manifesta, basicamente, sobre a quantidade e velocidade de perda de lixiviados, sem alterar, necessariamente, a classificação dos lotes (Hampton, 1995). No caso de sementes pequenas, como as de hortaliças, a lixiviação máxima pode ocorrer num período inferior a duas horas (Murphy \& Noland, 1982), ao passo que em sementes maiores, como soja, têm sido verificados aumentos da lixiviação até 2430 horas após o início da embebição, a 25드 (Loeffler et al., 1988). Além da temperatura de embebição, a de avaliação tem efeito significativo sobre os resultados da condutividade elétrica. Assim, Loeffler et al. (1988), com sementes de soja, demonstraram que aumentos ou reduções de $5^{\circ} \mathrm{C}$ na temperatura durante 
as leituras da condutividade elétrica provocaram alterações significativas nos resultados.

No tocante ao número de sementes por amostra avaliada, constatourse, na literatura, certa variabilidade nos procedimentos; porém, Loeffler et al. (1988), com soja, demonstraram que o uso de 50 sementes fisicamente puras, em comparação a 25, proporcionou redução no coeficiente de variação, determinando maior uniformidade dos resultados. Guimarães et al. (1993), com sementes de alface, consideraram a utilização de 50 sementes como a mais adequada para condução do teste. Já Rodo et al. (1998a), estudando a influência do tamanho da amostra de sementes de tomate sobre os resultados da condutividade elétrica, a $25^{\circ} \mathrm{C}$, verificaram a necessidade do estabelecimento de recomendações específicas para cada cultivar avaliado. Quanto ao volume de água utilizado Hampton et al. (1994), referindo-se a sementes de Lotus, verificaram que o aumento na quantidade de água minimizou o efeito no número de sementes, ou seja, quando trabalharam com volume maior de água $(250 \mathrm{~mL})$ os resultados do teste de condutividade elétrica não sofreram interferência do número de sementes (50 e 100), enquanto que, sob menor quantidade de água (125mL), variaram significativamente em função do número de sementes empregado. Portanto, observa-se que as variáveis quantidades de água e número de sementes apresentam-se interdependentes, pois estão diretamente relacionadas com a concentração da solução que será submetida àleitura. Nesse sentido, Mello et al. (1999) trabalhando com sementes de brócolos verificaram que a relação $25 \mathrm{~mL}$ de água/50 sementes, a $25^{\circ} \mathrm{C}$, proporcionou informações comparáveis às obtidas nos testes de germinação e emergência de plântulas, na identificação do potencial fisiológico dos lotes avaliados. Para sementes de alface, Guimarães et al. (1993) verificaram que a combinação $75 \mathrm{~mL}$ de água e 50 sementes, a $20^{\circ} \mathrm{C}$, foi a mais promissora. Já Rodo et al. (1998a), trabalhando com dois cultivares de tomate, verificaram que o volume de $50 \mathrm{~mL}$ de água foi o mais indicado, utilizando 25 ou 50 sementes, a $25^{\circ} \mathrm{C}$. 
O exame da literatura revela que ainda persistem algumas dificuldades para a definição do protocolo do teste de condutividade elétrica para avaliação do vigor de sementes de hortaliças. Lima (1993), trabalhando com sementes de cebola, constatou que o teste mostrourse pouco sensível na separação dos lotes de alto e baixo vigor. Resultados pouco consistentes também foram encontrados por Argerich \& Bradford (1989) e Novembre et al. (1995), com sementes de tomate. Por outro lado, Andrade et al. (1995), com sementes de cenoura, verificaram que o teste de condutividade elétrica foi o mais indicado para avaliar o vigor, em razão de sua facilidade de execução, objetividade e rapidez. Nesse mesmo sentido, Dias et al. (1996), com sementes de couve-flor, cebola e cenoura, verificaram que o teste permitiu a separação dos lotes em diferentes níveis de vigor; demonstraram, também, a possibilidade de redução do período de condicionamento das sementes. Tem-se verificado que 0 teste de condutividade elétrica é reconhecidamente eficiente para avaliação do vigor, proporcionando resultados consistentes e com isso permitindo a identificação segura de diferenças no potencial fisiológico de sementes de várias espécies. Porém, seu uso para sementes de hortaliças ainda é menos estudado, justificando, portanto, a necessidade de intensificação da pesquisa, visando o estabelecimento de procedimentos específicos para condução do teste, sobretudo para sementes de melão.

\subsubsection{Lixiviação de potássio}

O teste de lixiviação de potássio baseia-se no mesmo princípio ao da condutividade elétrica, variando apenas o parâmetro avaliado; apresenta vantagens de avaliar um íon específico, maior rapidez na determinação e obtenção dos resultados, permitindo agilizar a obtenção de informações sobre o potencial fisiológico das sementes. Dias \& Marcos Filho (1995) afirmaram que um dos objetivos básicos da avaliação do vigor das sementes é a obtenção de 
resultados confiáveis, em período de tempo relativamente curto, tornando mais eficientes as decisões, principalmente quanto æ̀ operações de colheita, processamento e comercialização.

De acordo com vários autores, os íons inorgânicos $\left(\mathrm{K}_{+}, \mathrm{Ca}++, \mathrm{Mg}++, \mathrm{Mn}\right.$ ${ }_{++}, \mathrm{Cl}-\mathrm{e} \mathrm{Na}+$ ) representam os principais eletrólitos liberados pelas sementes durante a embebição (Abdel-Samad \& Pearce, 1978; Loomis \& Smith, 1980; McKersie \& Stinson, 1980; Granqvist, 1987; Lott et al., 1991). Trabalhando com sementes de repolho, Loomis \& Smith (1980) determinaram que após 16 horas de embebição, $65 \%$ do potássio havia sido lixiviado das sementes submetidas ao envelhecimento acelerado. Em sementes de cenoura, Granqvist (1987), determinou que as perdas de potássio e cálcio foram da mesma magnitude, porém, superiores às perdas de sódio e magnésio. Lott et al. (1991) trabalhando com uma série de espécies, com sementes íntegras ou com partes de sementes, relataram que o potássio foi lixiviado em maiores quantidades que outros elementos. Desta forma, a determinação da quantidade de potássio lixiviado pode ser utilizada como indicador da integridade das membranas celulares e, consequentemente, do vigor da semente, conforme trabalhos realizados por Halloin (1975), Marcos Filho (1979), McKersie \& Stinson (1980), Dias et al. (1995 e 1996) e Custódio \& Marcos Filho (1977), fornecendo informações sobre o potencial fisiológico dos lotes em período de tempo consideravelmente reduzido em relação àcondutividade elétrica.

Nesse aspecto, a quantidade de potássio liberada por sementes embebidas tem sido utilizada como indicador da integridade do sistema de membranas celulares (Halloin, 1975; McKersie \& Stinson, 1980; Woodstock et al., 1985). Em trabalhos, mais recentes, Panobianco (2000) e Rodo \& Marcos Filho (2001b) concluíram para sementes de tomate e cebola, respectivamente, que o teste de lixiviação de potássio constituiu opção promissora, detectando de maneira consistente os lotes de qualidade inferior, com significativa rapidez. 
Por outro lado, trabalhos realizados por Marcos Filho et al. (1984) e Barros \& Marcos Filho (1997) não encontraram relações consistentes entre a lixiviação de potássio e o vigor de lotes de sementes de soja. Dias et al. (1998) trabalhando com sementes de feijão-de-vagem e quiabo concluíram, para ambas as espécies, que o teste de lixiviação de potássio necessita ainda estudos adicionais para ajustes na sua metodologia e viabilizar sua utilização mais ampla.

É importante salientar que, sementes de hortaliças, como aipo, alface e cenoura apresentaram 90\% da lixiviação do potássio num período de 5 a 15 minutos de embebição (Simon \& Mathavan, 1986); no entanto, essas observações não foram obtidas em pesquisas dirigidas ao estudo da lixiviação de potássio como um teste para avaliação do vigor de sementes.

Diante dessas informações, verifica-se que determinações feitas nos exsudatos de sementes, através do teste de lixiviação de potássio, podem se constituir em alternativa promissora para avaliação rápida do potencial fisiológico das sementes. No entanto, nota-se através da literatura a necessidade de continuidade das pesquisas no sentido de possibilitar a padronização do teste.

\subsubsection{Considerações gerais}

Em relação às espécies de hortaliças, o estudo de testes de vigor para avaliação do potencial fisiológico das sementes está em fase inicial, quando comparados com outras culturas de interesse econômico. Entretanto, alguns pesquisadores estão se voltando para o estudo do vigor em sementes destas espécies, utilizando-se dos testes disponíveis, a fim de estabelecer procedimentos específicos e padronizados, mostrando preferência ao desenvolvimento de testes de vigor capazes de fornecer resultados com rapidez e precisão, sendo este fator de fundamental importância para a evolução da indústria brasileira de sementes. 
Nesse aspecto, verifica-se que a metodologia de testes já consagrados tem sido alvo de estudos, visando seu aprimoramento e amplitude de utilização. É o caso do teste de envelhecimento acelerado, onde a alternativa da substituição da água no compartimento interno da caixa plástica por volume equivalente de solução salina, tem se mostrado promissora para avaliação do vigor de sementes pequenas, como as de hortaliças, severamente afetadas pela exposição à temperatura e umidade relativa do ar elevadas.

No tocante ao teste de deterioração controlada, ultimamente este vem sendo utilizado por diversos pesquisadores, para detectar diferenças no vigor de lotes de sementes, bem como avaliar o potencial de armazenamento de sementes de várias espécies de hortaliças.

Outros testes considerados eficientes para avaliação do vigor, com base na permeabilidade do sistema de membranas celulares, são os de condutividade elétrica e lixiviação de potássio. Para o teste de condutividade elétrica, o período de 24 horas de embebição das sementes, adotado rotineiramente, tem proporcionado resultados consistentes na diferenciação do potencial fisiológico para diversas espécies, principalmente dicotiledôneas; porém, estudos têm demonstrado que a redução deste período de embebição é possível para diversas espécies de hortaliças. No caso do teste de lixiviação de potássio, alguns estudos têm demonstrado que essa é uma alternativa promissora para ser incluída em programas de controle de qualidade, com a obtenção de resultados em torno de 30 minutos, além de demonstrar a independência das quantidades de potássio liberado durante a embebição e a quantidade de potássio existente na semente; isto indica que os resultados do teste refletem realmente o estado de organização das membranas (Custódio \& Marcos Filho, 1997; Panobianco, 2000).

Observa-se que os procedimentos para avaliação da qualidade das sementes de espécies hortícolas deveriam apresentar grau de desenvolvimento proporcional à sua magnitude e isto, infelizmente, não tem ocorrido. $O$ que se verifica é que os testes de vigor, de um modo geral, têm sido conduzidos, 
seguindo metodologia adaptada de procedimentos adotados para grandes culturas. Portanto, estes testes, em função de sua simplicidade e eficiência, merecem atenção dos tecnologistas de sementes para observações futuras. 


\section{MATERIAL E MÉTODOS}

A pesquisa foi conduzida, em duas etapas, no Laboratório de Análise de Sementes e no Campo Experimental do Departamento de Produção Vegetal da Escola Superior de Agricultura "Luiz de Queiroz" (USP/ESALQ), em Piracicaba, SP. A primeira etapa foi conduzida de março a outubro de 2000 , compreendendo o estudo preliminar de procedimentos alternativos para a condução dos testes de deterioração controlada, de envelhecimento acelerado, de condutividade elétrica e de lixiviação de potássio. A segunda teve início em novembro de 2000, estendendo-se até julho de 2001 e com o objetivo de comparar os procedimentos considerados mais eficientes, com base nas informações obtidas durante a primeira etapa. Nas duas etapas, os testes foram repetidos três vezes para verificação da consistência das informações.

\subsection{Sementes}

Foram utilizadas sementes tratadas (Benlate + Thiran, na proporção de $2 \mathrm{~g} / 100 \mathrm{~kg}$ de sementes) de dois híbridos de melão (AF-646 e AF-682), cada um representado por cinco lotes, provenientes da empresa SAKATA S.A., produzidas no ano agrícola de 1999/2000.

Durante o período experimental, os lotes permaneceram embalados em papel multifoliado e armazenados em câmara seca (18-20ํ C e 60\% UR), sendo homogeneizados periodicamente, em divisor tipo Solo. 


\subsection{Estudo dos testes de deterioração controlada, envelhecimento acelerado, condutividade elétrica e lixiviação de potássio (Etapa 1)}

Nesta etapa conduziram-se estudos específicos sobre a metodologia dos testes de deterioração controlada, de envelhecimento acelerado, de condutividade elétrica e lixiviação de potássio, procurando-se verificar sua eficiência para a identificação de diferentes níveis de vigor dos lotes estudados. Para isso, foram realizados os seguintes testes:

3.2.1 Determinação do grau de umidade: realizada em estufa a $105 \pm 3^{\circ} \mathrm{C} / 24 \mathrm{~h}$ (Brasil, 1992), utilizando-se duas amostras para cada lote, com aproximadamente $4,0 \mathrm{~g}$ de sementes cada. Os resultados foram expressos em porcentagem média para cada lote (base úmida).

3.2.2 Germinação: utilizaram-se quatro repetições de 50 sementes por lote, distribuídas em rolos de papel toalha Germitest, umedecidas com quantidade de água equivalente a 2,5 vezes o peso do substrato seco (Menezes et al., 1993) e colocadas para germinar a $25^{\circ} \mathrm{C}$. As avaliações foram realizadas aos quatro e oito dias após a semeadura, segundo os critérios estabelecidos pelas Regras para Análise de Sementes (Brasil, 1992); os resultados foram expressos em porcentagem média de plântulas normais, para cada lote.

3.2.3 Primeira contagem de germinação: conduzida juntamente com o teste de germinação, computando-se a porcentagem média de plântulas normais, aos quatro dias após a semeadura.

3.2.4 Deterioração controlada: para realização deste teste, inicialmente, o grau de umidade das sementes foi ajustado para 18, 21 e 24\% pelo método da atmosfera úmida (Rosseto et al., 1995), conduzido em caixas plásticas $(11 \times 11 \times 3 \mathrm{~cm})$ contendo aproximadamente $4 \mathrm{~g}$ de sementes, distribuídas em uma 
camada simples sobre a tela metálica suspensa em seu interior. As caixas, tampadas e com $40 \mathrm{~mL}$ de água, foram mantidas em incubadora, a $20^{\circ} \mathrm{C}$. Durante o umedecimento artificial, os graus de umidade das sementes foram monitorados através de pesagens sucessivas, até se obterem os valores desejados. Em seguida, cada amostra foi colocada em recipiente aluminizado, fechado hermeticamente, permanecendo por cinco dias em câmara fria (8$10^{\circ} \mathrm{C}$ ) para atingir o equilíbrio higroscópico. Após este período, as sementes foram mantidas em banho-maria, a $45^{\circ} \mathrm{C}$, por 24 e 48 horas; ao término deste período, os recipientes foram imersos rapidamente em água fria para reduzir a temperatura, sendo posteriormente instalado o teste de germinação Powell, 1995). As contagens foram realizadas no quarto dia após a semeadura e, os resultados, expressos em porcentagem média de plântulas normais para cada lote. Foi determinado, também, o grau de umidade das sementes após os períodos em banho-maria.

Identificaram-se, também nesta etapa, as combinações grau de umidade/período (24\%/24h e $24 \% / 48 \mathrm{~h}$ ) mais eficientes na condução do teste; portanto, novos testes foram realizados, utilizando-se estas combinações, objetivando identificar a mais promissora.

3.2.5 Envelhecimento acelerado (procedimento tradicional): realizado de acordo com o método conhecido como "gerbox", em câmara do tipo "jaquetada" de água (modelo 3015 VWR Scientific); utilizaram-se amostras de, aproximadamente, quatro gramas de sementes, distribuídas de maneira a formarem camada simples sobre a superfície da tela metálica suspensa no interior de cada caixa plástica (compartimento interno); estas continham 40m de água. As caixas, tampadas, permaneceram no interior da câmara durante três períodos de envelhecimento (48, 72 ou 96h), sendo utilizadas duas temperaturas ( $38^{\circ} \mathrm{C}$ ou $41^{\circ} \mathrm{C}$ ). Em seguida, as sementes foram submetidas ao teste de germinação conforme descrito no item 3.2.2. A avaliação foi realizada aos quatro dias após a semeadura e, os resultados, expressos em porcentagem 
média de plântulas normais para cada lote. Para fins de monitoramento do teste, foi determinado, também, o grau de umidade das sementes antes e após os períodos de incubação.

Identificaram-se ainda nesta etapa, as combinações temperatura/período ( $38^{\circ} \mathrm{C}$ e $41^{\circ} \mathrm{C} / 72$ e $96 \mathrm{~h}$ ) mais promissoras; portanto, novos testes foram conduzidos, usando-se estas combinações, visando determinar a mais eficiente na condução do teste.

3.2.6 Envelhecimento acelerado (solução saturada de sal): conduzido da mesma maneira descrita para o teste tradicional (item 3.2.5), com exceção de serem adicionados ao fundo de cada caixa plástica (compartimento individual), $40 \mathrm{ml}$ de solução saturada de $\mathrm{NaCl}$, em substituição à água. Essa solução foi obtida através da proporção $40 \mathrm{~g}$ de $\mathrm{NaCl} / 100 \mathrm{~mL}$ de água, estabelecendo, com isso, ambiente com $76 \%$ de umidade relativa do ar.

3.2.7 Condutividade elétrica (CE): esta etapa inicial consistiu na tentativa de identificação das combinações mais eficientes entre três variáveis, na separação do vigor dos lotes de sementes de cada híbrido. Para isso, foram estudadas variações no número de sementes (25 e 50), volume de água de embebição (50 e $75 \mathrm{~mL})$ e temperatura $\left(20^{\circ} \mathrm{C}, 2^{\circ} \mathrm{C}\right.$ e $\left.30^{\circ} \mathrm{C}\right)$, durante $1,2,4,8$, 12, 16, 20 e 24 horas de embebição. Desta forma, os tratamentos foram os seguintes:

1. 25 sementes embebidas em $50 \mathrm{~mL}$ de água destilada, a $20^{\circ} \mathrm{C}$;

2. 50 sementes embebidas em $50 \mathrm{~mL}$ de água destilada, a $20^{\circ} \mathrm{C}$;

3. 25 sementes embebidas em $75 \mathrm{~mL}$ de água destilada, a $20^{\circ} \mathrm{C}$;

4. 50 sementes embebidas em $75 \mathrm{~mL}$ de água destilada, a $20^{\circ} \mathrm{C}$;

5. 25 sementes embebidas em $50 \mathrm{~mL}$ de água destilada, a $25^{\circ} \mathrm{C}$;

6. 50 sementes embebidas em $50 \mathrm{~mL}$ de água destilada, a $25^{\circ} \mathrm{C}$;

7. 25 sementes embebidas em $75 \mathrm{~mL}$ de água destilada, a $25^{\circ} \mathrm{C}$; 
8. 50 sementes embebidas em $75 \mathrm{~mL}$ de água destilada, a $25^{\circ} \mathrm{C}$;

9. 25 sementes embebidas em $50 \mathrm{~mL}$ de água destilada, a $30^{\circ} \mathrm{C}$; 10. 50 sementes embebidas em $50 \mathrm{~mL}$ de água destilada, a $30^{\circ} \mathrm{C}$; 11. 25 sementes embebidas em $75 \mathrm{~mL}$ de água destilada, a $30^{\circ} \mathrm{C}$; 12. 50 sementes embebidas em $75 \mathrm{~mL}$ de água destilada, a $30^{\circ} \mathrm{C}$.

O teste foi conduzido pelo método massal, utilizando-se quatro subamostras de sementes fisicamente puras para cada lote. As sementes fisicamente puras, pesadas com precisão de $0,0001 \mathrm{~g}$, foram colocadas para embeber em copos plásticos contendo água destilada e mantidos em germinador durante cada período de embebição. As leituras da condutividade elétrica foram realizadas em condutivímetro DIGIMED DM-31 e os valores médios, para cada lote, expressos em $\mu \mathrm{mho} / \mathrm{cm} / \mathrm{g}$ de semente.

3.2.8 Lixiviação de potássio: conduzido de forma semelhante à descrita para o estudo sobre a condutividade elétrica, empregando-se, inicialmente, os mesmos tratamentos apresentados no item 3.2.7, com leituras feitas a cada 30 minutos até três horas e, a partir desta, a cada 60 minutos, até serem completadas cinco horas de embebição. De todas as combinações utilizadas preliminarmente, as que mantiveram o teste prático, rápido e com resultados confiáveis foram as seguintes:

1. 25 sementes embebidas em $50 \mathrm{~mL}$ de água destilada, a $25^{\circ} \mathrm{C}$;

2. 50 sementes embebidas em $75 \mathrm{~mL}$ de água destilada, a $25^{\circ} \mathrm{C}$;

3. 25 sementes embebidas em $50 \mathrm{~mL}$ de água destilada, a $30^{\circ} \mathrm{C}$;

4. 50 sementes embebidas em $75 \mathrm{~mL}$ de água destilada, a $30^{\circ} \mathrm{C}$.

As sementes foram pesadas com precisão de $0,0001 \mathrm{~g}$, colocadas para embeber em copos plásticos contendo água destilada e mantidos em germinador durante cada período de embebição. As leituras de potássio 
lixiviado das sementes foram feitas em fotômetro de chama DIGIMED NK-2004, utilizando-se o padrão 50 ppm de potássio, ajustado para leitura 50 . Escolheuse este padrão, porque proporcionou a realização de um maior número de leituras sem a necessidade de diluição, tornando o teste prático, rápido e confiável.

Inicialmente, foi estabelecida a curva de calibração do fotômetro de chama, para verificação da linearidade da curva da solução padrão de 50 ppm de potássio. Esta calibração foi estabelecida através de regressão linear e avaliada com seis observações, sendo uma observação com água destilada, ajustada para leitura zero e, as demais, realizadas com padrão de potássio de concentração conhecida e inferiores à calibração inicialmente ajustada, para verificar a linearidade da curva (Custódio \& Marcos Filho, 1997). O padrão estudado apresentou linearidade com coeficiente de determinação $\left(R^{2}=0,9948\right)$, o que confirmou a adequação da curva.

O cálculo da lixiviação de potássio foi feito pela multiplicação da leitura obtida no fotômetro de chama $(\mathrm{K} / \mathrm{mL})$ pelo volume de água destilada $(\mathrm{mL})$ e dividido pelo peso da amostra $(\mathrm{g})$. O resultado final foi expresso em $\mathrm{ppm} \mathrm{K/g}$ de semente.

As leituras das quantidades de potássio exsudado pelas sementes de melão, nos diferentes períodos de embebição, foram feitas no mesmo material; em função disso, na execução dos cálculos descontou-se $1 \mathrm{~mL}$ de solução, após cada leitura, porque o fotômetro de chama utiliza $1 \mathrm{~mL}$ de solução para determinar a quantidade de potássio lixiviado, segundo as informações técnicas do aparelho.

3.2.9 Método Agroflora para avaliação de vigor em melão: este método de controle interno de qualidade, utilizado pela empresa SAKATA S.A., foi realizado nas instalações da empresa, em Bragança Paulista, SP, utilizando-se quatro repetições de 50 sementes por lote. Cada repetição foi composta por cinco linhas de um metro linear, espaçadas $20 \mathrm{~cm}$ entre si, onde foram 
distribuídas 10 sementes, espaçadas entre si de $10 \mathrm{~cm}$ e cobertas com, aproximadamente, $2 \mathrm{~cm}$ de terra. A semeadura foi realizada em canteiros de alvenaria, localizados no interior de casa de vegetação, contendo solo esterilizado; os canteiros receberam irrigação três vezes ao dia. As avaliações foram efetuadas no quarto, oitavo e décimo dias, avaliando-se o vigor nessa última contagem. Para tanto, adotou-se o seguinte procedimento: a) contagem de plântulas emergentes (visíveis), sem considerar qualquer critério de classificação, obtendo-se desse modo, a Emergência Total de Plântulas - ETP); b) utilização de critérios de avaliação de vigor, por meio de uma escala (Normal, Fraca e Anormal), obtendo-se o valor PP (Plântulas Problemáticas), resultado da soma das plântulas fracas e anormais; e c) cálculo da EPN (Emergência de Plântulas Normais), como indicativo de vigor, pela fórmula: EPN = ETP - PP.

Os critérios adotados para avaliação da parte aérea de plântulas de melão pelo Método Agroflora (Figura 1) foram os seguintes: a) plântula normal - cotilédones (ambos fixos, completamente desenvolvidos, verdes, sem danos); hipocótilo (ereto, sem rachaduras ou lesões); epicótilo (presente, primeira folha verdadeira em expansão); raiz (presente, mas não visível); b) plântula normal fraca - cotilédones (no mínimo um, pouco expandido, totalmente presos pelo tegumento, verde, com dano menor ou igual a $50 \%$ da sua superfície); hipocótilo (ereto, levemente alongado, sem fendas ou lesões); epicótilo (presente, primeira folha verdadeira pouco desenvolvida); raiz (presente, mas não visível); c) plântula anormal - cotilédones (ausentes ou "cego", brancos ou amarelados, com dano maior ou igual a $50 \%$ da sua superfície); hipocótilo (cortado, fendido, estiolado); epicótilo (ausente); raiz (ausente ou presente acima da superfície do solo). 


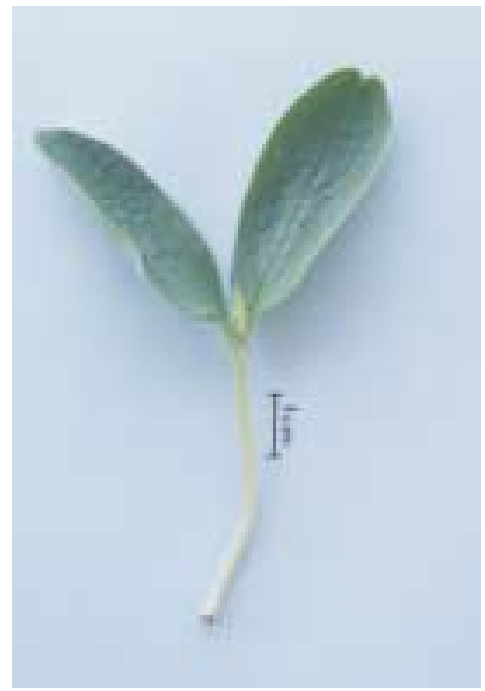

$\mathbf{N}$

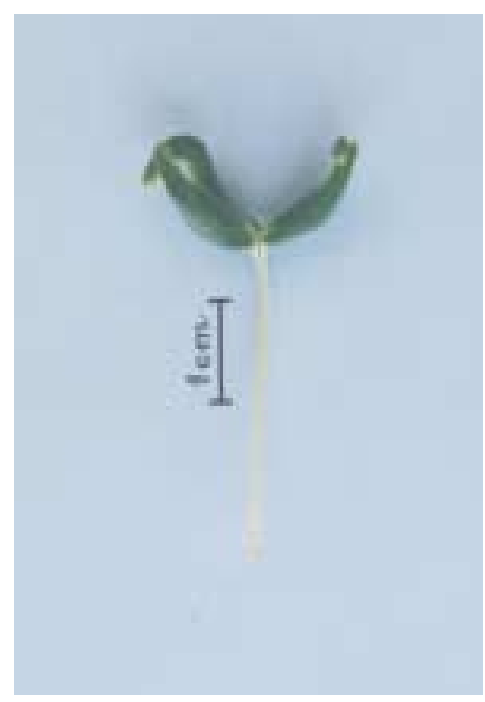

$\mathbf{N F}_{\mathrm{c}}$

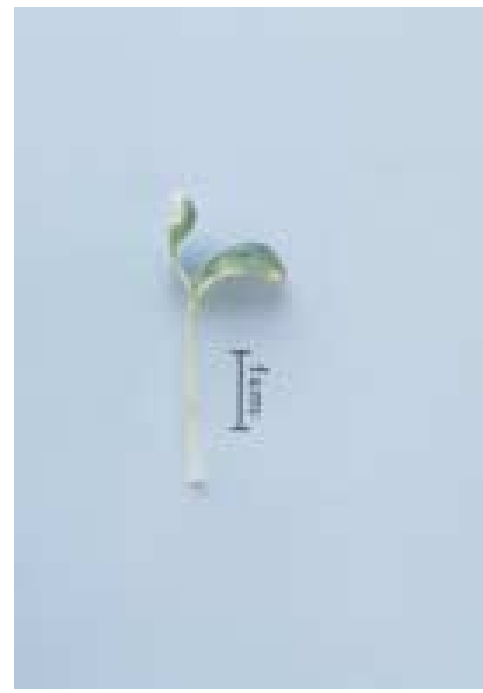

$\mathrm{NF}_{\mathrm{A}}$

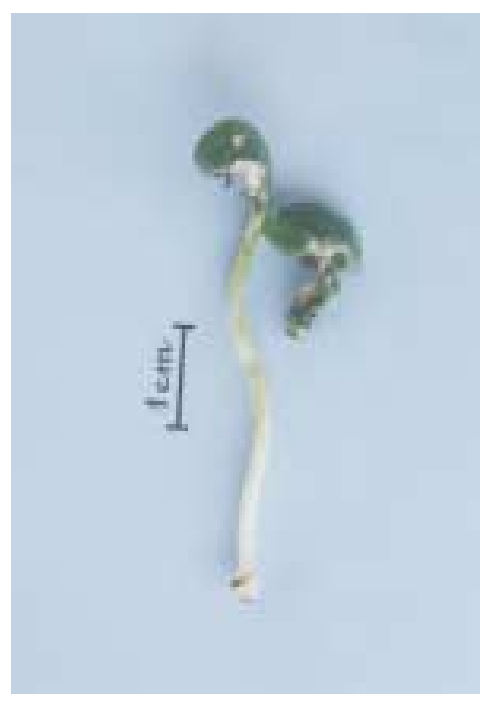

$A_{A}$

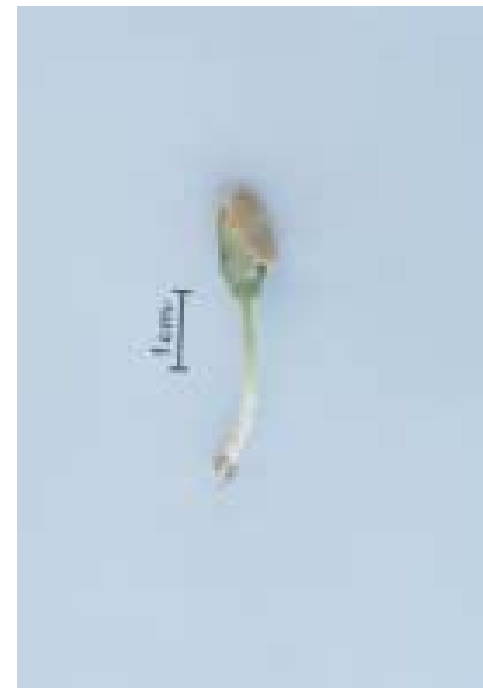

$\mathbf{N F}_{\mathrm{B}}$

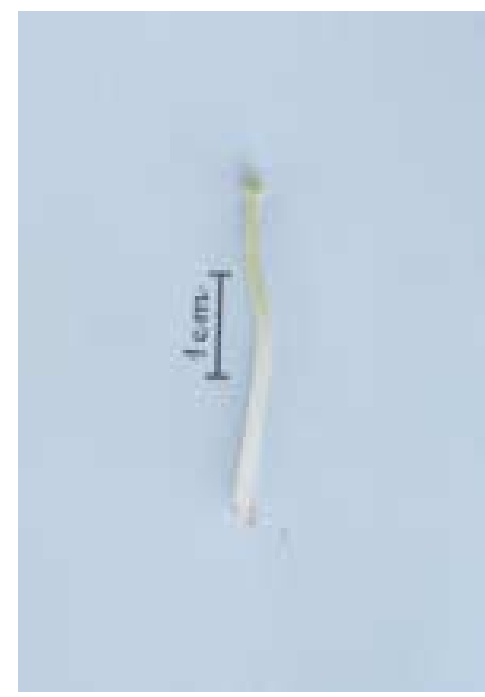

$A_{B}$

Figura 1- Critérios de avaliação da parte aérea de plântulas de melão pelo Método Agroflora: $\mathrm{N}$ (Normal); $\mathrm{NF}_{\mathrm{A}}$ (Fraca); $\mathrm{NF}_{\mathrm{B}}$ (Fraca/cotilédones presos pelo tegumento); $\mathrm{Nf}_{C}($ Fraca/dano $\leq 50 \%) ; \mathrm{A}_{\mathrm{A}}$ (Anormal/dano $\left.\geq 50 \%\right)$ e $\mathrm{A}_{B}$ (Anormal/“cotilédone cego"). 
3.2.10 Emergência de plântulas em casa de vegetação: foram utilizadas quatro repetições de 50 sementes por lote, semeadas em bandejas multicelulares de isopor, contendo substrato comercial obtido pela mistura de casca de pinus, fibra de coco, vermiculita e fertilizante, com a seguinte composição: $57,16 \%$ de água; $25,28 \%$ de matéria orgânica e $17,56 \%$ de resíduo mineral $(12,74 \%$ de resíduo mineral insolúvel; $1,98 \%$ de carbono mineral; $0,28 \%$ de $\mathrm{N} ; 0,10 \%$ de $\mathrm{P}_{2} \mathrm{O}_{5} ; 0,40 \%$ de $\mathrm{K}_{2} \mathrm{O} ; 0,70 \%$ de $\mathrm{Ca} ; 0,48 \%$ de Mg; 0,05\% de S; 0,0023\% de Cu; 0,6994 de Fe; 0,0354\% de Mn; 0,0025\% de $\mathrm{Zn}$ e $0,0925 \%$ de $\mathrm{Na}$ ). As bandejas foram mantidas a $25-30^{\circ} \mathrm{C}$, em casa de vegetação dotada de sistema de nebulização intermitente. As contagens, efetuadas aos 21 dias após a semeadura, permitiram avaliar a porcentagem de emergência de plântulas por lote (Nakagawa, 1994). 


\subsection{Comparação entre testes para avaliação do potencial fisiológico de sementes de melão (Etapa 2)}

Os resultados considerados promissores após os estudos da metodologia dos testes de deterioração controlada, envelhecimento acelerado, condutividade elétrica e lixiviação de potássio foram avaliados comparativamente.

3.3.1 Determinação do grau de umidade: adotou-se o mesmo procedimento descrito no item 3.2.1.

3.3.2 Germinação: conduzido conforme descrição no item 3.2.2.

3.3.3 Primeira contagem de germinação: realizado conforme o item 3.2.3.

3.3.4 Deterioração controlada: em função dos resultados, o grau e umidade das sementes foi ajustado para $24 \%$ e, a seguir, executou-se o procedimento descrito em 3.2.4, sendo as sementes mantidas em banho-maria, a $45^{\circ} \mathrm{C}$, durante 24 horas.

3.3.5 Envelhecimento acelerado (procedimento tradicional): adotou-se o mesmo procedimento descrito no item 3.2.5. Em função dos resultados da primeira etapa, adotou-se a combinação de $41^{\circ} \mathrm{C}$, durante $72 \mathrm{~h}$ como a mais promissora.

3.3.6 Envelhecimento acelerado (solução saturada de sal): empregou-se a mesma metodologia descrita no item 3.2 .5 e, em função dos resultados, utilizou-se a combinação $41^{\circ} \mathrm{C} / 72 \mathrm{~h}$. 
3.3.7 Condutividade elétrica: seguiu-se a metodologia descrita no item 3.2.7 que, em função dos resultados da primeira etapa adotou-se a combinação 50 sementes $/ 75 \mathrm{~mL} / 25^{\circ} \mathrm{C}$.

3.3.8 Lixiviação de potássio: adotou-se o mesmo procedimento do item 3.2.8 que, em função dos resultados utilizou-se a combinação 25 sementes $/ 50 \mathrm{~mL} / 30^{\circ} \mathrm{C}$.

3.3.9 Método Agroflora para avaliação de vigor em melão: conduzido do mesmo modo descrito no item 3.2.9.

3.3.10 Emergência de plântulas em casa de vegetação: adotado o mesmo procedimento descrito no item 3.2.10.

3.4 Procedimento estatístico: Os dados referentes aos testes de germinação, primeira contagem de germinação, envelhecimento acelerado, deterioração controlada, Método Agroflora e emergência de plântulas em casa de vegetação foram transformados em arc sen $\sqrt{x / 100}$, enquanto os dados de condutividade elétrica e de lixiviação de potássio não sofreram transformação.

Para o teste de envelhecimento acelerado, preliminarmente, os tratamentos constaram da combinação entre duas temperaturas e três períodos de envelhecimento, totalizando seis tratamentos (2x3); após identificação das melhores combinações, avaliaram-se quatro tratamentos $(2 \times 2)$, segundo esquemas apresentados nas Tabelas 2 e 3, respectivamente.

No teste de deterioração controlada, os tratamentos preliminares constituíram-se da combinação entre três graus de umidade e dois períodos em banho-maria, totalizando seis tratamentos $(2 \times 3)$; após identificação das melhores combinações, dois tratamentos foram constituídos, segundo esquemas nas Tabelas 2 e 3, respectivamente. 
As análises de variância foram realizadas separadamente para cada híbrido e teste conduzido, nas duas etapas, utilizando-se o delineamento inteiramente casualizado, com quatro repetições; e, a comparação múltipla das médias através do teste de Tukey, ao nível de 5\% de probabilidade. Para os cálculos estatísticos utilizou-se o Sistema de Análise Estatística-SANEST (Zonta \& Machado, 1984).

Os esquemas das análises de variância, referentes æ̀̀ Etapas 1 e 2, encontram-se nas Tabelas de 1 a 5.

Tabela 1. Análise da variância, para cada híbrido, dos dados de germinação, primeira contagem de germinação, Método Agroflora e emergência de plântulas, na Etapa 1.

\begin{tabular}{cc}
\hline Causas de variação & Graus de Liberdade \\
\hline Lotes & 4 \\
Resíduo & 15 \\
Total & 19 \\
\hline
\end{tabular}

Tabela 2. Análise da variância dos dados de envelhecimento acelerado (procedimento tradicional e com solução salina) e deterioração controlada, para cada híbrido, preliminarmente, na Etapa 1.

\begin{tabular}{cc}
\hline Causas de variação & Graus de Liberdade \\
\hline Tratamentos & 5 \\
Lotes & 4 \\
Tratamentos x Lotes & 20 \\
Resíduo & 90 \\
Total & 119 \\
\hline
\end{tabular}


Tabela 3. Análise da variância dos dados de envelhecimento acelerado (procedimento tradicional e com solução salina) e deterioração controlada, após identificação das melhores combinações, para cada híbrido, na Etapa 1.

\begin{tabular}{ccc}
\hline Causas de variação & $\begin{array}{c}\text { Graus de Liberdade } \\
\text { (Envelhecimento acelerado) }\end{array}$ & $\begin{array}{c}\text { Graus de Liberdade } \\
\text { (Deterioração controlada) }\end{array}$ \\
\hline Tratamentos & 3 & 1 \\
Lotes & 4 & 4 \\
Tratamentos x Lotes & 12 & 4 \\
Resíduo & 60 & 30 \\
Total & 79 & 39 \\
\hline
\end{tabular}

Tabela 4. Análise da variância dos dados de condutividade elétrica e lixiviação de potássio, para cada híbrido, na Etapa 1.

\begin{tabular}{ccc}
\hline Causas de variação & $\begin{array}{c}\text { Graus de Liberdade } \\
\text { (Condutividade elétrica) }\end{array}$ & $\begin{array}{c}\text { Graus de Liberdade } \\
\text { (Lixiviação de potássio) }\end{array}$ \\
\hline Tratamentos & 11 & 3 \\
Lotes & 4 & 4 \\
Tratamentos x Lotes & 44 & 12 \\
Resíduo & 180 & 60 \\
Total & 239 & 79 \\
\hline
\end{tabular}


Tabela 5. Análise da variância, para cada híbrido, dos dados de germinação, primeira contagem de germinação, Método Agroflora, emergência de plântulas, deterioração controlada, envelhecimento acelerado, condutividade elétrica e lixiviação de potássio, para cada híbrido, na Etapa 2.

\begin{tabular}{cc}
\hline Causas de variação & Graus de Liberdade \\
Lotes & 4 \\
Resíduo & 15 \\
Total & 19 \\
\hline
\end{tabular}




\section{RESULTADOS E DISCUSSÃO}

No presente item serão discutidos os resultados referentes aos testes empregados para a avaliação do potencial fisiológico de sementes de melão, separadamente para cada etapa e híbrido.

\subsection{Estudo dos testes de deterioração controlada, envelhecimento acelerado, condutividade elétrica e lixiviação de potássio (Etapa 1)}

\subsubsection{Avaliação inicial da qualidade dos lotes}

A avaliação inicial da qualidade dos lotes de sementes de melão foi efetuada através dos testes de germinação, primeira contagem de germinação, Método Agroflora e emergência de plântulas em casa de vegetação; determinou-se, também, o grau de umidade das sementes. Os resultados dessas avaliações encontram-se na Tabela 6.

Os dados referentes ao grau de umidade das sementes foram

semelhantes para os dez lotes estudados. Este fato é importante para a execução dos testes, considerando-se que a uniformização do teor de água das sementes é imprescindível para a padronização das avaliações e obtenção de resultados consistentes (Marcos Filho et al., 1987; Loeffler et al., 1988; Krzyzanowski et al., 1991; Marcos Filho, 1999b). Assim, quanto àgerminação e emergência de plântulas, as sementes mais úmidas, dentro de certos limites, germinam mais rapidamente. Por outro lado, o grau de umidade 
elevado prejudica o desempenho das sementes no teste de envelhecimento acelerado e pode favorecê-lo no teste de condutividade elétrica.

Tabela 6. Qualidade inicial de dez lotes de sementes de melão, híbridos AF-646 e AF-682.

\begin{tabular}{ccccccc}
\hline Híbridos & Lotes & $\begin{array}{c}\text { Grau de } \\
\text { Umidade }\end{array}$ & $\begin{array}{c}\text { Germina- } \\
\text { ção }\end{array}$ & $\begin{array}{c}\text { Primeira } \\
\text { Contagem }\end{array}$ & $\begin{array}{c}\text { Método } \\
\text { Agroflora }\end{array}$ & $\begin{array}{c}\text { Emergência } \\
\text { de plântulas }\end{array}$ \\
\hline \multirow{4}{*}{ AF-646 } & 1 & 7,2 & $92 \mathrm{a}^{*}$ & $83 \mathrm{~b}$ & $86 \mathrm{~b}$ & $88 \mathrm{~b}$ \\
& 2 & 7,1 & $98 \mathrm{a}$ & $97 \mathrm{a}$ & $96 \mathrm{a}$ & $97 \mathrm{a}$ \\
& 3 & 7,2 & $98 \mathrm{a}$ & $96 \mathrm{a}$ & $96 \mathrm{a}$ & $97 \mathrm{a}$ \\
& 4 & 7,4 & $98 \mathrm{a}$ & $98 \mathrm{a}$ & $99 \mathrm{a}$ & $98 \mathrm{a}$ \\
& 5 & 7,3 & $98 \mathrm{a}$ & $94 \mathrm{a}$ & $96 \mathrm{a}$ & $96 \mathrm{a}$ \\
& C.V.(\%) & - & 2,4 & 3,6 & 3,2 & 4,2 \\
& 6 & 7,0 & $98 \mathrm{a}$ & $98 \mathrm{a}$ & $98 \mathrm{a}$ & $97 \mathrm{a}$ \\
& 7 & 7,0 & $92 \mathrm{a}$ & $90 \mathrm{~b}$ & $88 \mathrm{bc}$ & $90 \mathrm{~b}$ \\
& 8 & 7,0 & $96 \mathrm{a}$ & $93 \mathrm{ab}$ & $93 \mathrm{~b}$ & $94 \mathrm{ab}$ \\
& 9 & 7,0 & $92 \mathrm{a}$ & $91 \mathrm{~b}$ & $90 \mathrm{bc}$ & $91 \mathrm{~b}$ \\
& 10 & 7,1 & $88 \mathrm{~b}$ & $76 \mathrm{c}$ & $85 \mathrm{c}$ & $84 \mathrm{c}$ \\
& C.V.(\%) & - & 3,2 & 4,7 & 3,6 & 4,7 \\
\hline${ }^{*}$ Comparação de médias dentro de cada coluna pelo teste de Tukey, $5 \%$ de \\
probabilidade.
\end{tabular}

Verifica-se que os lotes do híbrido AF-646 não diferiram entre si no teste de germinação; entretanto, os testes de primeira contagem de germinação, Método Agroflora e emergência de plântulas em casa de vegetação indicaram a menor qualidade do lote 1, diferindo estatisticamente dos lotes 2, 3, 4 e 5. 
Com relação aos lotes do híbrido AF-682, o teste de geminação revelou o lote 10 como de pior qualidade, enquanto que os lotes 6,7 , 8, e 9 foram agrupados num mesmo nível, não diferindo entre si. Os testes de primeira contagem de germinação, Método Agroflora e emergência de plântulas em casa de vegetação apontaram os lotes 6 e 10 como os de melhor e pior qualidade, respectivamente, e os lotes 7, 8 e 9 como de qualidade intermediária.

Vale ressaltar que todos os lotes apresentaram percentagens média de plântulas normais superiores à mínima estabelecida para comercialização de sementes de melão, ou seja, $80 \%$ de germinação. Segundo Marcos Filho (1999a), é importante e coerente a comparação de lotes de sementes com germinação semelhante e, de acordo com Powell (1986), preferencialmente situados na Fase I da curva de perda de viabilidade. Essa autora considera que a posição do lote dentro da Fase I determina seu nível de vigor. Neste estudo, todos os lotes apresentaram alta qualidade, com germinação variando entre $88 \mathrm{e}$ $98 \%$, estando situados, portanto, na Fase I da curva de perda de viabilidade da semente, caracterizada por ser relativamente longa e com poucas sementes mortas.

Normalmente a capacidade dos testes de laboratório para estimar o potencial de emergência das plântulas diminui à medida que as condições de ambiente vão se desviando das mais adequadas, tornando-se praticamente nula sob condições extremamente desfavoráveis. Portanto, de maneira geral, verificou-se para todos os lotes que os resultados de germinação foram semelhantes aos encontrados para à emergência de plântulas em casa de vegetação. Isso ocorreu, provavelmente, devido à condições favoráveis de ambiente em ambos os testes.

O teste de primeira contagem de germinação, mostrou-se mais sensível que o teste de germinação, principalmente para os lotes do híbrido AF-682, que classificou o lote 6 como de melhor potencial fisiológico, embora não diferindo estatisticamente do lote 8; o lote 10 foi identificado como de pior qualidade. Com relação aos lotes do híbrido AF-646, esses apresentam 
resultados semelhantes no teste de germinação, diferindo apenas para o lote 1 que apresentou menor percentagem de plântulas normais.

Embora a primeira contagem de germinação possa ser considerada um indicativo de vigor, sabe-se que a redução da velocidade da germinação não está entre os primeiros eventos do processo de deterioração de sementes (Delouche \& Baskin, 1973), justificando a menor eficiência deste teste em detectar pequenas diferenças de vigor e o conseqüente agrupamento dos lotes. Por outro lado, Bhéring et al. (2000) trabalhando com sementes de pepino, verificaram que o teste de primeira contagem de germinação pode ser utilizado rotineiramente para se obterem informações preliminares sobre o vigor de lotes de sementes desta espécie. Segundo Nakagawa (1999), o teste de primeira contagem de germinação, muitas vezes, expressa melhor as diferenças de velocidade de germinação entre lotes do que os índices de velocidade de germinação. Trata-se portanto, de um teste interessante por identificar lotes com capacidade de estabelecimento mais rápido e ser menos trabalhoso que o de velocidade de emergência, além de ser conduzido simultaneamente com o teste de germinação, não exigindo equipamento especial.

O Método Agroflora apresentou ordenação dos lotes semelhante à verificada para a primeira contagem de germinação, indicando o lote 1 do híbrido AF-646 como o menos vigoroso. No caso do híbrido AF-682, os lotes 6 e 10 foram considerados como os de melhor e pior qualidade, respectivamente; os demais apresentaram comportamento intermediário. Esse teste é incluído em programa interno de controle de qualidade da empresa SAKATA S.A., para sementes de melão, tem se mostrado, de forma geral, eficiente na classificação dos lotes em diferentes níveis de vigor.

O teste de emergência de plântulas em casa de vegetação classificou os lotes de melhor e pior desempenho, de maneira semelhante àverificada nos testes de primeira contagem de germinação e Método Agroflora, principalmente para o híbrido AF-682. Segundo Marcos Filho (1999a), o teste de emergência de plântulas constitui parâmetro indicador da eficiência dos testes para avaliação do 
potencial fisiológico de lotes de sementes. Portanto, verifica-se que essa eficiência em distinguir, com segurança, os lotes de baixo e alto vigor foi mais evidente para os lotes do híbrido AF-682, enquanto que os do híbrido AF-646, apresentaram qualidade relativamente uniforme, identificando-se apenas o lote 1 como de menor potencial fisiológico.

A análise comparativa dos dados indicou que, de uma maneira geral, os testes foram eficientes na identificação dos lotes que ocupam posições extremas, ou seja, separaram, de maneira consistente, diferenças acentuadas no potencial fisiológico das sementes. Assim pode-se afirmar, com segurança, que o lote 1 do híbrido AF-646 foi o menos vigoroso em relação aos demais; já os lotes 6 e 10, do híbrido AF-682, foram, respectivamente, o mais e menos vigoroso, enquanto os demais apresentam qualidade intermediária, ocupando posições diferentes de acordo com o teste realizado. Realmente, a identificação de lotes de vigor intermediário pode sofrer variações em função da metodologia adotada, principalmente quando se tratam de lotes com diferenças pouco acentuadas (McDonald \& Wilson, 1979; Kulik \& Yaklich, 1982; Marcos Filho et al., 1984).

Assim, enfatiza-se a importância do uso de mais de um teste para determinar o vigor dos lotes de sementes (Marcos Filho, 1998), devido à influência dos métodos adotados e uso de situações específicas de estresse para estimar o comportamento relativo dos lotes em campo (TeKrony \& Egly, 1977; Carvalho \& Nakagawa, 2000).

Portanto, verifica-se que é conveniente pesquisar tanto lotes com diferenças estreitas como outros com variação mais ampla no potencial fisiológico porque há possibilidade de detectar grau de sensibilidade dos testes estudados. Este foi o caso do híbrido AF-646 que apresentou pequenas diferenças e o híbrido AF-682, com diferenças mais amplas no potencial fisiológico, embora os lotes dos dois híbridos apresentassem poder germinativo elevado e relativamente uniforme. 


\subsubsection{Deterioração controlada}

Os dados obtidos para o teste de deterioração controlada, híbridos AF646 e AF-682, utilizando-se dez lotes de sementes com três graus de umidade diferentes e dois períodos de condicionamento em banho-maria, são apresentados na Tabela 7.

Examinando-se essa Tabela, verifica-se, de forma geral, que todas as combinações apontaram o lote 1 do híbrido AF-646, como menos vigoroso, confirmando os resultados obtidos na avaliação inicial dos lotes de sementes através dos testes de primeira contagem de germinação, Método Agroflora e emergência de plântulas (Tabela 6); o lote 4 foi indicado como de qualidade mais elevada e, os demais, apresentaram qualidade intermediária, ou seja, comportamento variável em função das combinações estudadas.

No tocante ao híbrido AF-682, os lotes 6 e 10 foram considerados os de maior e menor vigor, respectivamente; os demais, apresentaram comportamento intermediário de qualidade, de maneira semelhante à verificada para o híbrido AF-646. Esses resultados são concordantes com os obtidos nos testes de primeira contagem de germinação, Método Agroflora e emergência de plântulas em casa de vegetação.

Diante dos resultados obtidos, constatou-se que as combinações $24 \% / 24 \mathrm{~h}$ e $24 \% / 48 \mathrm{~h}$ apresentaram maior poder discriminatório da qualidade dos lotes, com relação ao potencial fisiológico, além de concordar com os resultados dos testes de primeira contagem de germinação, Método Agroflora e emergência de plântulas em casa de vegetação, para o híbrido AF-682 e, também, no que se refere ao lote 1 do híbrido AF-646. Esses resultados vão de encontro aos obtidos por Oluoch \& Welbaum (1996), que utilizaram o teste de deterioração controlada, com a combinação $21 \% / 45^{\circ} \mathrm{C} / 72 \mathrm{~h}$, para avaliar o vigor de sementes de melão durante o processo de maturação. 
Tabela 7. Dados médios obtidos para o teste de deterioração controlada de dez lotes de sementes de melão, híbridos AF-646 e AF-682.

\begin{tabular}{|c|c|c|c|c|c|c|c|}
\hline \multirow{3}{*}{ Híbridos } & \multirow{3}{*}{ Lotes } & \multicolumn{6}{|c|}{ Deterioração controlada } \\
\hline & & \multicolumn{3}{|c|}{$24 \mathrm{~h}$} & \multicolumn{3}{|c|}{$48 \mathrm{~h}$} \\
\hline & & $18 \%$ & $21 \%$ & $24 \%$ & $18 \%$ & $21 \%$ & $24 \%$ \\
\hline & & & & & & & \\
\hline \multirow[t]{6}{*}{ AF-646 } & 1 & $85 c^{*}$ & $82 \mathrm{c}$ & $80 c$ & $82 \mathrm{bc}$ & $80 \mathrm{bc}$ & $78 \mathrm{c}$ \\
\hline & 2 & $96 a b$ & $98 a$ & $94 \mathrm{~b}$ & $93 a b$ & $94 \mathrm{a}$ & $92 b$ \\
\hline & 3 & $93 a b$ & $93 a b$ & $94 \mathrm{~b}$ & $88 b$ & $87 \mathrm{~b}$ & $91 \mathrm{~b}$ \\
\hline & 4 & $98 \mathrm{a}$ & $96 a$ & $98 \mathrm{a}$ & $98 \mathrm{a}$ & $94 \mathrm{a}$ & $98 \mathrm{a}$ \\
\hline & 5 & $91 \mathrm{~b}$ & $90 \mathrm{~b}$ & $85 c$ & $88 b$ & $89 a b$ & $80 c$ \\
\hline & & \multicolumn{6}{|c|}{ C.V. $(\%)=3,6$} \\
\hline \multirow[t]{6}{*}{ AF-682 } & 6 & $97 \mathrm{a}$ & $95 \mathrm{a}$ & $95 \mathrm{a}$ & $93 \mathrm{a}$ & $90 \mathrm{a}$ & $89 a$ \\
\hline & 7 & $84 \mathrm{~b}$ & $83 b$ & $86 \mathrm{~b}$ & $83 b$ & $88 a b$ & $72 b$ \\
\hline & 8 & $97 \mathrm{a}$ & $94 \mathrm{a}$ & $88 \mathrm{~b}$ & $88 a b$ & $89 a b$ & $86 \mathrm{a}$ \\
\hline & 9 & $92 a b$ & 79 bc & $75 c$ & $91 \mathrm{a}$ & $88 a b$ & $85 a$ \\
\hline & 10 & $77 \mathrm{c}$ & $73 c$ & $67 d$ & $83 \mathrm{~b}$ & $80 \mathrm{~b}$ & $65 c$ \\
\hline & & \multicolumn{6}{|c|}{ C.V. $(\%)=4,5$} \\
\hline
\end{tabular}

${ }^{*}$ Comparação de médias dentro de cada coluna pelo teste de Tukey, $5 \%$ de probabilidade.

Verificou-se que quando o grau de umidade foi ajustado para $24 \%$, o teste de deterioração controlada, de forma geral, revelou-se mais severo, causando diminuição acentuada da germinação das sementes, provavelmente, devido aos graus de umidade atingidos pelas sementes terem sido mais elevados e contribuído para intensificar as atividades metabólicas das sementes, principalmente para os lotes de menor potencial fisiológico. Resultados nesse sentido também foram encontrados por Powell \& Matthews (1981), quando 
avaliaram o vigor de sementes de nabo, utilizando o teste de deterioração controlada. Por outro lado, verificou-se que o ajuste do grau de umidade para $18 \%$ e $21 \%$ proporcionou resultados menos drásticos.

$\mathrm{Na}$ Tabela 8 encontram-se os dados referentes ao grau de umidade das sementes após o período em banho-maria, no teste de deterioração controlada.

Tabela 8. Dados médios referentes ao grau de umidade após o teste de deterioração controlada de dez lotes de sementes de melão, híbridos AF-646 e AF-682.

\begin{tabular}{|c|c|c|c|c|c|c|c|}
\hline \multirow{3}{*}{ Híbridos } & \multirow{3}{*}{ Lotes } & \multicolumn{6}{|c|}{ Grau de umidade após o teste de deterioração controlada } \\
\hline & & \multicolumn{3}{|c|}{$24 \mathrm{~h}$} & \multicolumn{3}{|c|}{$48 \mathrm{~h}$} \\
\hline & & $18 \%$ & $21 \%$ & $24 \%$ & $18 \%$ & $21 \%$ & $24 \%$ \\
\hline & & $\ldots . .$. & $\ldots .$. & . & .......... & . & .......... \\
\hline \multirow[t]{5}{*}{ AF-646 } & 1 & 18,4 & 21,0 & 24,1 & 18,2 & 21,3 & 24,0 \\
\hline & 2 & 18,1 & 21,4 & 24,3 & 18,0 & 21,1 & 24,1 \\
\hline & 3 & 18,0 & 21,2 & 24,2 & 18,3 & 21,0 & 24,2 \\
\hline & 4 & 17,9 , & 20,9 & 24,0 & 18,4 & 21,4 & 24,3 \\
\hline & 5 & 18,3 & 21,1 & 24,2 & 18,3 & 21,2 & 24,0 \\
\hline \multirow[t]{5}{*}{ AF-682 } & 6 & 18,2 & 21,2 & 24,0 & 18,0 & 21,0 & 24,1 \\
\hline & 7 & 17,9 & 21,4 & 24,2 & 18,0 & 21,1 & 24,2 \\
\hline & 8 & 18,2 & 21,2 & 24,2 & 18,2 & 21,2 & 23,9 \\
\hline & 9 & 18,0 & 20,3 & 24,1 & 18,1 & 21,2 & 24,1 \\
\hline & 10 & 18,1 & 21,2 & 24,3 & 18,0 & 21,4 & 24,3 \\
\hline
\end{tabular}

Examinando-se os resultados, verifica-se que o grau de umidade das sementes se manteve aproximadamente constante durante o decorrer do teste de deterioração controlada. Esse fato que se constitui em um dos pré-requisitos 
básicos na condução deste teste Matthews, 1980), foi assegurado pelo uso eficiente da embalagem aluminizada.

Visando confirmar a combinação mais consistente temperatura/período na classificação dos lotes em diferentes níveis de vigor, novos testes foram realizados empregando-se as combinações mais promissoras, encontradas anteriormente (24\%/24h e $24 \% / 48 \mathrm{~h})$.

Os resultados dessas observações encontram-se na Tabela 9; pode-se verificar que o período de 24 horas de condicionamento em banho-maria, a $45^{\circ} \mathrm{C}$ e sementes com $24 \%$ de água, proporcionou separação mais eficiente dos lotes de sementes em diferentes níveis de vigor, confirmando, indiscutivelmente, o lote 4 do híbrido AF-646 e o lote 6 do híbrido AF-682 como os de melhor potencial fisiológico. Por outro lado, o lote 1 do híbrido AF-646 e o lote 10 do híbrido AF-682 foram confirmados como os de pior qualidade. Esse período de condicionamento em banho-maria também apresentou a vantagem de possibilitar respostas mais rápidas sobre a qualidade dos lotes.

É importante salientar que essa ordenação dos lotes, de maneira geral, foi semelhante à verificada nos testes de primeira contagem de germinação, Método Agroflora e emergência de plântulas, para os lotes referentes ao híbrido AF-682 (Tabela 6); já para o híbrido AF-646, houve concordância na indicação do lote 1 , considerado também de baixa qualidade nos resultados dos mesmos testes.

Esses resultados confirmam os encontrados por diversos autores para sementes de hortaliças, dentre os quais podem-se citar os de Osman \& George (1988) e Panobianco \& Marcos Filho (1998), com sementes de pimentão; os relatos da ISTA (1995), com beterraba e cenoura; Strydom \& Van de Venter (1998), com repolho; Alsadon et al. (1995) e Panobianco \& Marcos Filho (2001), com tomate. Esses autores afirmam que o ajuste do grau de umidade das sementes para $24 \%$ foi o mais adequado para a condução do teste. Por outro lado, Bhéring et al. (2000) verificaram, para sementes de pepino, que esse teor de água só se mostrou eficiente na condução do teste de deterioração, 
controlada quando as sementes foram submetidas ao período de 48 horas de condicionamento em banho-maria.

Tabela 9. Dados médios obtidos para o teste de deterioração controlada de dez lotes de sementes de melão, híbridos AF-646 e AF-682.

\begin{tabular}{|c|c|c|c|}
\hline \multirow{2}{*}{ Híbridos } & \multirow{2}{*}{ Lotes } & \multicolumn{2}{|c|}{ Deterioração controlada } \\
\hline & & $24 \% / 24 h$ & $24 \% / 48 h$ \\
\hline & & ….............. & …............... \\
\hline \multirow[t]{6}{*}{ AF-646 } & 1 & $78 \mathrm{~d}$ & $72 b$ \\
\hline & 2 & $94 \mathrm{~b}$ & $90 \mathrm{a}$ \\
\hline & 3 & $92 \mathrm{~b}$ & $90 \mathrm{a}$ \\
\hline & 4 & $98 a$ & $92 \mathrm{a}$ \\
\hline & 5 & $88 \mathrm{c}$ & $76 b$ \\
\hline & & & \\
\hline \multirow[t]{6}{*}{ AF-682 } & 6 & $96 \mathrm{a}$ & $90 \mathrm{a}$ \\
\hline & 7 & $86 b$ & $71 \mathrm{~b}$ \\
\hline & 8 & $88 \mathrm{~b}$ & $88 a$ \\
\hline & 9 & $74 \mathrm{c}$ & $76 a b$ \\
\hline & 10 & $68 d$ & $68 \mathrm{bc}$ \\
\hline & & \multicolumn{2}{|c|}{ C.V. $(\%)=4,5$} \\
\hline
\end{tabular}

${ }^{*}$ Comparação de médias dentro de cada coluna pelo teste de Tukey, $5 \%$ de probabilidade.

A combinação utilizando o período de 48 horas, sementes com $24 \%$ de água e temperatura de $45^{\circ} \mathrm{C}$, foi menos discriminante na separação dos lotes em diferentes níveis de vigor quando comparada com a combinação $24 \% / 45^{\circ} \mathrm{C} / 24 \mathrm{~h}$, o que não aconteceu com Bhéring et al. (2000) quando utilizaram sementes de pepino. Ainda com relação a esse aspecto, Bhéring et al. (2001a, b), verificaram 
que o teste de deterioração controlada foi mais adequado para sementes de melancia e berinjela, respectivamente, quando utilizaram o período de 48 horas, a $41^{\circ} \mathrm{C}$ e sementes com $24 \%$ de água.

$\mathrm{Na}$ Tabela 10 encontram-se os graus de umidade para as combinações $24 \% / 24 h$ e $24 \% / 48 h$. Verificou-se que os mesmos foram uniformes e semelhantes aos encontrados anteriormente (Tabela 8), confirmando, dessa forma, a eficiência da técnica utilizada.

Tabela 10. Dados médios referentes ao grau de umidade após o teste de deterioração controlada de dez lotes de sementes de melão, híbridos AF-646 e AF-682.

\begin{tabular}{cccc}
\hline \multirow{2}{*}{ Híbridos } & \multirow{2}{*}{ Lotes } & \multicolumn{3}{c}{ Deterioração controlada } \\
\cline { 3 - 4 } AF-646 & & $24 \% / 24 \mathrm{~h}$ & $24 \% / 48 \mathrm{~h}$ \\
\hline & 1 & 24,0 & 23,8 \\
& 3 & 24,0 & 24,1 \\
& 3 & 24,1 & 24,0 \\
& 4 & 24,4 & 24,2 \\
& 5 & 24,0 & 24,4 \\
& & & \\
AF-682 & 6 & 24,3 & 24,4 \\
& 7 & 24,0 & 24,1 \\
& 8 & 23,9 & 24,3 \\
& 9 & 24,1 & 24,0 \\
& 10 & 24,2 & 24,2 \\
\hline
\end{tabular}

Assim, verificou-se que apesar da existência de um número razoável de testes para avaliação do vigor de sementes, a intensificação dos estudos sobre o teste de deterioração controlada, em nossas condições, constitui alternativa 
interessante. É um teste relativamente simples, não exigindo equipamentos sofisticados e não apresentando dificuldades consideráveis para sua padronização.

Portanto, neste estudo verificou-se que o período de 24 horas em banho-maria, a $45^{\circ} \mathrm{C}$, com ajuste do grau de umidade das sementes para $24 \%$ demonstrou eficiência, devendo ser considerado em programas de controle de qualidade de sementes de melão.

\subsubsection{Envelhecimento acelerado (procedimento tradicional)}

Os resultados do teste de envelhecimento acelerado (procedimento tradicional), utilizando-se duas temperaturas e três períodos de condicionamento, estão apresentados na Tabela 11.

Verificou-se que, de forma geral, ambos os períodos de envelhecimento, tanto a $38^{\circ} \mathrm{C}$ como a $41^{\circ} \mathrm{C}$, proporcionaram a identificação dos lotes 1 e 10 como de menor potencial fisiológico, respectivamente para os híbridos AF-646 e AF-682, havendo, nesse sentido, concordância com o teste de germinação (híbrido AF-682) e, para ambos os híbridos, os testes de primeira contagem de germinação, Método Agroflora, emergência de plântulas em casa de vegetação (Tabela 6) e deterioração controlada (Tabelas 7 e 9).

Apesar da semelhança entre as informações proporcionadas para 0 híbrido AF-646 (Tabela 6), indicando o lote de menor qualidade, o período de 48 horas de envelhecimento, para ambas as temperaturas, mostrou-se pouco eficiente na separação dos lotes em diferentes níveis de vigor (Tabela 11). Utilizando este mesmo período, a $42^{\circ} \mathrm{C}$, para avaliação de sementes de melão, Cano-Ríos et al. (2000), também constatou que o período de 48 horas mostrouse pouco sensível para estimar o potencial de armazenamento das sementes.

De um modo geral, constatou-se que a temperatura de $41^{\circ} \mathrm{C}$ promoveu efeitos mais drásticos sobre a germinação que a de $38^{\circ} \mathrm{C}$, principalmente para os lotes considerados de menor potencial fisiológico; a duração dos períodos de 
envelhecimento se mostrou menos severa que a elevação da temperatura. Esse fato concorda com Tomes et al. (1988), que sugeriu atenção especial ao monitoramento da temperatura durante o teste, para que sejam obtidos resultados consistentes.

Neste estudo, constatou-se que os períodos de 72 e 96 horas, para ambas as temperaturas, exibiram maior sensibilidade para identificação dos lotes em diferentes níveis de potencial fisiológico. Dessa forma, o híbrido AF-646 apresentou os lotes 2, 3 e 4 como de melhor potencial fisiológico; o lote 1 como de pior qualidade e o 5 com qualidade intermediária. Esses resultados concordam com os obtidos para os testes de primeira contagem de germinação, Método Agroflora, emergência de plântulas em casa de vegetação quando indicam a inferioridade do lote 1 (Tabela 6) e a deterioração controlada (Tabelas 7 e 9). Os resultados do híbrido AF-682 indicam que os lote 6 e 10 apresentaram melhor e pior qualidade, respectivamente; de forma geral, os lotes 7, 8 e 9 revelaram-se como de qualidade intermediária, havendo, nesse aspecto, concordância com os resultados da avaliação inicial dos lotes de sementes (Tabela 6) e com a deterioração controlada (Tabelas 7 e 9). Esses períodos apresentam a vantagem de possibilitar respostas mais rápidas sobre a qualidade dos lotes do que o período de 192 horas de envelhecimento, a $42^{\circ} \mathrm{C}$, sugerido por Pesis \& Timothy (1983), também para sementes de melão.

A literatura indica que, apesar de vários estudos terem sido conduzidos, ainda não há consenso entre os pesquisadores, quanto aos períodos mais adequados na execução do teste de envelhecimento acelerado para sementes de diversas espécies de importância econômica. Portanto, o que predomina nas pesquisas desse teste, segundo Marcos Filho (1999b) é a avaliação mediante a sensibilidade de amostras ao envelhecimento, através de tentativas do uso de vários períodos de exposição. Nesse aspecto, alguns trabalhos com sementes de hortaliças, envolvendo diferentes períodos e temperaturas foram realizados, entre os quais destacam-se o de sementes de melancia, 45은 $144 \mathrm{~h}$ (Delouche \& Baskin,1973); ervilha, 37ํㅡ/72h (Menêzes \& Nascimento, 1988); cebola, 
$41^{\circ} \mathrm{C} / 72 \mathrm{~h}$ (Idiarte, 1995); quiabo, $42^{\circ} \mathrm{C} / 72$ e $96 \mathrm{~h}$ (Lima et al. 1997); pepino, $41^{\circ} \mathrm{C} / 48 \mathrm{~h}$ (Bhéring et al., 2000); tomate, $41^{\circ} \mathrm{C} / 72 \mathrm{~h}$ (Panobianco \& Marcos Filho, 2001). Essas pesquisas, de certa forma, concordam com as combinações (38으 $\mathrm{C} / 72$ e $96 \mathrm{~h} ; 41^{\circ} \mathrm{C} / 72$ e $96 \mathrm{~h}$ ), consideradas promissoras neste estudo.

Tabela 11. Dados médios obtidos para o teste de envelhecimento acelerado (procedimento tradicional) de dez lotes de sementes de melão, híbridos AF-646 e AF-682.

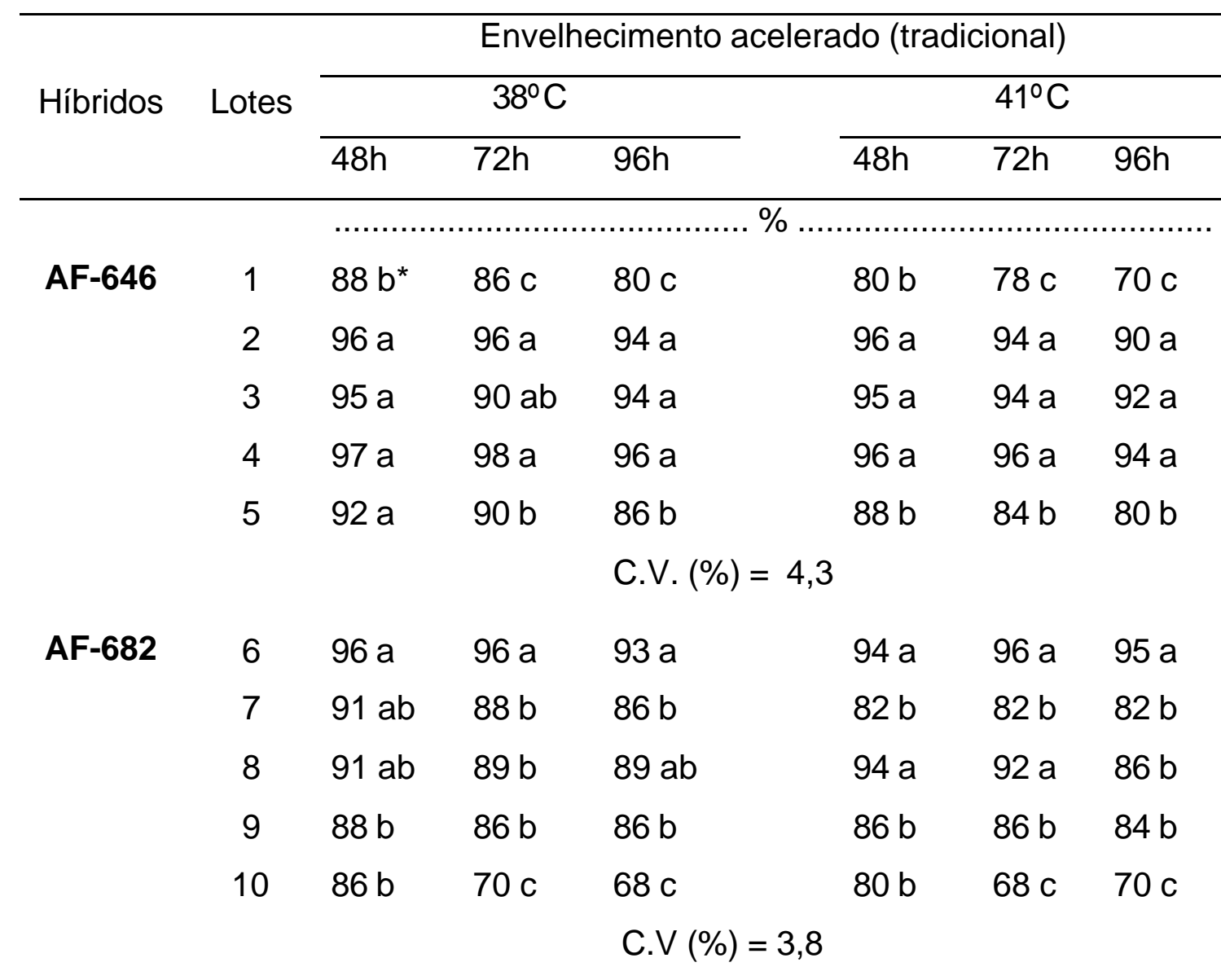

${ }^{*}$ Comparação de médias dentro de cada coluna pelo teste de Tukey, 5\% de probabilidade. 
O grau de umidade das sementes, após os períodos de envelhecimento (Tabela 12), variou entre os lotes de 0,8 a 2,3\%, dependendo da combinação período/temperatura utilizada. Esta variação relativamente pequena no grau de umidade das sementes foi devida, provavelmente, ao tamanho das sementes de melão, maior que o da maioria das hortaliças. Nesse sentido, Panobianco \& Marcos Filho (1998) trabalhando com sementes de pimentão constataram elevação acentuada no grau de umidade dessas sementes, atingindo valores entre 29,5 e 37,8\%. Já Rodo et al. (2000) verificaram para sementes de cenoura variações de 4,0 a $9,2 \%$, consideradas excessivas, ao final do envelhecimento acelerado.

Segundo Marcos Filho (1999b), é conveniente a comparação de amostras que apresentem graus de umidade semelhantes antes do envelhecimento, embora diferenças de 1 a $2 \%$ não sejam comprometedoras. Para este estudo, verificou-se que o grau inicial de umidade das sementes foi praticamente o mesmo, variando em torno de 7,1\% (Tabela 6). Por outro lado, um dos principais indicadores da uniformidade das condições do envelhecimento acelerado é o grau de umidade das sementes ao final do teste, pois variações de 3 a 4\% entre amostras são consideradas toleráveis (Tomes et al., 1988; Marcos Filho, 1999b); portanto, verificou-se que a variação máxima encontrada foi de 2,3\%, ou seja, abaixo dos limites toleráveis (Tabela 12).

Em função das combinações $38^{\circ} \mathrm{C} / 72$ e 96 horas e $41^{\circ} \mathrm{C} / 72$ e 96 horas terem se mostrado como as mais eficientes na identificação dos lotes de sementes com diferentes níveis vigor, novos testes foram conduzidos com a finalidade de confirmar a eficiência dos procedimentos considerados mais adequados. Na Tabela 13 encontram-se os dados referentes a esse estudo.

De maneira geral, os resultados obtidos com as melhores combinações revelaram tendências semelhantes na separação dos lotes, àquelas observadas anteriormente (Tabela 11), embora pequenas variações tenham ocorrido. 
Tabela 12. Dados médios do grau de umidade obtidos após os períodos de envelhecimento acelerado (procedimento tradicional) de dez lotes de sementes de melão, híbridos AF-646 e AF-682.

\begin{tabular}{|c|c|c|c|c|c|c|c|}
\hline \multirow{3}{*}{ Híbridos } & \multirow{3}{*}{ Lotes } & \multicolumn{6}{|c|}{ Grau de umidade após o EA (Tradicional) } \\
\hline & & \multicolumn{3}{|c|}{$38^{\circ} \mathrm{C}$} & \multicolumn{3}{|c|}{$41^{\circ} \mathrm{C}$} \\
\hline & & $48 \mathrm{~h} \%$ & $72 \mathrm{~h}$ & $96 \mathrm{~h}$ & $48 \mathrm{~h} \%$ & $72 \mathrm{~h}$ & $96 \mathrm{~h}$ \\
\hline \multirow[t]{5}{*}{ AF-646 } & 1 & 27,0 & 29,0 & 29,8 & 26,4 & 27,8 & 28,3 \\
\hline & 2 & 26,6 & 29,1 & 29,8 & 25,9 & 29,0 & 28,0 \\
\hline & 3 & 26,9 & 29,0 & 29,4 & 25,4 & 28,0 & 28,6 \\
\hline & 4 & 27,6 & 30,5 & 31,0 & 26,6 & 28,2 & 28,8 \\
\hline & 5 & 25,4 & 29,0 & 30,0 & 25,6 & 27,6 & 26,3 \\
\hline \multirow[t]{5}{*}{ AF-682 } & 6 & 25,7 & 27,8 & 28,8 & 26,4 & 27,8 & 28,2 \\
\hline & 7 & 26,9 & 28,1 & 28,8 & 27,2 & 29,0 & 30,1 \\
\hline & 8 & 25,8 & 27,8 & 28,4 & 26,4 & 28,0 & 29,4 \\
\hline & 9 & 26,0 & 29,1 & 29,0 & 27,1 & 29,2 & 29,8 \\
\hline & 10 & 26,7 & 27,7 & 29,3 & 26,6 & 27,6 & 28,2 \\
\hline
\end{tabular}

Verificou-se que o período de 72 horas de envelhecimento, a $38^{\circ} \mathrm{C}$ ou $41^{\circ} \mathrm{C}$, mostrou-se o mais eficiente na separação dos lotes em função do potencial fisiológico, além de apresentar maior grau de semelhança com os resultados dos testes de primeira contagem de germinação, Método Agroflora, emergência de plântulas em casa de vegetação (Tabela 6) e deterioração controlada (Tabela 9), revelando, respectivamente, o melhor e pior desempenho dos lotes 6 e 10 para o híbrido AF-682; os demais comportaram-se de forma intermediária. Os lotes 2 e 4 do híbrido AF-646, apresentaram qualidade superior; o lote 1 foi confirmado como de pior qualidade, concordando com os resultados encontrados nos testes de avaliação da qualidade inicial dos lotes de sementes (Tabela 6) e deterioração controlada (Tabela 9). De um modo geral, 
segundo Marcos Filho (1999b), como é verificado para outros testes de vigor, o de envelhecimento acelerado também apresenta dificuldade para a identificação de lotes com vigor médio, fato constatado neste estudo.

O período de 96 horas, para as duas temperaturas, apesar de apresentar resultados concordantes quanto à identificação dos lotes de menor potencial fisiológico, para os dois híbridos, mostrou-se menos eficiente na classificação dos lotes em diferentes níveis de qualidade (Tabela, 13).

Tabela 13. Dados médios obtidos para o teste de envelhecimento acelerado (procedimento tradicional) de dez lotes de sementes de melão, híbridos AF-646 e AF-682.

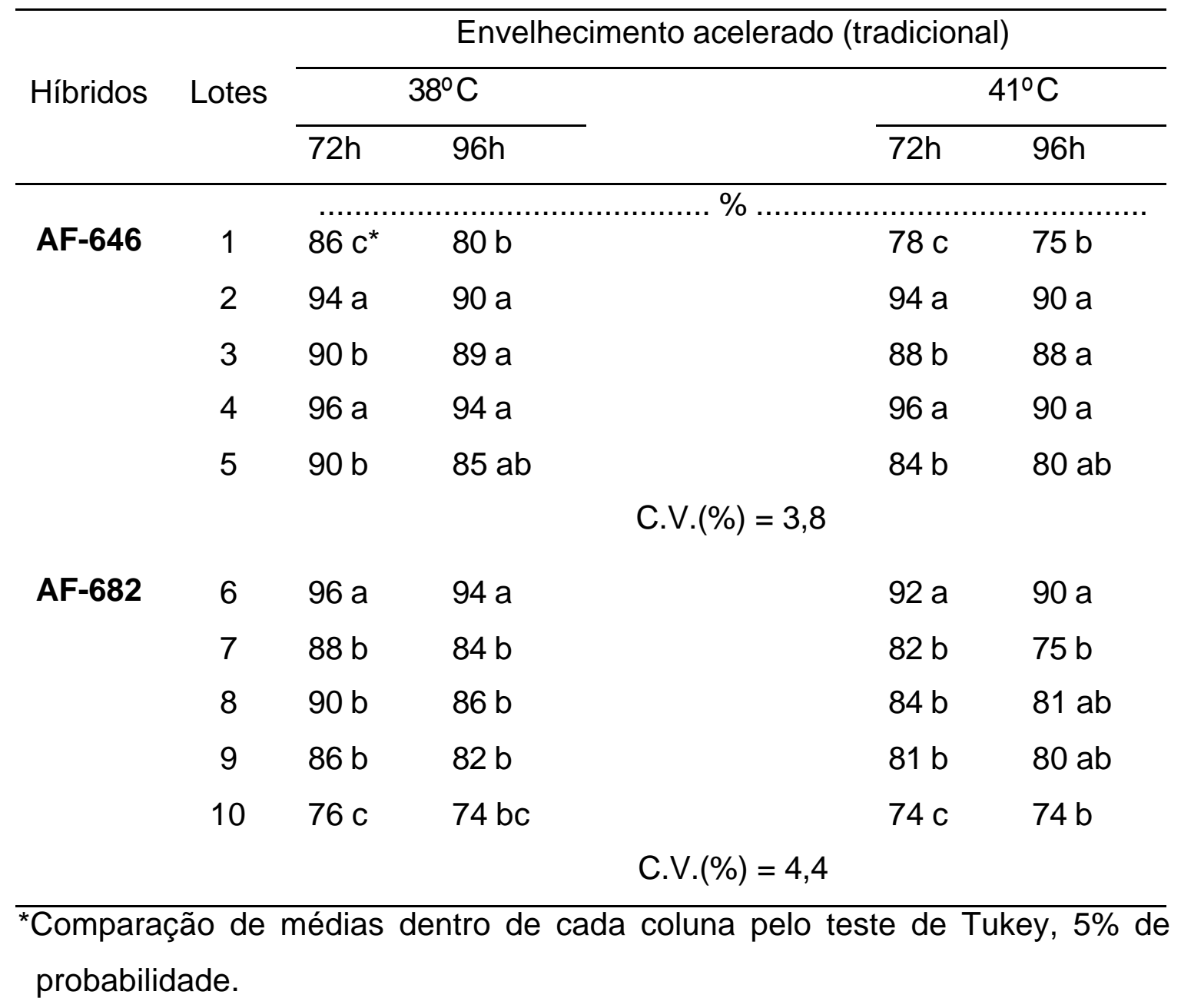


Quanto ao grau de umidade das sementes após os períodos de envelhecimento (Tabela 14), verificou-se que o valores, em geral, mostraram-se semelhantes aos encontrados anteriormente (Tabela 12), com variação de 0,8 a $3,2 \%$ entre lotes, dependendo da combinação utilizada.

Tabela 14. Dados médios do grau de umidade obtidos após os períodos de envelhecimento acelerado (procedimento tradicional) de dez lotes de sementes de melão, híbridos AF-646 e AF-682.

\begin{tabular}{|c|c|c|c|c|c|}
\hline \multirow{3}{*}{ Híbridos } & \multirow{3}{*}{ Lotes } & \multicolumn{4}{|c|}{ Grau de umidade após o EA (tradicional) } \\
\hline & & \multicolumn{2}{|c|}{$38^{\circ} \mathrm{C}$} & \multicolumn{2}{|c|}{$41^{\circ} \mathrm{C}$} \\
\hline & & $\overline{72 h}$ & $96 \mathrm{~h}$ & $72 \mathrm{~h}$ & $96 \mathrm{~h}$ \\
\hline & & $\ldots \ldots$. & ........... & $\ldots \ldots \ldots$ & .......... \\
\hline \multirow[t]{5}{*}{ AF-646 } & 1 & 29,0 & 29,3 & 27,4 & 28,3 \\
\hline & 2 & 29,1 & 29,2 & 26,7 & 28,0 \\
\hline & 3 & 29,0 & 29,0 & 28,2 & 28,0 \\
\hline & 4 & 30,5 & 31,0 & 28,3 & 28,8 \\
\hline & 5 & 29,0 & 30,2 & 26,8 & 26,3 \\
\hline \multirow[t]{5}{*}{ AF-682 } & 6 & 28,8 & 29,8 & 27,2 & 27,8 \\
\hline & 7 & 28,5 & 29,8 & 29,2 & 30,1 \\
\hline & 8 & 29,8 & 29,4 & 28,4 & 29,0 \\
\hline & 9 & 29,4 & 29,0 & 29,2 & 31,0 \\
\hline & 10 & 28,7 & 29,1 & 28,6 & 28,4 \\
\hline
\end{tabular}

Verificou-se que as combinações $38^{\circ} \mathrm{C}$ e $41^{\circ} \mathrm{C} / 72 \mathrm{~h}$ de envelhecimento foram as mais eficientes para a realização desse teste para sementes de melão, proporcionando a separação adequada dos lotes em diferentes níveis de vigor e fornecendo informações compatíveis com os resultados dos testes de primeira contagem de germinação, Método Agroflora e emergência de plântulas, 
principalmente para o híbrido AF-682; isto ocorreu, também para o lote de menor potencial fisiológico do híbrido AF-646.

Portanto, em razão do uso mais freqüente da temperatura de $41^{\circ} \mathrm{C}$ para realização do teste de envelhecimento acelerado, foi considerada como mais adequada a combinação $41^{\circ} \mathrm{C} / 72$ horas.

\subsubsection{Envelhecimento acelerado (solução saturada de sal)}

Os dados obtidos para o teste de envelhecimento acelerado, com solução salina, utilizando-se duas temperaturas e três períodos de condicionamento, híbridos AF-646 e AF-682, encontram-se na Tabela 15.

Analisando-se os resultados, notou-se que o período de 48 horas, em ambas as temperaturas, apesar da menor eficiência na separação dos lotes, para os dois híbridos, revelou, de modo geral, resultados semelhantes aos obtidos para o envelhecimento tradicional (Tabela 11), concordando dessa forma com os testes de primeira contagem de germinação, Método Agroflora e emergência de plântulas em casa de vegetação (Tabela 6), em termos de identificação dos lotes de menor potencial fisiológico.

Por outro lado, os períodos de 72 e 96 horas, em ambas as temperaturas, apresentaram melhor classificação dos lotes em diferentes níveis de vigor. Assim, para o híbrido AF-646, apontaram os lotes 2, 3, 4 como os mais vigorosos, o lote 1 como de pior qualidade e o $5 \mathrm{com}$ qualidade intermediária. Para o híbrido AF-682, o lote 6 foi identificado como o de maior potencial fisiológico, enquanto o lote 10 foi confirmado como de pior qualidade. De forma geral, esses resultados concordam com os obtidos nos testes de primeira contagem de germinação, Método Agroflora, emergência de plântulas em casa de vegetação (Tabela 6), deterioração controlada (Tabela 9) e envelhecimento acelerado tradicional (Tabelas 11 e 13) para o híbrido AF-682. No caso do híbrido AF-646, também houve concordância com os testes de deterioração controlada (Tabela 9), envelhecimento acelerado tradicional (Tabelas 11 e 13) e 
foi confirmada a inferioridade da qualidade do lote 1 encontrada nos testes inicias (Tabela 6).

Tabela 15. Dados médios obtidos para o teste de envelhecimento acelerado, com solução salina, de dez lotes de sementes de melão, híbridos AF-646 e AF-682.

\begin{tabular}{|c|c|c|c|c|c|c|c|}
\hline \multirow{3}{*}{ Híbridos } & \multirow{3}{*}{ Lotes } & \multicolumn{6}{|c|}{ Envelhecimento acelerado (com solução salina) } \\
\hline & & \multicolumn{3}{|c|}{$38^{\circ} \mathrm{C}$} & \multicolumn{3}{|c|}{$41^{\circ} \mathrm{C}$} \\
\hline & & $\overline{48 h}$ & $72 \mathrm{~h}$ & $96 \mathrm{~h}$ & $\overline{48 h}$ & $72 \mathrm{~h}$ & $96 \mathrm{~h}$ \\
\hline & & & & & ........ & ........ & $\ldots \ldots$ \\
\hline \multirow[t]{6}{*}{ AF-646 } & 1 & $88 b^{*}$ & $78 \mathrm{c}$ & $75 c$ & $87 \mathrm{~b}$ & $78 \mathrm{c}$ & $72 \mathrm{c}$ \\
\hline & 2 & $95 a$ & $96 \mathrm{a}$ & $94 \mathrm{a}$ & $96 \mathrm{a}$ & $96 \mathrm{a}$ & $94 a b$ \\
\hline & 3 & $96 a$ & $95 \mathrm{a}$ & $94 \mathrm{a}$ & $94 \mathrm{ab}$ & $92 a b$ & $90 \mathrm{ab}$ \\
\hline & 4 & $96 a$ & $98 \mathrm{a}$ & $96 \mathrm{a}$ & $96 \mathrm{a}$ & $96 \mathrm{a}$ & $96 \mathrm{a}$ \\
\hline & 5 & $92 \mathrm{a}$ & $88 \mathrm{~b}$ & $84 \mathrm{~b}$ & $92 a b$ & $88 b$ & $87 \mathrm{~b}$ \\
\hline & & \multicolumn{6}{|c|}{ C.V. $(\%)=3,4$} \\
\hline \multirow[t]{6}{*}{ AF-682 } & 6 & $96 a$ & $94 a$ & $95 a$ & $94 a$ & $92 a$ & $90 a$ \\
\hline & 7 & $90 a b$ & $84 \mathrm{bc}$ & $83 b$ & $86 \mathrm{~b}$ & $84 b$ & $82 \mathrm{~b}$ \\
\hline & 8 & $90 a b$ & $89 a b$ & $86 b$ & $90 a b$ & $86 b$ & $88 a b$ \\
\hline & 9 & $82 b$ & $80 c$ & $83 b$ & $84 \mathrm{~b}$ & $82 b$ & $82 \mathrm{~b}$ \\
\hline & 10 & $82 b$ & $70 d$ & $68 c$ & $85 b$ & $72 \mathrm{c}$ & $70 \mathrm{c}$ \\
\hline & & \multicolumn{6}{|c|}{ C.V. $(\%)=3,7$} \\
\hline
\end{tabular}

Com relação ao grau de umidade das sementes após os períodos de envelhecimento (Tabela 16), os resultados mostraram-se, em geral semelhantes para os dez lotes estudados. Verificou-se que o grau de umidade das sementes 
expostas à solução saturada de $\mathrm{NaCl}$ apresentou valores menores e mais uniformes, após os períodos de envelhecimento em relação aos observados para as envelhecidas tradicionalmente (Tabela 13); isto indica que o uso de solução salina contribuiu para retardar a absorção de água pelas sementes no teste de envelhecimento acelerado. Dessa forma, poderia ser esperado que as condições de envelhecimento com o uso de solução salina promovessem efeitos menos drásticos no grau de deterioração das sementes, em decorrência dos menores teores de água atingidos durante o envelhecimento; todavia, verificouse que esse benefício não foi evidente, conforme indicaram os resultados das Tabelas 11 e 15. Os resultados obtidos até o momento, com esse teste, demonstram que mesmo com grau de umidade inferior, há estresse suficiente para reduzir a germinação (Jianhua \& McDonald, 1997; Panobianco \& Marcos Filho, 1998; Rodo et al., 2000). Esse método alternativo de envelhecimento tem se revelado mais apropriado para sementes pequenas de hortaliças; porém as de melão são relativamente maiores que as da maioria das hortaliças e por isso, provavelmente essa vantagem não tenha se manifestado com tanta nitidez.

Constatou-se neste estudo que a utilização de soluções saturadas de sais fizeram com que os valores de umidade relativa permanecessem em níveis inferiores, suficientes para reduzir acentuadamente ou impedir o desenvolvimento de microrganismos (Figura 2), minimizando, assim, a preocupação com efeitos de microrganismos associados às sementes, interferindo nos resultados do teste (Jianhua \& McDonald, 1997).

Dessa forma, as combinações $38^{\circ} \mathrm{C} / 72$ e 96 horas e $41^{\circ} \mathrm{C} / 72$ e 96 horas revelaram-se como as mais promissoras; assim, novos testes foram conduzidos visando comprovar a adequação desses procedimentos para a condução do teste de envelhecimento acelerado com sementes de melão. Os resultados com esse estudo estão apresentados na Tabela 17. 
Tabela 16. Dados médios do grau de umidade obtidos após os períodos de envelhecimento acelerado, com solução salina, de dez lotes de sementes de melão, híbridos AF-646 e AF-682.

\begin{tabular}{|c|c|c|c|c|c|c|c|}
\hline \multirow{3}{*}{ Híbridos } & \multirow{3}{*}{ Lotes } & \multicolumn{6}{|c|}{ Grau de umidade após o EA (com solução salina) } \\
\hline & & \multicolumn{3}{|c|}{$38^{\circ} \mathrm{C}$} & \multicolumn{3}{|c|}{$41^{\circ} \mathrm{C}$} \\
\hline & & $48 \mathrm{~h}$ & $72 \mathrm{~h}$ & $96 h$ & $48 \mathrm{~h}$ & $72 \mathrm{~h}$ & $96 h$ \\
\hline & & $\ldots \ldots$. & .......... & (n......... & (n....... & .......... & 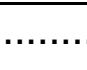 \\
\hline \multirow[t]{5}{*}{ AF-646 } & 1 & 9,2 & 10,2 & 10,2 & 8,6 & 9,4 & 9,2 \\
\hline & 2 & 9,2 & 9,9 & 10,2 & 8,4 & 9,0 & 9,2 \\
\hline & 3 & 9,5 & 10,2 & 9,8 & 7,6 & 9,8 & 9,9 \\
\hline & 4 & 9,4 & 10,1 & 9,6 & 9,0 & 9,6 & 9,4 \\
\hline & 5 & 9,6 & 9,8 & 9,9 & 8,2 & 9,4 & 9,2 \\
\hline \multirow[t]{5}{*}{ AF-682 } & 6 & 9,2 & 10,2 & 10,2 & 8,6 & 9,5 & 9,4 \\
\hline & 7 & 9,3 & 10,1 & 10,2 & 8,4 & 9,6 & 9,8 \\
\hline & 8 & 9,6 & 9,8 & 9,6 & 8,4 & 9,4 & 9,8 \\
\hline & 9 & 9,3 & 10,2 & 9,8 & 9,0 & 9,9 & 9,3 \\
\hline & 10 & 9,2 & 9,9 & 9,7 & 9,1 & 9,9 & 9,9 \\
\hline
\end{tabular}

Comparando os resultados da Tabela $17 \mathrm{com}$ os do envelhecimento acelerado tradicional (Tabela 13), constatou-se semelhança na ordenação dos lotes, para os dois períodos de envelhecimento e ambas as temperaturas. Entretanto, verificou-se que o período de 72 horas, tanto a $38^{\circ} \mathrm{C}$ quanto a $41^{\circ} \mathrm{C}$, proporcionou melhor classificação dos lotes em diferentes níveis de vigor, como também forneceu, de maneira geral, informações compatíveis com os resultados dos testes de primeira contagem de germinação, Método Agroflora e emergência de plântulas em casa de vegetação (Tabela 6) e deterioração controlada (Tabela 9). Para sementes de pepino, Bhéring et al. (2000) recomendam o mesmo período, procedimento e a temperatura de $41^{\circ} \mathrm{C}$. Ainda nesse sentido, Rodo \& 
Marcos Filho (2000), com sementes de cenoura também indicam o período de 72 horas, a $41^{\circ} \mathrm{C}$, com o uso de solução saturada de $\mathrm{NaCl}$.
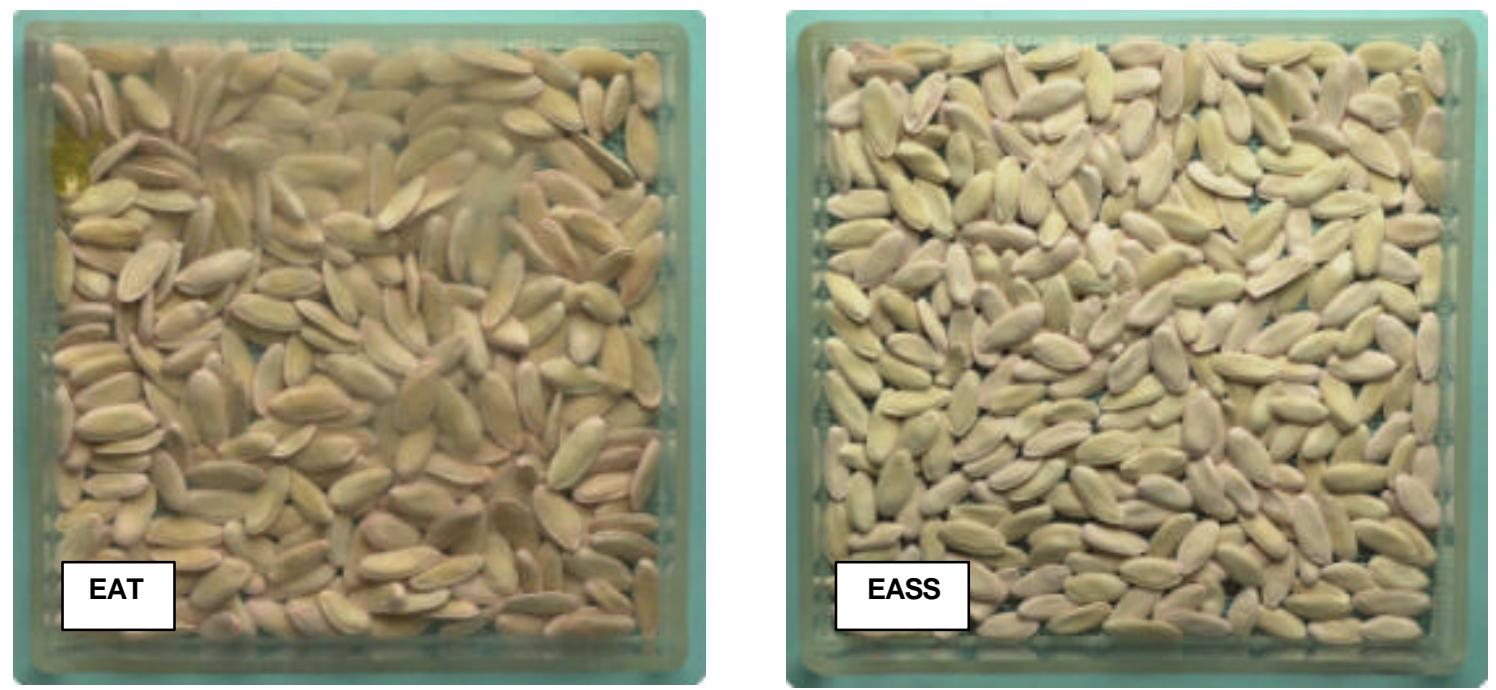

Figura 2 - Desenvolvimento de microrganismos em amostras de sementes de melão submetidas aos testes de Envelhecimento Acelerado Tradicional (EAT) e Envelhecimento Acelerado com Solução Salina (EASS), 96 horas.

A descrição do teste de envelhecimento acelerado cita a possibilidade da utilização de temperaturas de 40 a $45^{\circ} \mathrm{C}$; porém, recentemente, grande parte dos pesquisadores que se dedicam a estudos sobre o teste têm dado preferência a $41^{\circ} \mathrm{C}$ (Marcos Filho, 1999b). Portanto, a combinação de $41^{\circ} \mathrm{C} / 72$ horas com uso de solução saturada de sais foi considerada como a mais adequada para as sementes dos dois híbridos. 
Tabela 17. Dados médios obtidos para o teste de envelhecimento acelerado, com solução salina, de dez lotes de sementes de melão, híbridos AF-646 e AF-682.

\begin{tabular}{|c|c|c|c|c|c|c|}
\hline \multirow{3}{*}{ Híbridos } & \multirow{3}{*}{ Lotes } & \multicolumn{5}{|c|}{ Envelhecimento acelerado (com solução salina) } \\
\hline & & \multicolumn{2}{|c|}{$38^{\circ} \mathrm{C}$} & & \multicolumn{2}{|c|}{$41^{\circ} \mathrm{C}$} \\
\hline & & $72 \mathrm{~h}$ & $96 h$ & & $72 \mathrm{~h}$ & $96 \mathrm{~h}$ \\
\hline & & (n........ & …......... & 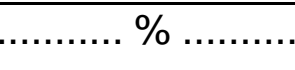 & …..... & $\ldots \ldots \ldots . . . .$. \\
\hline \multirow[t]{6}{*}{ AF-646 } & 1 & $80 c^{*}$ & $75 b$ & & $80 \mathrm{c}$ & $78 b$ \\
\hline & 2 & $98 a$ & $92 \mathrm{a}$ & & $96 \mathrm{a}$ & $94 \mathrm{a}$ \\
\hline & 3 & $90 \mathrm{a}$ & $90 \mathrm{a}$ & & $92 b$ & $88 \mathrm{~b}$ \\
\hline & 4 & $94 \mathrm{a}$ & $92 \mathrm{a}$ & & $96 \mathrm{a}$ & $92 \mathrm{a}$ \\
\hline & 5 & $88 b$ & $86 a b$ & & $90 \mathrm{~b}$ & $86 b$ \\
\hline & & & & C.V. $(\%)=3,8$ & & \\
\hline \multirow[t]{6}{*}{ AF-682 } & 6 & $94 \mathrm{a}$ & $92 \mathrm{a}$ & & $94 \mathrm{a}$ & $90 \mathrm{a}$ \\
\hline & 7 & $82 \mathrm{bc}$ & $80 \mathrm{~b}$ & & $90 \mathrm{~b}$ & $84 a b$ \\
\hline & 8 & $86 b$ & $84 b$ & & $90 \mathrm{~b}$ & $86 a b$ \\
\hline & 9 & $80 c$ & $76 \mathrm{bc}$ & & $84 c$ & $84 a b$ \\
\hline & 10 & $74 d$ & $70 \mathrm{c}$ & & $72 d$ & $74 \mathrm{~b}$ \\
\hline & & & & C.V. $(\%)=3,6$ & & \\
\hline
\end{tabular}

O grau de umidade das sementes após os períodos de envelhecimento (Tabela 18) foi, de maneira geral, semelhante para todos os lotes, concordando com o grau de umidade obtido anteriormente (Tabela 16), revelando, portanto, a eficiência do método em retardar a absorção de água pelas sementes. 
Tabela 18. Dados médios do grau de umidade obtidos após os períodos de envelhecimento acelerado, com solução salina, de dez lotes de sementes de melão, híbridos AF-646 e AF-682.

\begin{tabular}{|c|c|c|c|c|c|}
\hline \multirow{3}{*}{ Híbridos } & \multirow{3}{*}{ Lotes } & \multicolumn{4}{|c|}{ Grau de umidade após o EA (com solução salina) } \\
\hline & & \multicolumn{2}{|c|}{$38^{\circ} \mathrm{C}$} & \multicolumn{2}{|c|}{$41^{\circ} \mathrm{C}$} \\
\hline & & $72 \mathrm{~h}$ & $96 \mathrm{~h}$ & $72 \mathrm{~h}$ & $96 \mathrm{~h}$ \\
\hline & & $\ldots . .$. & .......... & .......... & ….... \\
\hline \multirow[t]{5}{*}{ AF-646 } & 1 & 9,9 & 9,8 & 9,3 & 9,2 \\
\hline & 2 & 9,6 & 9,6 & 9,2 & 9,5 \\
\hline & 3 & 9,0 & 9,4 & 9,8 & 9,9 \\
\hline & 4 & 9,8 & 9,6 & 9,4 & 9,8 \\
\hline & 5 & 9,8 & 9,9 & 9,2 & 9,7 \\
\hline \multirow[t]{5}{*}{ AF-682 } & 6 & 9,9 & 9,6 & 9,3 & 9,4 \\
\hline & 7 & 9,5 & 9,8 & 9,0 & 8,5 \\
\hline & 8 & 9,8 & 9,6 & 9,0 & 9,2 \\
\hline & 9 & 9,3 & 9,8 & 9,3 & 9,3 \\
\hline & 10 & 9,9 & 9,7 & 9,5 & 9,4 \\
\hline
\end{tabular}

\subsubsection{Condutividade elétrica}

Os resultados do teste de condutividade elétrica, envolvendo as combinações número de sementes, quantidade de água e temperatura, nos diferentes períodos de embebição, estão apresentados nas Tabelas de 19 a 24 .

A análise dos resultados permitiu verificar, de maneira geral, que as diversas combinações de número de sementes e volumes de água para as temperaturas de $20^{\circ} \mathrm{C}, 25^{\circ} \mathrm{C}$ e $30^{\circ} \mathrm{C}$, estudadas no teste de condutividade elétrica apresentaram semelhança na distinção dos lotes em relação ao seu 
potencial fisiológico. Assim, constatou-se que ambos os procedimentos indicaram os lotes 1 e 5 do híbrido AF-646 e 6, 810 do híbrido AF-682 como os mais vigorosos. Por outro lado, os lotes 3 e 4 do híbrido AF-646 e o lote 9 do híbrido AF-682 foram considerados os piores.

Portanto, verificou-se que independentemente da combinação número de sementes/quantidade de água/temperatura utilizada, as informações fornecidas pela condutividade elétrica, para ambos os híbridos, não mostraram relação direta com os testes de avaliação da qualidade inicial dos lotes sementes (Tabela 6). Por exemplo, o lote 1, considerado de baixa qualidade pelos testes de primeira contagem de germinação, Método Agroflora, emergência de plântulas em casa de vegetação (Tabela 6), deterioração controlada (Tabela 9) e envelhecimento acelerado (tradicional e com solução salina, conforme as Tabelas 13 e 17), destacou-se como vigoroso no teste de condutividade elétrica, o mesmo ocorrendo com o lote 5. O mesmo ocorreu com o híbrido AF-682, onde os lotes 6 e 10 não diferiram entre si; aliás, o lote 10 fora considerado, de maneira consistente, como o menos vigoroso nos demais testes conduzidos nesta pesquisa. Informações nesse sentido também foram encontradas por Lima (1983), com sementes de cebola, onde teste de condutividade elétrica não mostrou sensibilidade na separação dos lotes de alto e baixo vigor. Da mesma forma, Argerich \& Bradford (1989) e Novembre et al. (1995), não obtiveram resultados consistentes ao trabalharem com sementes de tomate. Por outro lado, Andrade et al. (1995) verificou, para sementes de cenoura, que o teste de condutividade elétrica foi considerado o mais indicado para estimar o vigor, devido à facilidade de execução, objetividade e rapidez. Também nesse sentido Dias et al. (1998), trabalhando com sementes de feijãode-vagem e quiabo, concluíram que o teste de condutividade elétrica mostrou-se eficiente para a avaliação do potencial fisiológico dessas sementes. 
Tabela 19. Dados médios de condutividade elétrica $(\mu \mathrm{mho} / \mathrm{cm} / \mathrm{g})$ utilizando as combinações 25 sementes $/ 50 \mathrm{~mL}$ e 50 sementes $/ 50 \mathrm{~mL}$, a $20^{\circ} \mathrm{C}$, respectivamente, de dez lotes de sementes de melão, híbridos AF-646 e AF-682, em cada período de embebição.

\begin{tabular}{|c|c|c|c|c|c|c|c|c|c|}
\hline \multirow{2}{*}{ Híbridos } & \multirow{2}{*}{ Lotes } & \multicolumn{8}{|c|}{ Períodos de embebição (h) } \\
\hline & & 1 & 2 & 4 & 8 & 12 & 16 & 20 & 24 \\
\hline & & $\ldots \ldots$ & $\ldots \ldots$ & $\ldots .$. & semente & $/ 50 \mathrm{~mL} / 2$ & & & \\
\hline \multirow[t]{6}{*}{ AF-646 } & 1 & $25,0 a^{*}$ & $29,5 \mathrm{a}$ & $33,6 \mathrm{a}$ & $36,7 \mathrm{a}$ & $40,6 \mathrm{a}$ & $45,1 \mathrm{a}$ & $48,7 \mathrm{a}$ & $55,9 a$ \\
\hline & 2 & $30,5 a b$ & $34,8 a b$ & $38,4 a b$ & $46,7 \mathrm{~b}$ & $52,8 b$ & $57,0 \mathrm{~b}$ & $61,7 b$ & $69,2 \mathrm{~b}$ \\
\hline & 3 & $42,9 \mathrm{~b}$ & $44,6 \mathrm{~b}$ & $45,4 \mathrm{~b}$ & $55,7 \mathrm{c}$ & $60,1 \mathrm{c}$ & $66,3 c$ & $70,2 \mathrm{c}$ & $82,2 \mathrm{c}$ \\
\hline & 4 & $40,9 \mathrm{~b}$ & $42,6 b$ & $48,6 \mathrm{~b}$ & $57,1 \mathrm{c}$ & $62,5 \mathrm{c}$ & $68,9 \mathrm{c}$ & $73,6 \mathrm{c}$ & $86,9 \mathrm{c}$ \\
\hline & 5 & $26,6 \mathrm{a}$ & $30,2 \mathrm{a}$ & $38,9 a b$ & $37,8 \mathrm{a}$ & $42,1 \mathrm{a}$ & $46,3 \mathrm{a}$ & $49,2 \mathrm{a}$ & $58,9 a$ \\
\hline & & \multicolumn{8}{|c|}{ C.V. $(\%)=5,5$} \\
\hline \multirow[t]{7}{*}{ AF-682 } & 6 & $34,5 \mathrm{a}$ & $39,9 a$ & $45,3 \mathrm{a}$ & $51,9 \mathrm{a}$ & $57,1 \mathrm{a}$ & $59,5 \mathrm{a}$ & $63,9 \mathrm{a}$ & $67,2 \mathrm{a}$ \\
\hline & 7 & $79,2 \mathrm{~b}$ & $82,3 b$ & $85,6 \mathrm{~b}$ & $88,5 b$ & $90,2 \mathrm{~b}$ & $92,6 b$ & $93,9 \mathrm{~b}$ & $95,2 \mathrm{~b}$ \\
\hline & 8 & $37,6 \mathrm{a}$ & $39,5 \mathrm{a}$ & $43,3 a$ & $46,8 \mathrm{a}$ & $51,6 \mathrm{a}$ & $55,5 a$ & $60,7 \mathrm{a}$ & $65,1 \mathrm{a}$ \\
\hline & 9 & $85,8 \mathrm{bc}$ & $89,4 \mathrm{bc}$ & $93,7 \mathrm{bc}$ & $96,2 \mathrm{c}$ & $99,5 \mathrm{c}$ & $105,8 \mathrm{c}$ & $109,1 \mathrm{c}$ & $112,8 \mathrm{c}$ \\
\hline & 10 & $36,4 \mathrm{a}$ & $40,5 \mathrm{a}$ & $44,8 \mathrm{a}$ & $50,5 \mathrm{a}$ & $55,7 \mathrm{a}$ & $56,3 a$ & $62,4 \mathrm{a}$ & $66,9 \mathrm{a}$ \\
\hline & & \multicolumn{8}{|c|}{ C.V. $(\%)=6,3$} \\
\hline & & & & 50 & semente & $/ 50 \mathrm{~mL} / 2$ & & & ....... \\
\hline \multirow[t]{6}{*}{ AF-646 } & 1 & $28,0 \mathrm{a}$ & $33,5 \mathrm{a}$ & $39,6 \mathrm{a}$ & $46,7 \mathrm{a}$ & $52,6 \mathrm{a}$ & $57,1 \mathrm{a}$ & $62,7 \mathrm{a}$ & $68,9 a$ \\
\hline & 2 & $32,5 \mathrm{a}$ & $39,8 b$ & $46,4 \mathrm{~b}$ & $54,7 \mathrm{~b}$ & $63,8 b$ & $71,0 \mathrm{~b}$ & $76,7 \mathrm{~b}$ & $85,2 \mathrm{~b}$ \\
\hline & 3 & $52,9 \mathrm{~b}$ & $58,6 \mathrm{c}$ & $66,4 \mathrm{c}$ & $74,7 \mathrm{c}$ & $81,1 \mathrm{c}$ & $86,3 c$ & $92,2 \mathrm{c}$ & $104,2 \mathrm{c}$ \\
\hline & 4 & $47,9 \mathrm{~b}$ & $54,6 \mathrm{c}$ & 58,6 bc & $70,1 \mathrm{c}$ & $78,5 \mathrm{c}$ & $86,9 \mathrm{c}$ & $95,6 \mathrm{c}$ & $103,9 \mathrm{c}$ \\
\hline & 5 & $29,6 \mathrm{a}$ & $35,2 a b$ & $39,9 \mathrm{a}$ & $47,8 \mathrm{a}$ & $56,1 \mathrm{a}$ & $61,3 \mathrm{a}$ & $65,2 \mathrm{a}$ & $70,9 a$ \\
\hline & & \multicolumn{8}{|c|}{ C.V. $(\%)=3,9$} \\
\hline \multirow[t]{6}{*}{ AF-682 } & 6 & $39,5 \mathrm{a}$ & $44,9 \mathrm{a}$ & $50,3 a$ & $56,9 \mathrm{a}$ & $62,1 \mathrm{a}$ & $63,5 \mathrm{a}$ & $66,9 \mathrm{a}$ & $71,2 \mathrm{a}$ \\
\hline & 7 & $88,2 b$ & $90,3 \mathrm{~b}$ & $92,6 \mathrm{~b}$ & $93,5 b$ & $94,2 \mathrm{~b}$ & $94,6 \mathrm{~b}$ & $96,9 \mathrm{~b}$ & $98,2 \mathrm{~b}$ \\
\hline & 8 & $43,6 a$ & $47,5 \mathrm{a}$ & $51,3 \mathrm{a}$ & $53,8 \mathrm{a}$ & $56,6 \mathrm{a}$ & $59,5 a$ & $61,7 \mathrm{a}$ & $68,1 \mathrm{a}$ \\
\hline & 9 & $90,8 \mathrm{~b}$ & $94,4 \mathrm{~b}$ & $107,7 \mathrm{bc}$ & $111,2 \mathrm{c}$ & $112,5 \mathrm{c}$ & $113,8 \mathrm{c}$ & $114,8 \mathrm{c}$ & $116,8 \mathrm{c}$ \\
\hline & 10 & $36,4 \mathrm{a}$ & $42,5 \mathrm{a}$ & $47,8 \mathrm{a}$ & $52,5 \mathrm{a}$ & $57,7 \mathrm{a}$ & $59,3 \mathrm{a}$ & $63,4 \mathrm{a}$ & $68,9 \mathrm{a}$ \\
\hline & & \multicolumn{8}{|c|}{ C.V. $(\%)=4,3$} \\
\hline
\end{tabular}

${ }^{*}$ Comparação de médias dentro de cada coluna pelo teste de Tukey, $5 \%$ de probabilidade. 
Tabela 20. Dados médios de condutividade elétrica $(\mu \mathrm{mho} / \mathrm{cm} / \mathrm{g})$ utilizando as combinações 25 sementes $/ 75 \mathrm{~mL}$ e 50 sementes $/ 75 \mathrm{~mL}$, a $20^{\circ} \mathrm{C}$, respectivamente, de dez lotes de sementes de melão, híbridos AF-646 e AF-682, em cada período de embebição.

\begin{tabular}{|c|c|c|c|c|c|c|c|c|c|}
\hline \multirow{2}{*}{ Híbridos } & \multirow{2}{*}{ Lotes } & \multicolumn{8}{|c|}{ Períodos de embebição (h) } \\
\hline & & 1 & 2 & 4 & 8 & 12 & 16 & 20 & 24 \\
\hline & & .. & & 25 & sement & $/ 75 \mathrm{~mL} / \mathrm{a}$ & & & \\
\hline \multirow[t]{6}{*}{ AF-646 } & 1 & $19,5 a^{*}$ & $23,4 \mathrm{a}$ & $28,7 \mathrm{a}$ & $34,5 \mathrm{a}$ & $38,8 \mathrm{a}$ & $41,0 \mathrm{a}$ & $44,3 \mathrm{a}$ & $47,2 \mathrm{a}$ \\
\hline & 2 & $20,1 \mathrm{a}$ & $22,5 \mathrm{a}$ & $35,4 a b$ & $38,4 \mathrm{~b}$ & $43,9 \mathrm{~b}$ & $47,0 \mathrm{~b}$ & $52,1 \mathrm{~b}$ & $57,5 b$ \\
\hline & 3 & $34,3 \mathrm{~b}$ & $37,0 \mathrm{~b}$ & $41,2 \mathrm{~b}$ & $46,4 \mathrm{c}$ & $48,6 \mathrm{c}$ & $52,7 \mathrm{c}$ & $63,4 \mathrm{c}$ & $70,9 \mathrm{c}$ \\
\hline & 4 & $32,8 b$ & $35,6 \mathrm{~b}$ & $38,6 a b$ & $45,6 \mathrm{c}$ & $47,1 \mathrm{c}$ & $54,8 \mathrm{c}$ & $60,9 c$ & $68,4 c$ \\
\hline & 5 & $20,1 \mathrm{a}$ & $22,0 \mathrm{a}$ & $26,2 \mathrm{a}$ & $33,3 \mathrm{a}$ & $37,4 \mathrm{a}$ & $40,4 \mathrm{a}$ & $43,3 \mathrm{a}$ & $46,0 \mathrm{a}$ \\
\hline & & \multicolumn{8}{|c|}{ C.V. $(\%)=5,8$} \\
\hline \multirow[t]{7}{*}{ AF-682 } & 6 & $24,1 \mathrm{a}$ & $29,3 \mathrm{a}$ & $32,6 \mathrm{a}$ & $35,8 \mathrm{a}$ & $37,6 \mathrm{a}$ & $38,6 \mathrm{a}$ & $40,4 a$ & $47,2 \mathrm{a}$ \\
\hline & 7 & $49.9 \mathrm{~b}$ & $52,7 \mathrm{~b}$ & $62,6 \mathrm{~b}$ & $54,6 \mathrm{~b}$ & $56,4 \mathrm{~b}$ & $59,4 \mathrm{~b}$ & $61,9 \mathrm{~b}$ & $65,2 \mathrm{~b}$ \\
\hline & 8 & $25,8 \mathrm{a}$ & $29,7 \mathrm{a}$ & $31,1 \mathrm{a}$ & $34,0 \mathrm{a}$ & $36,8 \mathrm{a}$ & $38,5 \mathrm{a}$ & $41,8 \mathrm{a}$ & $46,4 \mathrm{a}$ \\
\hline & 9 & $52,3 \mathrm{~b}$ & $57,8 \mathrm{~b}$ & $68,3 \mathrm{bc}$ & $75,5 \mathrm{c}$ & $77,4 \mathrm{c}$ & $81,5 \mathrm{c}$ & $84,4 \mathrm{c}$ & $88,3 \mathrm{c}$ \\
\hline & 10 & $21,8 \mathrm{a}$ & $26,3 a$ & $30,9 a$ & $33,8 \mathrm{a}$ & $37,7 \mathrm{a}$ & $39,7 \mathrm{a}$ & $42,6 \mathrm{a}$ & $48,3 a$ \\
\hline & & \multicolumn{8}{|c|}{ C.V. $(\%)=6,2$} \\
\hline & & & & $\ldots \quad 50$ & sement & $/ 75 \mathrm{~mL} / \mathrm{c}$ & & & \\
\hline \multirow[t]{6}{*}{ AF-646 } & 1 & $22,9 a$ & $25,1 \mathrm{a}$ & $32,1 \mathrm{a}$ & $37,9 a$ & $43,1 \mathrm{a}$ & $48,4 \mathrm{a}$ & $53,7 a$ & $59,2 \mathrm{a}$ \\
\hline & 2 & $22,3 \mathrm{a}$ & $27,5 \mathrm{a}$ & $33,4 \mathrm{a}$ & $41,0 \mathrm{a}$ & $46,9 a$ & $52,0 \mathrm{a}$ & $56,4 a$ & $57,8 a$ \\
\hline & 3 & $37,4 \mathrm{~b}$ & $43,3 \mathrm{~b}$ & $49,9 \mathrm{~b}$ & $55,0 \mathrm{~b}$ & $63,3 \mathrm{~b}$ & $67,0 \mathrm{~b}$ & $72,6 \mathrm{~b}$ & $76,5 \mathrm{~b}$ \\
\hline & 4 & $33,9 a b$ & $38,7 a b$ & $39,9 a b$ & $51,0 \mathrm{~b}$ & $58,0 \mathrm{~b}$ & $64,1 \mathrm{~b}$ & $68,7 \mathrm{~b}$ & $75,5 b$ \\
\hline & 5 & $23,1 \mathrm{a}$ & $26,8 \mathrm{a}$ & $30,3 \mathrm{a}$ & $40,7 \mathrm{a}$ & $45,6 \mathrm{a}$ & $49,4 \mathrm{a}$ & $55,2 \mathrm{a}$ & $60,3 \mathrm{a}$ \\
\hline & & \multicolumn{8}{|c|}{ C.V. $(\%)=5,0$} \\
\hline \multirow[t]{6}{*}{ AF-682 } & 6 & $27,3 \mathrm{a}$ & $31,2 \mathrm{a}$ & $35,3 a$ & $40,2 \mathrm{a}$ & $43,8 a$ & $47,3 \mathrm{a}$ & $49,3 a$ & $53,5 \mathrm{a}$ \\
\hline & 7 & $60,5 \mathrm{~b}$ & $62,8 b$ & $63,1 \mathrm{~b}$ & $63,5 b$ & $63,8 \mathrm{~b}$ & $64,5 \mathrm{~b}$ & $64,7 \mathrm{~b}$ & $64,4 \mathrm{~b}$ \\
\hline & 8 & $28,1 \mathrm{a}$ & $30,8 \mathrm{a}$ & $33,1 \mathrm{a}$ & $35,2 a$ & $38,5 \mathrm{a}$ & $44,4 \mathrm{a}$ & $46,8 \mathrm{a}$ & $54,3 \mathrm{a}$ \\
\hline & 9 & $62,2 b$ & $65,4 b$ & $69,8 \mathrm{bc}$ & $75,5 \mathrm{c}$ & $84,2 \mathrm{c}$ & $85,7 \mathrm{c}$ & $87,4 \mathrm{c}$ & $90,5 \mathrm{c}$ \\
\hline & 10 & $25,4 \mathrm{a}$ & $28,8 \mathrm{a}$ & $32,2 \mathrm{a}$ & $38,3 \mathrm{a}$ & $41,6 \mathrm{a}$ & $45,5 \mathrm{a}$ & $47,1 \mathrm{a}$ & $51,6 \mathrm{a}$ \\
\hline & & \multicolumn{8}{|c|}{ C.V. $(\%)=5,5$} \\
\hline
\end{tabular}


Tabela 21. Dados médios de condutividade elétrica $\mu \mathrm{mho} / \mathrm{cm} / \mathrm{g}$ ) utilizando as combinações 25 sementes $/ 50 \mathrm{~mL}$ e 50 sementes $/ 50 \mathrm{~mL}$, a $25^{\circ} \mathrm{C}$, respectivamente, de dez lotes de sementes de melão, híbridos AF-646 e AF-682, em cada período de embebição.

\begin{tabular}{|c|c|c|c|c|c|c|c|c|c|}
\hline \multirow{2}{*}{ Híbridos } & \multirow{2}{*}{ Lotes } & \multicolumn{8}{|c|}{ Períodos de embebição (h) } \\
\hline & & 1 & 2 & 4 & 8 & 12 & 16 & 20 & 24 \\
\hline & & $\ldots \ldots \ldots$ & $\ldots \ldots$. & $\begin{array}{ll}\ldots . . & 25\end{array}$ & semente & $/ 50 \mathrm{~mL} / 2$ & & & \\
\hline \multirow[t]{6}{*}{ AF-646 } & 1 & $32,0 a^{*}$ & $36,8 \mathrm{a}$ & $45,9 a$ & $56,9 a$ & $63,5 \mathrm{a}$ & $74,8 \mathrm{a}$ & $89,0 \mathrm{a}$ & $97,2 \mathrm{a}$ \\
\hline & 2 & $34,3 \mathrm{a}$ & $42,4 \mathrm{~b}$ & $60,8 \mathrm{~b}$ & $66,0 \mathrm{~b}$ & $76,5 b$ & $85,6 b$ & $97,1 \mathrm{~b}$ & $100,4 \mathrm{~b}$ \\
\hline & 3 & $54,9 \mathrm{~b}$ & $56,0 \mathrm{bc}$ & $78,9 \mathrm{bc}$ & $83,9 \mathrm{c}$ & $93,5 \mathrm{c}$ & $99,9 \mathrm{c}$ & $112,9 \mathrm{c}$ & $124,2 \mathrm{c}$ \\
\hline & 4 & $50,4 \mathrm{~b}$ & $55,5 \mathrm{bc}$ & $77,5 \mathrm{bc}$ & $80,4 \mathrm{c}$ & $90,7 \mathrm{c}$ & $102,5 \mathrm{C}$ & $118,6 \mathrm{c}$ & $130,4 \mathrm{c}$ \\
\hline & 5 & $32,8 \mathrm{a}$ & $37,7 \mathrm{a}$ & $46,5 \mathrm{a}$ & $57,8 \mathrm{a}$ & $62,4 \mathrm{a}$ & $74,5 \mathrm{a}$ & $93,5 \mathrm{a}$ & $98,6 \mathrm{a}$ \\
\hline & & \multicolumn{8}{|c|}{ C.V. $(\%)=5,8$} \\
\hline \multirow[t]{7}{*}{ AF-682 } & 6 & $43,2 \mathrm{a}$ & $48,3 \mathrm{a}$ & $54,6 \mathrm{a}$ & $62,7 \mathrm{a}$ & $70,6 \mathrm{a}$ & $78,2 \mathrm{a}$ & $90,3 \mathrm{a}$ & $96,4 \mathrm{a}$ \\
\hline & 7 & 89,4 b & $94,3 \mathrm{~b}$ & $96,4 \mathrm{~b}$ & $97,5 \mathrm{~b}$ & $99,5 \mathrm{~b}$ & $100,2 b$ & $107,4 \mathrm{~b}$ & $111,0 \mathrm{~b}$ \\
\hline & 8 & $45,3 \mathrm{a}$ & $49,3 \mathrm{a}$ & $53,7 \mathrm{a}$ & $59,4 \mathrm{a}$ & $70,2 \mathrm{a}$ & $78,4 \mathrm{a}$ & $87,8 \mathrm{a}$ & $98,6 \mathrm{a}$ \\
\hline & 9 & $101,8 \mathrm{bc}$ & $106,5 \mathrm{bc}$ & $109,8 \mathrm{bc}$ & $115,7 \mathrm{c}$ & $120,4 \mathrm{c}$ & $125,4 \mathrm{C}$ & $137,4 \mathrm{c}$ & $145,3 \mathrm{c}$ \\
\hline & 10 & $39,6 \mathrm{a}$ & $44,5 \mathrm{a}$ & $52,5 \mathrm{a}$ & $59,7 \mathrm{a}$ & $68,6 \mathrm{a}$ & $75,4 \mathrm{a}$ & $86,4 \mathrm{a}$ & $95,2 \mathrm{a}$ \\
\hline & & \multicolumn{8}{|c|}{ C.V. $(\%)=6,6$} \\
\hline & & & & 50 & semente & $/ 50 \mathrm{~mL} / 2$ & & & \\
\hline \multirow[t]{6}{*}{ AF-646 } & 1 & $37,9 a$ & $41,9 a$ & $52,6 \mathrm{a}$ & $63,9 a$ & $72,7 \mathrm{a}$ & $80,1 \mathrm{a}$ & $89,6 \mathrm{a}$ & $98,7 \mathrm{a}$ \\
\hline & 2 & $39,3 \mathrm{a}$ & $48,1 \mathrm{~b}$ & $65,3 b$ & $77,1 \mathrm{~b}$ & $91,0 \mathrm{~b}$ & $98,8 b$ & 104,7 b & $110,3 b$ \\
\hline & 3 & $60,7 \mathrm{~b}$ & $62,6 \mathrm{bc}$ & $77,9 \mathrm{bc}$ & $97,8 \mathrm{c}$ & $99,0 \mathrm{c}$ & $105,6 \mathrm{c}$ & $116,5 \mathrm{c}$ & $129,1 \mathrm{c}$ \\
\hline & 4 & $56,1 \mathrm{~b}$ & $62,8 \mathrm{bc}$ & 75,9 bc & $93,4 \mathrm{c}$ & $97,3 \mathrm{c}$ & $107,3 \mathrm{c}$ & $119,3 \mathrm{c}$ & $132,2 \mathrm{c}$ \\
\hline & 5 & $37,6 \mathrm{a}$ & $42,6 \mathrm{a}$ & $52,4 \mathrm{a}$ & $65,9 a$ & $74,9 \mathrm{a}$ & $84,9 a$ & $90,4 \mathrm{a}$ & $101,1 \mathrm{a}$ \\
\hline & & \multicolumn{8}{|c|}{ C.V. $(\%)=4,9$} \\
\hline \multirow[t]{6}{*}{ AF-682 } & 6 & $44,4 \mathrm{a}$ & $50,9 a$ & $60,3 \mathrm{a}$ & $71,3 \mathrm{a}$ & $79,5 \mathrm{a}$ & $85,4 \mathrm{a}$ & $92,4 \mathrm{a}$ & $98,3 \mathrm{a}$ \\
\hline & 7 & $91,2 b$ & $95,8 \mathrm{~b}$ & $100,0 \mathrm{~b}$ & $103,0 \mathrm{~b}$ & $104,7 b$ & $108,5 b$ & $114,3 \mathrm{~b}$ & $125,7 b$ \\
\hline & 8 & $48,2 \mathrm{a}$ & $52,4 a$ & $61,6 \mathrm{a}$ & $68,2 \mathrm{a}$ & $75,1 \mathrm{~b}$ & $84,1 \mathrm{a}$ & $95,5 \mathrm{a}$ & $99,3 \mathrm{a}$ \\
\hline & 9 & $102,5 \mathrm{bc}$ & $112,0 \mathrm{bc}$ & $118,8 \mathrm{bc}$ & $130,6 \mathrm{c}$ & $140,2 \mathrm{c}$ & $144,4 \mathrm{c}$ & $153,3 \mathrm{c}$ & $167,5 \mathrm{c}$ \\
\hline & 10 & $38,3 \mathrm{a}$ & $45,1 \mathrm{a}$ & $53,3 \mathrm{a}$ & $67,9 \mathrm{a}$ & $76,7 \mathrm{a}$ & $83,2 \mathrm{a}$ & $91,5 \mathrm{a}$ & $97,4 \mathrm{a}$ \\
\hline & & \multicolumn{8}{|c|}{ C.V. $(\%)=5,5$} \\
\hline
\end{tabular}

${ }^{*}$ Comparação de médias dentro de cada coluna pelo teste de Tukey, $5 \%$ de probabilidade. 
Tabela 22. Dados médios de condutividade elétrica $\mu \mathrm{mho} / \mathrm{cm} / \mathrm{g}$ ) utilizando as combinações 25 sementes $/ 75 \mathrm{~mL}$ e 50 sementes $/ 75 \mathrm{~mL}$, a $25^{\circ} \mathrm{C}$, respectivamente, de dez lotes de sementes de melão, híbridos AF-646 e AF-682, em cada período de embebição.

\begin{tabular}{|c|c|c|c|c|c|c|c|c|c|}
\hline \multirow{2}{*}{ Híbridos } & \multirow{2}{*}{ Lotes } & \multicolumn{8}{|c|}{ Períodos de embebição (h) } \\
\hline & & 1 & 2 & 4 & 8 & 12 & 16 & 20 & 24 \\
\hline & & $\ldots \ldots$. & $\ldots \ldots \ldots$ & $\ldots$. & sement & $/ 75 \mathrm{~mL} / \mathrm{c}$ & & & $\ldots \ldots$ \\
\hline \multirow[t]{6}{*}{ AF-646 } & 1 & $20,8 a^{*}$ & $25,4 \mathrm{a}$ & $31,6 \mathrm{a}$ & $40,3 \mathrm{a}$ & $50,9 a$ & $56,8 \mathrm{a}$ & $63,6 \mathrm{a}$ & $70,5 \mathrm{a}$ \\
\hline & 2 & $23,1 \mathrm{a}$ & $29,5 a$ & $36,8 \mathrm{a}$ & $48,8 \mathrm{~b}$ & $59,9 b$ & $65,2 \mathrm{~b}$ & $72,4 \mathrm{~b}$ & $76.2 b$ \\
\hline & 3 & $39,9 \mathrm{~b}$ & $46,1 \mathrm{~b}$ & $50,6 b$ & $64,1 \mathrm{c}$ & $71,9 \mathrm{c}$ & $78,7 \mathrm{c}$ & $82,8 \mathrm{c}$ & $89,4 \mathrm{c}$ \\
\hline & 4 & $35,6 \mathrm{~b}$ & $41,7 \mathrm{~b}$ & $49,2 b$ & $69,9 \mathrm{c}$ & $72,8 \mathrm{c}$ & $77,1 \mathrm{c}$ & $85,9 \mathrm{c}$ & $90,3 \mathrm{c}$ \\
\hline & 5 & $22,3 \mathrm{a}$ & $27,4 \mathrm{a}$ & $33,2 \mathrm{a}$ & $42,0 \mathrm{a}$ & $51,7 \mathrm{a}$ & $59,6 \mathrm{a}$ & $65,3 \mathrm{a}$ & $72,6 \mathrm{a}$ \\
\hline & & \multicolumn{8}{|c|}{ C.V. $(\%)=6,4$} \\
\hline \multirow[t]{7}{*}{ AF-682 } & 6 & $25,6 \mathrm{a}$ & $28,8 \mathrm{a}$ & $35,6 \mathrm{a}$ & $45,4 \mathrm{a}$ & $52,0 \mathrm{a}$ & $56,3 \mathrm{a}$ & $60,9 a$ & $67,3 \mathrm{a}$ \\
\hline & 7 & $59,4 \mathrm{~b}$ & $62,4 \mathrm{~b}$ & $63,0 \mathrm{~b}$ & $66,3 \mathrm{~b}$ & $67,0 \mathrm{~b}$ & $69,3 \mathrm{~b}$ & $72,4 \mathrm{~b}$ & $73,6 b$ \\
\hline & 8 & $33,0 \mathrm{a}$ & $35,2 \mathrm{a}$ & $38,9 a$ & $44,3 \mathrm{a}$ & $49,7 \mathrm{a}$ & $50,2 \mathrm{a}$ & $59,4 a$ & $64,5 \mathrm{a}$ \\
\hline & 9 & $65,1 \mathrm{bc}$ & $72,5 \mathrm{bc}$ & $76,4 \mathrm{bc}$ & $83,6 \mathrm{c}$ & $87,3 \mathrm{c}$ & $92,0 \mathrm{c}$ & $96,3 \mathrm{c}$ & $99,5 \mathrm{c}$ \\
\hline & 10 & $25,9 a$ & $29,5 \mathrm{a}$ & $34,5 \mathrm{a}$ & $43,3 \mathrm{a}$ & $48,3 \mathrm{a}$ & $56,1 \mathrm{a}$ & $63,2 \mathrm{a}$ & $66,3 \mathrm{a}$ \\
\hline & & \multicolumn{8}{|c|}{ C.V. $(\%)=7,7$} \\
\hline & & & & $\ldots \ldots$ & sement & $/ 75 \mathrm{~mL} / \mathrm{c}$ & ${ }^{\circ} \mathrm{C}$ & & \\
\hline \multirow[t]{6}{*}{ AF-646 } & 1 & $22,2 \mathrm{a}$ & $30,2 \mathrm{a}$ & $34,2 \mathrm{a}$ & $44,6 \mathrm{a}$ & $51,0 \mathrm{a}$ & $56,8 \mathrm{a}$ & $62,0 \mathrm{a}$ & $65,7 \mathrm{a}$ \\
\hline & 2 & $25,3 a$ & $33,6 \mathrm{~b}$ & $42,0 \mathrm{~b}$ & $52,6 b$ & $61,9 b$ & $68,8 \mathrm{~b}$ & $73,6 b$ & $79,7 \mathrm{~b}$ \\
\hline & 3 & $43,6 b$ & $48,4 \mathrm{bc}$ & $55,8 \mathrm{bc}$ & $71,5 \mathrm{c}$ & $81,8 \mathrm{c}$ & $87,9 \mathrm{c}$ & $97,7 \mathrm{c}$ & $112,6 \mathrm{c}$ \\
\hline & 4 & $38,0 \mathrm{~b}$ & $45,5 \mathrm{bc}$ & $53,1 \mathrm{bc}$ & $66,1 \mathrm{c}$ & $77,4 \mathrm{c}$ & $84,3 \mathrm{c}$ & $91,5 \mathrm{c}$ & $110,1 \mathrm{c}$ \\
\hline & 5 & $23,7 a$ & $28,5 \mathrm{a}$ & $32,6 \mathrm{a}$ & $40,7 \mathrm{a}$ & $48,2 \mathrm{a}$ & $55,1 \mathrm{a}$ & $60,3 \mathrm{a}$ & $62,9 \mathrm{a}$ \\
\hline & & \multicolumn{8}{|c|}{ C.V. $(\%)=5,0$} \\
\hline \multirow[t]{6}{*}{ AF-682 } & 6 & $30,3 \mathrm{a}$ & $35,5 \mathrm{a}$ & $40,3 \mathrm{a}$ & $51,3 \mathrm{a}$ & $56,1 \mathrm{a}$ & $59,0 \mathrm{a}$ & $62,4 \mathrm{a}$ & $68,3 \mathrm{a}$ \\
\hline & 7 & $60,1 \mathrm{~b}$ & $62,4 \mathrm{~b}$ & $65,7 b$ & $72,2 \mathrm{~b}$ & $74,3 \mathrm{~b}$ & $73,6 b$ & $76,3 \mathrm{~b}$ & $78,3 \mathrm{~b}$ \\
\hline & 8 & $38,3 \mathrm{ab}$ & $42,6 \mathrm{ab}$ & $48,7 \mathrm{ab}$ & $53,8 a$ & $58,5 a$ & $61,7 \mathrm{a}$ & $66,8 \mathrm{a}$ & $71,2 \mathrm{a}$ \\
\hline & 9 & $64,4 \mathrm{~b}$ & $65,0 \mathrm{~b}$ & $75,7 b$ & $85,3 \mathrm{c}$ & $95,4 \mathrm{c}$ & $101,5 \mathrm{c}$ & $107,4 \mathrm{c}$ & $111,5 \mathrm{c}$ \\
\hline & 10 & $31,3 \mathrm{a}$ & $34,4 \mathrm{a}$ & $38,3 \mathrm{a}$ & $47,2 \mathrm{a}$ & $55,4 \mathrm{a}$ & $59,4 \mathrm{a}$ & $66,3 \mathrm{a}$ & $70,5 \mathrm{a}$ \\
\hline & & \multicolumn{8}{|c|}{ C.V. $(\%)=5,5$} \\
\hline
\end{tabular}

${ }^{*}$ Comparação de médias dentro de cada coluna pelo teste de Tukey, 5\% de probabilidade. 
Tabela 23. Dados médios de condutividade elétrica $\mu \mathrm{mho} / \mathrm{cm} / \mathrm{g}$ ) utilizando as combinações 25 sementes $/ 50 \mathrm{~mL}$ e 50 sementes $/ 50 \mathrm{~mL}$, a $30^{\circ} \mathrm{C}$, respectivamente, de dez lotes de sementes de melão, híbridos AF-646 e AF-682, em cada período de embebição.

\begin{tabular}{|c|c|c|c|c|c|c|c|c|c|}
\hline \multirow{2}{*}{ Híbridos } & \multirow{2}{*}{ Lotes } & \multicolumn{8}{|c|}{ Períodos de embebição (h) } \\
\hline & & 1 & 2 & 4 & 8 & 12 & 16 & 20 & 24 \\
\hline & & & & $25 s$ & semente & $/ 50 \mathrm{~mL} / 3$ & & & \\
\hline \multirow[t]{6}{*}{ AF-646 } & 1 & $36,1 a^{*}$ & $43,7 a$ & $52,3 \mathrm{a}$ & $67,0 \mathrm{a}$ & $82,7 \mathrm{a}$ & $92,9 \mathrm{a}$ & 109,8 a & $110,6 \mathrm{a}$ \\
\hline & 2 & $40,0 \mathrm{a}$ & $48,5 \mathrm{a}$ & $60,2 b$ & $80,2 b$ & $93,5 b$ & $104,5 b$ & $111,2 b$ & $116,9 b$ \\
\hline & 3 & $59,5 b$ & $69,7 \mathrm{~b}$ & $81,3 \mathrm{c}$ & $90,1 \mathrm{c}$ & $109,3 \mathrm{c}$ & $120,4 \mathrm{c}$ & 129,7 c & $139,9 c$ \\
\hline & 4 & $56,5 b$ & $65,8 \mathrm{ab}$ & $73,0 \mathrm{bc}$ & $91,3 \mathrm{c}$ & $104,5 \mathrm{c}$ & $118,7 \mathrm{c}$ & $125,4 \mathrm{c}$ & $137,2 \mathrm{c}$ \\
\hline & 5 & $35,6 \mathrm{a}$ & $43,8 \mathrm{a}$ & $51,4 \mathrm{a}$ & $67,3 \mathrm{a}$ & $85,4 \mathrm{a}$ & $94,8 \mathrm{a}$ & $107,3 \mathrm{a}$ & $110,3 \mathrm{a}$ \\
\hline & & \multicolumn{8}{|c|}{ C.V. $(\%)=5,9$} \\
\hline \multirow[t]{7}{*}{ AF-682 } & 6 & $47,4 \mathrm{a}$ & $52,5 \mathrm{a}$ & $61,4 \mathrm{a}$ & $70,5 \mathrm{a}$ & $80,6 \mathrm{a}$ & $87,4 \mathrm{a}$ & $90,4 \mathrm{a}$ & $94,9 \mathrm{a}$ \\
\hline & 7 & $95,9 \mathrm{~b}$ & $97,3 b$ & $99,4 \mathrm{~b}$ & $104,4 \mathrm{~b}$ & $108,5 b$ & $109,5 b$ & $111,6 b$ & $119,9 \mathrm{~b}$ \\
\hline & 8 & $47,4 a$ & $53,3 \mathrm{a}$ & $58,4 \mathrm{a}$ & $72,3 \mathrm{a}$ & $80,3 \mathrm{a}$ & $84,1 \mathrm{a}$ & $87,7 \mathrm{a}$ & $95,5 \mathrm{a}$ \\
\hline & 9 & $101,5 \mathrm{bc}$ & $106,4 \mathrm{bc}$ & $115,5 \mathrm{bc}$ & $130,4 \mathrm{c}$ & $134,2 \mathrm{c}$ & $135,7 \mathrm{c}$ & $138,9 \mathrm{c}$ & $140,4 \mathrm{c}$ \\
\hline & 10 & $51,6 \mathrm{a}$ & $49,4 \mathrm{a}$ & $63,6 \mathrm{a}$ & $68,6 \mathrm{a}$ & $79,7 \mathrm{a}$ & $88,7 \mathrm{a}$ & $89,4 \mathrm{a}$ & $92,8 \mathrm{a}$ \\
\hline & & \multicolumn{8}{|c|}{ C.V. $(\%)=6,3$} \\
\hline & & \multicolumn{8}{|c|}{50 sementes $/ 50 \mathrm{~mL} / 30^{\circ} \mathrm{C}$} \\
\hline \multirow[t]{6}{*}{ AF-646 } & 1 & $38,3 \mathrm{a}$ & $45,2 \mathrm{a}$ & $58,8 \mathrm{a}$ & $73,9 a$ & $83,6 \mathrm{a}$ & $96,7 \mathrm{a}$ & $106,6 \mathrm{a}$ & $110,7 \mathrm{a}$ \\
\hline & 2 & $52,3 b$ & $54,0 \mathrm{~b}$ & $70,2 \mathrm{~b}$ & $91,1 \mathrm{~b}$ & $105,9 \mathrm{~b}$ & $114,5 b$ & $126,8 \mathrm{~b}$ & $133,2 b$ \\
\hline & 3 & $60,8 \mathrm{bc}$ & $65,5 \mathrm{bc}$ & $85,1 \mathrm{bc}$ & $112,5 \mathrm{c}$ & $124,8 \mathrm{c}$ & $139,7 \mathrm{c}$ & $156,7 \mathrm{c}$ & $167,8 \mathrm{c}$ \\
\hline & 4 & $59,8 \mathrm{bc}$ & $68,3 \mathrm{bc}$ & $88,9 \mathrm{bc}$ & $111,8 \mathrm{c}$ & $123,0 \mathrm{c}$ & $134,6 \mathrm{c}$ & $147,2 \mathrm{c}$ & $157,5 c$ \\
\hline & 5 & $37,8 \mathrm{a}$ & $45,3 a$ & $55,7 \mathrm{a}$ & $71,9 a$ & $85,9 a$ & $95,2 \mathrm{a}$ & $102,6 \mathrm{a}$ & $103,3 \mathrm{a}$ \\
\hline & & \multicolumn{8}{|c|}{ C.V. $(\%)=4,3$} \\
\hline \multirow[t]{6}{*}{ AF-682 } & 6 & $46,4 \mathrm{a}$ & $55,0 \mathrm{a}$ & $65,7 \mathrm{a}$ & $74,5 \mathrm{a}$ & $82,8 \mathrm{a}$ & $89,6 \mathrm{a}$ & $94,3 \mathrm{a}$ & $101,3 \mathrm{a}$ \\
\hline & 7 & $97,3 \mathrm{~b}$ & $99,5 \mathrm{~b}$ & $115,4 \mathrm{~b}$ & $105,8 \mathrm{~b}$ & $107,2 \mathrm{~b}$ & $111,2 \mathrm{~b}$ & $112,6 b$ & $121,7 \mathrm{~b}$ \\
\hline & 8 & $49,9 a$ & $56,7 \mathrm{a}$ & $62,6 \mathrm{a}$ & $72,3 \mathrm{a}$ & $84,5 \mathrm{a}$ & $95,4 \mathrm{a}$ & $97,8 \mathrm{a}$ & $103,7 \mathrm{a}$ \\
\hline & 9 & $99,6 \mathrm{bc}$ & $119,4 \mathrm{bc}$ & $125,4 \mathrm{bc}$ & $137,5 \mathrm{c}$ & $146,4 \mathrm{c}$ & $148,6 \mathrm{c}$ & 155,2 c & $171,5 \mathrm{c}$ \\
\hline & 10 & $41,2 \mathrm{a}$ & $49,6 \mathrm{a}$ & $59,1 \mathrm{a}$ & $70,5 a$ & $80,7 \mathrm{a}$ & $92,7 \mathrm{a}$ & $93,8 \mathrm{a}$ & $102,4 \mathrm{a}$ \\
\hline & & \multicolumn{8}{|c|}{ C.V. $(\%)=5,1$} \\
\hline
\end{tabular}

${ }^{*}$ Comparação de médias dentro de cada coluna pelo teste de Tukey, $5 \%$ de probabilidade. 
Tabela 24. Dados médios de condutividade elétrica $\mu \mathrm{mho} / \mathrm{cm} / \mathrm{g}$ ) utilizando as combinações 25 sementes $/ 75 \mathrm{~mL}$ e 50 sementes $/ 75 \mathrm{~mL}$, a $30^{\circ} \mathrm{C}$, respectivamente, de dez lotes de sementes de melão, híbridos AF-646 e AF-682, em cada período de embebição.

\begin{tabular}{|c|c|c|c|c|c|c|c|c|c|}
\hline \multirow{2}{*}{ Híbridos } & \multirow{2}{*}{ Lotes } & \multicolumn{8}{|c|}{ Períodos de embebição (h) } \\
\hline & & 1 & 2 & 4 & 8 & 12 & 16 & 20 & 24 \\
\hline & & & & 25 & sement & $/ 75 \mathrm{~mL} / 3$ & & & \\
\hline \multirow[t]{6}{*}{ AF-646 } & 1 & $23,4 a^{*}$ & $28,8 \mathrm{a}$ & $34,8 \mathrm{a}$ & $44,5 \mathrm{a}$ & $54,7 \mathrm{a}$ & $63,4 \mathrm{a}$ & $67,3 \mathrm{a}$ & $69,3 \mathrm{a}$ \\
\hline & 2 & $25,8 \mathrm{a}$ & $31,4 \mathrm{a}$ & $40,8 \mathrm{~b}$ & $54,0 \mathrm{~b}$ & $62,1 \mathrm{~b}$ & $67,4 \mathrm{~b}$ & $73,3 b$ & $76,3 \mathrm{~b}$ \\
\hline & 3 & $38,5 b$ & $45,9 \mathrm{~b}$ & $58,6 \mathrm{bc}$ & $69,0 \mathrm{c}$ & $78,2 \mathrm{c}$ & $89,3 c$ & $103,5 \mathrm{c}$ & $115,3 c$ \\
\hline & 4 & $37,1 \mathrm{~b}$ & $43,2 b$ & $53,0 \mathrm{bc}$ & $63,4 \mathrm{c}$ & $73,6 \mathrm{c}$ & $85,9 \mathrm{c}$ & $93,6 \mathrm{c}$ & $110,3 c$ \\
\hline & 5 & $22,2 \mathrm{a}$ & $26,5 \mathrm{a}$ & $33,6 \mathrm{a}$ & $43,5 \mathrm{a}$ & $55,6 \mathrm{a}$ & $60,7 \mathrm{a}$ & $65,7 \mathrm{a}$ & $68,7 \mathrm{a}$ \\
\hline & & \multicolumn{8}{|c|}{ C.V. $(\%)=5,8$} \\
\hline \multirow[t]{7}{*}{ AF-682 } & 6 & $30,5 \mathrm{a}$ & $35,4 a$ & $41,3 \mathrm{a}$ & $50,8 \mathrm{a}$ & $56,6 \mathrm{a}$ & $61,3 \mathrm{a}$ & $62,6 \mathrm{a}$ & $73,0 \mathrm{a}$ \\
\hline & 7 & $62,4 \mathrm{~b}$ & $62,0 \mathrm{~b}$ & $65,0 \mathrm{~b}$ & $69,5 \mathrm{~b}$ & $70,4 \mathrm{~b}$ & $71,0 \mathrm{~b}$ & $78,0 \mathrm{~b}$ & $85,8 b$ \\
\hline & 8 & $33,6 \mathrm{a}$ & $40,6 \mathrm{a}$ & $42,5 \mathrm{a}$ & $50,5 a$ & $54,5 \mathrm{a}$ & $57,5 \mathrm{a}$ & $63,9 \mathrm{a}$ & $72,1 \mathrm{a}$ \\
\hline & 9 & $68,5 \mathrm{bc}$ & $70,5 \mathrm{bc}$ & $75,4 \mathrm{bc}$ & $85,6 \mathrm{c}$ & $88,4 \mathrm{c}$ & $90,9 c$ & $95,0 \mathrm{c}$ & $99,5 \mathrm{c}$ \\
\hline & 10 & $28,5 \mathrm{a}$ & $31,3 a$ & $37,5 \mathrm{a}$ & $45,6 \mathrm{a}$ & $51,2 \mathrm{a}$ & 59,6 a & $64,3 \mathrm{a}$ & $71,8 \mathrm{a}$ \\
\hline & & \multicolumn{8}{|c|}{ C.V. $(\%)=6,4$} \\
\hline & & & & 50 & sement & $/ 75 \mathrm{~mL} / 3$ & & & \\
\hline \multirow[t]{6}{*}{ AF-646 } & 1 & $24,5 \mathrm{a}$ & $30,5 \mathrm{a}$ & $38,7 \mathrm{a}$ & $50,4 a$ & $59,2 \mathrm{a}$ & $66,4 \mathrm{a}$ & $72,9 a$ & $79,4 \mathrm{a}$ \\
\hline & 2 & $42,1 \mathrm{~b}$ & $45,5 b$ & $55,4 \mathrm{~b}$ & $58,7 b$ & $70,4 \mathrm{~b}$ & $76,1 \mathrm{~b}$ & $83,4 \mathrm{~b}$ & $90,2 \mathrm{~b}$ \\
\hline & 3 & $41,9 \mathrm{~b}$ & $49,6 \mathrm{~b}$ & $62,0 \mathrm{~b}$ & $74,9 \mathrm{c}$ & $85,9 \mathrm{c}$ & $94,0 \mathrm{c}$ & $99,8 \mathrm{c}$ & $119,5 \mathrm{c}$ \\
\hline & 4 & $40,0 \mathrm{~b}$ & $48,2 \mathrm{~b}$ & $59,5 b$ & $78,1 \mathrm{c}$ & $83,1 \mathrm{c}$ & $89,9 \mathrm{c}$ & $98,4 \mathrm{c}$ & $117,3 \mathrm{c}$ \\
\hline & 5 & $25,1 \mathrm{a}$ & $30,1 \mathrm{a}$ & $38,5 \mathrm{a}$ & $51,3 a$ & $62,5 \mathrm{a}$ & $66,6 \mathrm{a}$ & $73,2 \mathrm{a}$ & $77,2 \mathrm{a}$ \\
\hline & & \multicolumn{8}{|c|}{ C.V. $(\%)=4,0$} \\
\hline \multirow[t]{6}{*}{ AF-682 } & 6 & $32,5 \mathrm{a}$ & $36,2 \mathrm{a}$ & $43,2 \mathrm{a}$ & $52,1 \mathrm{a}$ & $60,8 \mathrm{a}$ & $63,4 \mathrm{a}$ & $68,7 \mathrm{a}$ & $77,4 \mathrm{a}$ \\
\hline & 7 & $68,7 \mathrm{~b}$ & $64,3 \mathrm{~b}$ & $67,8 \mathrm{~b}$ & $72,5 b$ & $73,6 \mathrm{~b}$ & $75,6 \mathrm{~b}$ & $79,6 \mathrm{~b}$ & $88,5 b$ \\
\hline & 8 & $36,4 \mathrm{a}$ & $46,0 \mathrm{ab}$ & $48,6 \mathrm{a}$ & $55,8 \mathrm{a}$ & $63,7 \mathrm{a}$ & $67,6 \mathrm{a}$ & $70,5 \mathrm{a}$ & $77,7 \mathrm{a}$ \\
\hline & 9 & $69,0 \mathrm{~b}$ & $66,5 \mathrm{~b}$ & $76,4 \mathrm{bc}$ & $96,4 \mathrm{c}$ & $101,5 \mathrm{c}$ & $112,4 \mathrm{c}$ & $118,6 \mathrm{c}$ & $119,5 c$ \\
\hline & 10 & $34,3 \mathrm{a}$ & $35,6 \mathrm{a}$ & $46,5 \mathrm{a}$ & $53,8 \mathrm{a}$ & $60,3 \mathrm{a}$ & $62,0 \mathrm{a}$ & $67,6 \mathrm{a}$ & $75,0 \mathrm{a}$ \\
\hline & & \multicolumn{8}{|c|}{ C.V. $(\%)=4,9$} \\
\hline
\end{tabular}

${ }^{*}$ Comparação de médias dentro de cada coluna pelo teste de Tukey, $5 \%$ de probabilidade. 
Os resultados obtidos com o teste de condutividade elétrica para ambos os híbridos, nas diversas combinações, indicaram um aumento progressivo das leituras com o decorrer do período de embebição o que se mostra coerente com as observações de Loeffler et al. (1988), Marcos Filho et al. (1990) e Dias et al. (1996). Observou-se que, todos os tratamentos apresentaram significativa lixiviação após o período inicial de 1 hora de embebição, permitindo estratificação dos lotes quanto ao potencial fisiológico. Entretanto, essa classificação dos lotes, para ambos os híbridos, tornou-se mais evidente após o período de 8 horas de embebição, onde valores de condutividade elétrica indicaram a possibilidade de separar lotes em diferentes níveis de vigor, com redução no período de condicionamento das sementes, em relação ao período de 24 horas, estabelecido como padrão. Esses resultados, de certa forma, confirmam aqueles obtidos por Loomis \& Smith (1980), com repolho; Dias et al. (1996; 1998), com couve-flor, cebola, cenoura e quiabo; Rodo et al. (1998), com tomate e Torres et al. (1998), com maxixe, que buscando a padronização do teste de condutividade elétrica dessas sementes pequenas de hortaliças, obtiveram significativa lixiviação durante o período de 3 a 4 horas de embebição. As sementes de melão são relativamente maiores que as mencionadas nos estudos anteriores, portanto esse período de 8 horas, pode ser atribuído a esse fator; Halmer \& Bewley (1984), a duração do período em que ocorre a lixiviação varia consideravelmente entre espécies e cultivares e está, provavelmente, relacionada com o tamanho das sementes.

Em relação àtemperatura, verificou-se que a lixiviação de exsudatos foi proporcional ao aumento da temperatura empregada. De acordo com Vieira (1994), elevação da temperatura de embebição provoca dano térmico às membranas, causando aumento da energia de ativação das moléculas, alterando a viscosidade da água e, consequentemente, aumentando os valores de condutividade. Por outro lado, verifica-se que em baixas temperaturas, o processo de reorganização de membranas é mais lento e o período de perda de lixiviados pelas sementes é mais longo (Givelberg et al., 1984). 
Constatou-se que a elevação da temperatura de $20^{\circ} \mathrm{C}$ para $25^{\circ} \mathrm{C}$ ou 30들 proporcionou aumento na lixiviação dos exsudatos, mas manteve as tendências ordenadas de acréscimo dos lixiviados durante os períodos de embebição, sem alterar a classificação dos lotes. Segundo Matthews \& Powell (1981), Marcos Filho et al. (1987), Krzyzanowski et al. (1991) e Hampton \& TeKrony (1995) a temperatura de $20^{\circ} \mathrm{C}$ ainda é comum no condicionamento das sementes para o teste de condutividade elétrica. Porém, considerando os efeitos das temperaturas de embebição e de avaliação, recomenda-se o uso de 25ㄷ, por ser esta temperatura mais coerente com as condições ambientais dos laboratórios de análise de sementes, ou seja, essa temperatura está, normalmente, mais próxima das condições internas, do que as de $20^{\circ} \mathrm{C}$ e $30^{\circ} \mathrm{C}$ (Vieira \& Krzyzanowski, 1999). Portanto, em função dos resultados, optou-se pela temperatura de $25^{\circ} \mathrm{C}$ para condução do teste de condutividade elétrica em sementes de melão.

Com relação ao número de sementes, em geral, verificou-se que, mantendo constantes a temperatura, o volume e período de embebição os valores da lixiviação apresentaram pequenos aumentos de condutividade em função do aumento do número de sementes, para ambos os híbridos, nas diversas combinações. Portanto, para evitar maior variabilidade entre os resultados, recomenda-se o uso de quatro repetições de 50 sementes (Loeffler et al., 1988; Hampton et al., 1992). Neste sentido, constatou-se que as combinações de 50 sementes, em ambos os híbridos, apresentaram coeficiente de variação médio de 4,9\%, enquanto que o de 25 sementes foi de 6,2\%. Baseado neste aspecto, foi adotado o emprego de quatro repetições de 50 sementes de melão para a condução do teste de condutividade elétrica.

Verificou-se que a redução do volume de água, quando se mantiveram constantes os outros fatores (número de sementes, temperatura e período de embebição), estabeleceu, em geral, relação direta com o aumento do valor da lixiviação. Essa tendência foi observada para os dois híbridos estudados nos diferentes procedimentos; os valores de lixiviação, no menor volume, foram 
superiores ou próximos aos do tratamento com maior volume. Esse fato concorda com os verificados por Loeffler (1981), quando verificou maiores valores de lixiviados em menores volumes de água e atribuiu ao fato de que a embebição em um volume maior de água implica em maior diluição dos lixiviados. Portanto, em função dos volumes 50 e $75 \mathrm{~mL}$, apresentarem resultados similares de condutividade elétrica, adotou-se o volume de $75 \mathrm{~mL}$, tendo em vista o tamanho das sementes de melão como também por ser esse volume considerado o mais usual para outras espécies.

Para ambas as combinações, o teste de condutividade não apresentou resultados consistentes. Porém em função da combinação 50 sementes $/ 75 \mathrm{~mL} / 25^{\circ} \mathrm{C}$, geralmente ser mais empregada na execução do teste, nova tentativa de estudo com esta combinação foi executada na segunda etapa da pesquisa. A escolha dessa combinação se deu ao fato dela permitir a classificação dos lotes, mesmo apresentando resultados contraditórios com os demais testes estudados.

\subsubsection{Lixiviação de potássio}

Os dados do teste de lixiviação de potássio, envolvendo as combinações número de sementes/volume de água/temperatura, encontram-se nas Tabelas 25 e 26 e, constatou-se que as diferentes combinações apresentaram diferenciação dos lotes, para ambos os híbridos, com relação ao potencial fisiológico das sementes. 
Tabela 25. Dados médios de lixiviação de potássio $(\mathrm{ppm} / \mathrm{g})$ utilizando as combinações 25 sementes $/ 50 \mathrm{~mL}$ e 50 sementes $/ 75 \mathrm{~mL}$, a $25^{\circ} \mathrm{C}$, respectivamente, de dez lotes de sementes de melão, híbridos AF-646 e AF-682, em cada período de embebição.

\begin{tabular}{|c|c|c|c|c|c|c|c|c|c|}
\hline \multirow{2}{*}{ Híbridos } & \multirow[b]{2}{*}{ Lotes } & \multicolumn{8}{|c|}{ Períodos de embebição (h) } \\
\hline & & 0,5 & 1 & $1: 30$ & 2 & $2: 30$ & 3 & 4 & 5 \\
\hline & & $\ldots$ & … & 25 & sementes & $/ 50 \mathrm{~mL} / 25$ & & & ...... \\
\hline \multirow[t]{6}{*}{ AF-646 } & 1 & $418 a^{*}$ & $491 \mathrm{a}$ & $610 \mathrm{a}$ & $691 \mathrm{a}$ & $739 a$ & $768 \mathrm{a}$ & $854 a$ & 877 a \\
\hline & 2 & $424 \mathrm{a}$ & $502 \mathrm{a}$ & $627 \mathrm{a}$ & 748 a & $829 b$ & $859 \mathrm{~b}$ & $933 \mathrm{~b}$ & $1170 \mathrm{~b}$ \\
\hline & 3 & $825 c$ & $1036 \mathrm{c}$ & $1100 \mathrm{c}$ & $1160 \mathrm{c}$ & $1216 \mathrm{c}$ & $1230 \mathrm{c}$ & $1241 b$ & $1245 b$ \\
\hline & 4 & $761 \mathrm{bc}$ & 864 bc & $930 \mathrm{bc}$ & $1008 \mathrm{bc}$ & 1083 bc & $1106 \mathrm{bc}$ & $1127 b$ & $1142 b$ \\
\hline & 5 & $375 a$ & $473 a$ & $636 a$ & $674 \mathrm{a}$ & $776 \mathrm{a}$ & $778 a$ & $887 a$ & 913 a \\
\hline & & \multicolumn{8}{|c|}{ C.V. $(\%)=4,9$} \\
\hline \multirow[t]{7}{*}{ AF-682 } & 6 & $819 a b$ & $912 a b$ & $1001 a b$ & $1021 \mathrm{ab}$ & $1035 a b$ & $1041 \mathrm{ab}$ & $1050 a b$ & $1062 a b$ \\
\hline & 7 & $1194 b$ & $1301 \mathrm{~b}$ & $1354 \mathrm{~b}$ & $1372 b$ & $1375 b$ & $1380 \mathrm{~b}$ & $1285 b$ & $1390 \mathrm{~b}$ \\
\hline & 8 & $715 a$ & $784 a$ & $833 a$ & $834 \mathrm{a}$ & $845 a$ & $827 \mathrm{a}$ & $853 a$ & 912 a \\
\hline & 9 & $1554 \mathrm{c}$ & $1624 \mathrm{c}$ & $1691 \mathrm{c}$ & $1704 \mathrm{c}$ & $1760 \mathrm{c}$ & $1763 c$ & $1768 c$ & $1770 \mathrm{c}$ \\
\hline & 10 & $629 a$ & $721 \mathrm{a}$ & $780 a$ & $835 a$ & $836 \mathrm{a}$ & $842 \mathrm{a}$ & $892 \mathrm{a}$ & $915 a$ \\
\hline & & \multicolumn{8}{|c|}{ C.V. $(\%)=6,8$} \\
\hline & & \multicolumn{8}{|c|}{50 sementes $/ 75 \mathrm{~mL} / 25^{\circ} \mathrm{C}$} \\
\hline \multirow[t]{6}{*}{ AF-646 } & 1 & $412 \mathrm{a}$ & $543 a$ & $572 \mathrm{a}$ & $636 \mathrm{a}$ & $686 \mathrm{a}$ & $724 \mathrm{a}$ & $771 \mathrm{a}$ & 839 a \\
\hline & 2 & $446 a b$ & $579 a$ & $649 a$ & 691 a & $757 \mathrm{a}$ & $784 a$ & $871 \mathrm{a}$ & $931 \mathrm{a}$ \\
\hline & 3 & $693 \mathrm{~b}$ & $1000 \mathrm{~b}$ & $1040 \mathrm{~b}$ & $1100 \mathrm{~b}$ & $1126 b$ & $1162 b$ & $1206 \mathrm{~b}$ & $1249 b$ \\
\hline & 4 & $633 \mathrm{~b}$ & $841 \mathrm{~b}$ & $908 \mathrm{~b}$ & $972 b$ & $1009 \mathrm{~b}$ & $1080 \mathrm{~b}$ & $1120 b$ & $1195 b$ \\
\hline & 5 & $420 a b$ & $547 \mathrm{a}$ & $613 a$ & $653 a$ & $692 \mathrm{a}$ & $717 \mathrm{a}$ & $776 \mathrm{a}$ & $833 a$ \\
\hline & & \multicolumn{8}{|c|}{ C.V. $(\%)=4,7$} \\
\hline \multirow[t]{6}{*}{ AF-682 } & 6 & $674 a$ & $760 \mathrm{a}$ & $851 \mathrm{a}$ & $855 a$ & $887 \mathrm{a}$ & $924 \mathrm{a}$ & $977 \mathrm{a}$ & $1029 a$ \\
\hline & 7 & $1172 b$ & $1255 b$ & $1262 b$ & $1268 b$ & $1270 \mathrm{~b}$ & $1280 \mathrm{~b}$ & $1296 \mathrm{~b}$ & $1323 b$ \\
\hline & 8 & $713 a$ & $776 \mathrm{a}$ & $780 \mathrm{a}$ & $814 \mathrm{a}$ & $837 \mathrm{a}$ & $860 \mathrm{a}$ & $870 \mathrm{a}$ & 924 a \\
\hline & 9 & $1310 b$ & $1407 b$ & $1438 \mathrm{~b}$ & $1439 b$ & $1441 \mathrm{~b}$ & $1450 \mathrm{~b}$ & $1489 b$ & $1502 b$ \\
\hline & 10 & $601 \mathrm{a}$ & $680 \mathrm{a}$ & $748 a$ & $758 a$ & $779 a$ & $810 a$ & $859 a$ & 891 a \\
\hline & & \multicolumn{8}{|c|}{ C.V. $(\%)=9,1$} \\
\hline
\end{tabular}

${ }^{*}$ Comparação de médias dentro de cada coluna pelo teste de Tukey, $5 \%$ de probabilidade. 
Tabela 26. Dados médios de lixiviação de potássio $(\mathrm{ppm} / \mathrm{g})$ utilizando as combinações 25 sementes $/ 50 \mathrm{~mL}$ e 50 sementes/75mL, a $30^{\circ} \mathrm{C}$, respectivamente, de dez lotes de sementes de melão, híbridos AF-646 e AF-682, em cada período de embebição.

\begin{tabular}{|c|c|c|c|c|c|c|c|c|c|}
\hline \multirow{2}{*}{ Híbridos } & \multirow{2}{*}{ Lotes } & \multicolumn{8}{|c|}{ Períodos de embebição (h) } \\
\hline & & 0,5 & 1 & $1: 30$ & 2 & $2: 30$ & 3 & 4 & 5 \\
\hline & & …...... & $\cdots \cdots$ & $\ldots .25$ & sementes & $50 \mathrm{~mL} / 30$ & $\mathrm{C}$ & & ....... \\
\hline \multirow[t]{6}{*}{ AF-646 } & 1 & $462 a^{*}$ & $648 \mathrm{a}$ & $713 a$ & $777 \mathrm{a}$ & $852 \mathrm{a}$ & $892 \mathrm{a}$ & $990 \mathrm{a}$ & $1053 \mathrm{a}$ \\
\hline & 2 & $464 \mathrm{a}$ & $656 \mathrm{a}$ & $742 \mathrm{a}$ & $824 \mathrm{a}$ & $854 \mathrm{a}$ & 928 a & 998 a & $1123 \mathrm{a}$ \\
\hline & 3 & $889 \mathrm{~b}$ & $1041 b$ & $1120 \mathrm{~b}$ & $1267 \mathrm{c}$ & 1297 c & $1366 \mathrm{c}$ & $1403 c$ & $1515 c$ \\
\hline & 4 & $848 b$ & $937 \mathrm{~b}$ & $1057 b$ & $1137 b$ & $1162 b$ & $1283 b$ & $1318 b$ & $1428 b$ \\
\hline & 5 & $436 \mathrm{a}$ & $587 \mathrm{a}$ & $682 \mathrm{a}$ & 759 a & $788 \mathrm{a}$ & $858 \mathrm{a}$ & $924 \mathrm{a}$ & $1014 \mathrm{a}$ \\
\hline & & \multicolumn{8}{|c|}{ C.V. $(\%)=5,8$} \\
\hline \multirow[t]{7}{*}{ AF-682 } & 6 & $775 a$ & $868 \mathrm{a}$ & $930 \mathrm{a}$ & $989 a$ & $1031 \mathrm{a}$ & $1046 \mathrm{a}$ & 1099 a & $1114 \mathrm{a}$ \\
\hline & 7 & $1283 b$ & $1393 b$ & $1328 b$ & $1348 b$ & $1350 b$ & $1352 b$ & $1366 b$ & $1399 \mathrm{~b}$ \\
\hline & 8 & $796 \mathrm{a}$ & $892 \mathrm{a}$ & $890 \mathrm{a}$ & 933 a & $936 \mathrm{a}$ & $951 \mathrm{a}$ & $1076 \mathrm{a}$ & 1119 a \\
\hline & 9 & $1468 b$ & $1558 b$ & $1565 b$ & $1568 \mathrm{c}$ & $1590 \mathrm{c}$ & $1603 c$ & $1674 \mathrm{c}$ & $1698 \mathrm{c}$ \\
\hline & 10 & $632 \mathrm{a}$ & $731 \mathrm{a}$ & $772 \mathrm{a}$ & $809 a$ & $859 a$ & 992 a & $1100 \mathrm{a}$ & 1199 a \\
\hline & & \multicolumn{8}{|c|}{ C.V. $(\%)=7,3$} \\
\hline & & & & $50 \mathrm{~s}$ & ementes & $75 \mathrm{~mL} / 30$ & & & \\
\hline \multirow[t]{6}{*}{ AF-646 } & 1 & $472 \mathrm{a}$ & $588 \mathrm{a}$ & $653 a$ & $727 \mathrm{a}$ & $788 \mathrm{a}$ & $823 a$ & $908 \mathrm{a}$ & $991 \mathrm{a}$ \\
\hline & 2 & $459 a$ & $600 a$ & $687 \mathrm{a}$ & $779 a$ & $845 a$ & 1056 b & $1105 b$ & $1163 b$ \\
\hline & 3 & $884 \mathrm{c}$ & $1013 c$ & $1086 \mathrm{c}$ & $1134 \mathrm{c}$ & $1192 \mathrm{c}$ & $1227 \mathrm{c}$ & $1311 \mathrm{c}$ & $1362 \mathrm{c}$ \\
\hline & 4 & $741 \mathrm{bc}$ & 857 bc & 929 bc & $1018 \mathrm{bc}$ & $1076 \mathrm{bc}$ & $1108 \mathrm{bc}$ & $1190 \mathrm{bc}$ & $1225 \mathrm{bc}$ \\
\hline & 5 & $512 \mathrm{a}$ & $590 a$ & $653 a$ & $703 a$ & $762 \mathrm{a}$ & $797 \mathrm{a}$ & $879 a$ & $970 \mathrm{a}$ \\
\hline & & \multicolumn{8}{|c|}{ C.V. $(\%)=7,1$} \\
\hline \multirow[t]{6}{*}{ AF-682 } & 6 & $728 \mathrm{a}$ & $866 \mathrm{a}$ & $948 a$ & $945 a$ & $983 a$ & $1009 a$ & $1064 \mathrm{a}$ & $1065 \mathrm{a}$ \\
\hline & 7 & 1176 b & $1295 b$ & $1337 b$ & $1340 \mathrm{~b}$ & $1343 b$ & 1352 b & $1356 b$ & 1357 b \\
\hline & 8 & $712 \mathrm{a}$ & $824 a$ & $873 a$ & $885 a$ & $889 a$ & $906 a$ & $910 \mathrm{a}$ & $912 \mathrm{a}$ \\
\hline & 9 & 1322 bc & $1429 \mathrm{bc}$ & 1483 bc & $1485 b c$ & $1490 \mathrm{bc}$ & 1492 bc & 1492 bc & 1494 bc \\
\hline & 10 & $654 a$ & $774 a$ & $848 \mathrm{a}$ & $858 a$ & $887 \mathrm{a}$ & $905 a$ & $962 \mathrm{a}$ & 948 a \\
\hline & & \multicolumn{8}{|c|}{ C.V. $(\%)=8,1$} \\
\hline
\end{tabular}

${ }^{*}$ Comparação de médias dentro de cada coluna pelo teste de Tukey, $5 \%$ de probabilidade. 
Analisando os resultados, verificou-se que a combinação 25 sementes $/ 50 \mathrm{~mL} / 30^{\circ} \mathrm{C}$ (Tabela 26 ), apresentou classificação mais evidente dos lotes, a partir de 2 horas de condicionamento das sementes para ambos os híbridos. Assim, os lotes 1, 2 e 5 do híbrido AF-646 foram indicados como de melhor potencial fisiológico e o lote 3 como de pior desempenho; o lote 4, por sua vez, foi considerado como de qualidade intermediária. Contudo, de forma geral, a indicação dos melhores e piores lotes não se mostraram coerentes com os resultados dos testes de primeira contagem de germinação, Método Agroflora e emergência de plântulas em casa de vegetação (Tabela 6), que apontaram o lote 1 como de qualidade inferior. Também, verificou-se de forma geral que os resultados de lixiviação de potássio foram semelhantes quanto a indicação dos lotes em melhor e pior qualidade com os de condutividade elétrica (Tabelas 19, 20, 21, 22, 23 e 24); porém, constatou-se que o lote 4, considerado de qualidade intermediária no teste de lixiviação de potássio, apresentou resultado mais drástico no teste de condutividade elétrica, exceto para a combinação 50 sementes $/ 75 \mathrm{~mL} / 20^{\circ} \mathrm{C}$ (Tabela 20 ), onde apresentou classificação semelhante.

Com relação aos lotes do híbrido AF-682, o teste de lixiviação de potássio não apresentou total coerência com os testes de primeira contagem de germinação, Método Agroflora e emergência de plântulas em casa de vegetação (Tabela 6) quanto à indicação de melhor potencial fisiológico dos lotes 8 e 10, sendo este último lote indicado como de pior qualidade por todos os outros testes. Por outro lado, verificou-se que os resultados de lixiviação de potássio se relacionaram aos de condutividade elétrica, apresentando ordenação semelhante dos lotes. Isso provavelmente é devido aos princípios semelhantes de ambos os testes. Nesse sentido, algumas pesquisas têm relacionado os resultados de lixiviação de potássio aos de condutividade elétrica (Pandey, 1989; Dias et al.,1996). Porém, em trabalho realizado por Custódio \& Marcos Filho (1997) o teste de lixiviação de potássio mostrou-se mais sensível.

Com relação à quantidade de potássio lixiviado, verificou-se de forma geral, que os lotes de sementes de ambos os híbridos, para as diversas 
combinações, apresentaram significativa lixiviação de potássio já nos primeiros trinta minutos de condicionamento das sementes, continuando a aumentar, de forma menos intensa, até o período de 5 horas de embebição. Este fato foi devido, provavelmente, ao próprio processo de embebição, onde a absorção de água em sementes com grau de umidade inicial em torno de $7,1 \%$ (Tabela 6) apresenta velocidade favorecida pelo alto gradiente de potencial hídrico entre o interior da semente e a água circundante, além do tamanho relativamente pequeno dessas sementes. Nesse sentido também, Dias et al. (1998) trabalhando com sementes de feijão-de-vagem encontraram leituras mais elevadas de lixiviação de potássio aos 120 minutos de embebição das sementes.

De modo geral, o teste de lixiviação de potássio revelou eficiência no sentido de identificar os lotes de melhor qualidade: lote 2 (híbrido AF-646) e lote 6 (híbrido AF-682), concordando com testes iniciais (Tabela 6), deterioração controlada (Tabela 9) e envelhecimento acelerado (Tabelas 13 e 17); no entanto, com relação a indicação do lote de pior qualidade, não apresentou relação efetiva com esses testes. 


\subsection{Comparação entre os testes para avaliação do potencial fisiológico de sementes de melão (Etapa 2)}

Nesta etapa foram analisados comparativamente os protocolos considerados mais eficientes após os estudos durante a primeira etapa, dos testes de deterioração controlada, envelhecimento acelerado, condutividade elétrica e lixiviação de potássio, utilizando-se os mesmos lotes de sementes.

Analisando os resultados apresentados na Tabela 27, verificou-se que, o teste de germinação, para ambos os híbridos, agrupou os lotes em dois níveis de vigor, indicando inferioridade dos lotes 1 (híbrido AF-646) e 10 (híbrido AF-682) e os demais apresentaram desempenho superior.

$O$ teste de primeira contagem de germinação (Tabela 27) também identificou o lote 1 do híbrido AF-646 como de qualidade inferior, enquanto que os demais lotes apresentaram qualidade superior, não diferindo estatisticamente entre si. Em relação aos lotes do híbrido AF-682, o teste de primeira contagem de geminação mostrou-se mais sensível que o de germinação, classificando os lotes em três níveis de vigor. Assim, o lotes 6 e 8 foram tidos como os de melhor potencial fisiológico e o lote 10 como o de pior qualidade; os lotes 7 e 9 apresentaram qualidade intermediária.

Com relação ao Método Agroflora, os resultados foram semelhantes aos dos testes de germinação e primeira contagem de germinação, para os lotes do híbrido AF-646 (Tabela 27). No tocante ao híbrido AF-682, esse método de avaliação identificou os lotes 6 e 8 como os de melhor qualidade, enquanto que o lote 10 foi considerado como de pior qualidade; e os lotes 7 e 9 tidos como de qualidade intermediária. Essas informações concordam integralmente com as do teste de primeira contagem de germinação e, de forma parcial, com os resultados de germinação. 
Tabela 27. Dados médios do grau de umidade, primeira contagem de germinação, Método Agroflora, emergência de plântulas de dez lotes de sementes de melão, híbridos AF-646 e AF-682.

\begin{tabular}{ccccccc}
\hline Híbridos & Lotes & $\begin{array}{c}\text { Grau de } \\
\text { Umidade }\end{array}$ & $\begin{array}{c}\text { Germina- } \\
\text { ção }\end{array}$ & $\begin{array}{c}\text { Primeira } \\
\text { Contagem }\end{array}$ & $\begin{array}{c}\text { Método } \\
\text { Agroflora }\end{array}$ & $\begin{array}{c}\text { Emergência } \\
\text { de plântulas }\end{array}$ \\
\hline \multirow{4}{*}{ AF-646 } & 1 & 7,0 & $88 \mathrm{~b}^{*}$ & $80 \mathrm{~b}$ & $82 \mathrm{~b}$ & $84 \mathrm{~b}$ \\
& 2 & 7,2 & $94 \mathrm{a}$ & $90 \mathrm{a}$ & $90 \mathrm{a}$ & $92 \mathrm{a}$ \\
& 3 & 7,1 & $94 \mathrm{a}$ & $90 \mathrm{a}$ & $90 \mathrm{a}$ & $92 \mathrm{a}$ \\
& 4 & 7,3 & $96 \mathrm{a}$ & $92 \mathrm{a}$ & $90 \mathrm{a}$ & $92 \mathrm{a}$ \\
& 5 & 7,4 & $94 \mathrm{a}$ & $92 \mathrm{a}$ & $92 \mathrm{a}$ & $92 \mathrm{a}$ \\
& C.V.(\%) & - & 3,3 & 2,8 & 3,0 & 4,2 \\
& 6 & 7,2 & $96 \mathrm{a}$ & $92 \mathrm{a}$ & $94 \mathrm{a}$ & $94 \mathrm{a}$ \\
& 7 & 7,0 & $94 \mathrm{a}$ & $88 \mathrm{~b}$ & $88 \mathrm{~b}$ & $87 \mathrm{~b}$ \\
& 8 & 7,1 & $94 \mathrm{a}$ & $92 \mathrm{a}$ & $94 \mathrm{a}$ & $91 \mathrm{ab}$ \\
& 9 & 7,3 & $92 \mathrm{a}$ & $89 \mathrm{~b}$ & $88 \mathrm{~b}$ & $86 \mathrm{~b}$ \\
& 10 & 7,1 & $84 \mathrm{~b}$ & $72 \mathrm{c}$ & $78 \mathrm{c}$ & $80 \mathrm{c}$ \\
& C.V.(\%) & - & 3,9 & 4,4 & 4,6 & 4,7 \\
\hline
\end{tabular}

${ }^{*}$ Comparação de médias dentro de cada coluna pelo teste de Tukey, $5 \%$ de probabilidade.

O teste de emergência de plântulas em casa de vegetação (Tabela 27) apresentou, para o híbrido AF-646, resultados concordantes com os encontrados nos testes de germinação, primeira contagem de germinação e Método Agroflora, apontando o lote 1 como de baixa qualidade e, os demais, como de qualidade superior. Em relação ao híbrido AF-682, o lote 6 foi considerado como de melhor potencial fisiológico, não diferindo do lote 8; o lote 10 apresentou pior qualidade e os lotes 7 e 9 apresentaram comportamento intermediário. 
Com relação ao grau de umidade das sementes antes da realização dos testes (Tabela 27), verificou-se que os valores foram semelhantes entre os lotes estudados, fato este considerado importante para padronização das avaliações e obtenção de resultados confiáveis.

$\mathrm{Na}$ Tabela 28 encontram-se os resultados obtidos para os testes de deterioração controlada e envelhecimento acelerado (procedimento tradicional e com o uso de solução saturada de sal) para ambos os híbridos.

O teste de deterioração controlada, utilizando a combinação $24 \% / 24 \mathrm{~h}$, revelou eficiência no sentido de indicar o lote 4 do híbrido AF-646 como o de melhor potencial fisiológico e os lotes 1 e 5 como de qualidade inferior, sendo o lote 1 ainda pior; os lotes 2 e 3 apresentaram desempenho intermediário. Desse modo, verificou-se que os resultados desse teste apresentaram concordância com os de germinação, primeira contagem de germinação, Método Agroflora e emergência de plântulas em casa de vegetação (Tabela 27) quanto à indicação dos lotes 1 e 4 como de pior e melhor potencial fisiológico, respectivamente. No que se refere ao híbrido AF-682, o lote 6 apresentou melhor desempenho e os lotes 9 e 10 mostraram comportamento inferior, sendo ainda pior para o lote 10. Esses resultados indicando a superioridade do lote 6 e inferioridade do lote 10 concordam com os de germinação, primeira contagem de geminação, Método Agroflora e emergência de plântulas em casa de vegetação (Tabela 27).

O teste de deterioração controlada que se revelou promissor na avaliação do potencial fisiológico de sementes de melão, constitui um teste relativamente simples, não exigindo equipamentos específicos e com possibilidade considerável de padronização. Entretanto, apresenta desvantagem em relação ao envelhecimento acelerado, por ser mais trabalhoso, principalmente no que se refere à uniformização no ajuste do grau de umidade das sementes no início do teste. 
Tabela 28. Dados médios obtidos para os testes de deterioração controlada (DC) e de envelhecimento acelerado $\{E A$ (procedimento tradicional e com solução salina)\} de dez lotes de sementes de melão, híbridos AF646 e AF-682.

\begin{tabular}{|c|c|c|c|c|}
\hline \multirow{2}{*}{ Híbridos } & \multirow{2}{*}{ Lotes } & $\mathrm{DC}$ & \multicolumn{2}{|c|}{ EA-tradicional EA-solução salina } \\
\hline & & $24 \% / 24 h$ & \multicolumn{2}{|c|}{$41^{\circ} \mathrm{C} / 72 \mathrm{~h}$} \\
\hline & & $\ldots . . . \% \quad \% \ldots .$. & n........... & 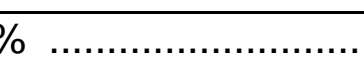 \\
\hline \multirow[t]{6}{*}{ AF-646 } & 1 & $75 d^{*}$ & $76 \mathrm{c}$ & $80 \mathrm{c}$ \\
\hline & 2 & $91 \mathrm{~b}$ & $90 \mathrm{a}$ & $92 \mathrm{a}$ \\
\hline & 3 & $89 b$ & $86 \mathrm{~b}$ & $88 b$ \\
\hline & 4 & $96 a$ & $92 \mathrm{a}$ & $94 \mathrm{a}$ \\
\hline & 5 & $85 c$ & $86 b$ & $86 b$ \\
\hline & C.V.(\%) & 4,3 & 6,3 & 4,5 \\
\hline \multirow[t]{6}{*}{ AF-682 } & 6 & $94 \mathrm{a}$ & $90 \mathrm{a}$ & $92 \mathrm{a}$ \\
\hline & 7 & $84 \mathrm{~b}$ & $80 \mathrm{~b}$ & $86 b$ \\
\hline & 8 & $86 \mathrm{~b}$ & $84 \mathrm{~b}$ & $88 \mathrm{~b}$ \\
\hline & 9 & $78 \mathrm{c}$ & $82 \mathrm{~b}$ & $80 b c$ \\
\hline & 10 & $66 \mathrm{~d}$ & $74 \mathrm{c}$ & $76 c$ \\
\hline & C.V.(\%) & 5,3 & 5,7 & 4,9 \\
\hline
\end{tabular}

O teste de envelhecimento acelerado (tradicional), com a combinação $41^{\circ} \mathrm{C} / 72 \mathrm{~h}$, proporcionou a separação dos lotes em três níveis de vigor para ambos os híbridos. Assim, o lote 1 do híbrido AF-646 foi indicado como de pior qualidade e os lotes 2 e 4 como de melhor potencial fisiológico; os lotes 3 e 5 foram considerados como intermediários. No Caso do híbrido AF-682, o lote 6 apresentou o melhor desempenho e o lote 10 foi tido como de pior qualidade; os 
lotes 7, 8 e 9 apresentaram comportamento intermediário. Portanto, verificou-se que esse teste exibiu concordância com os resultados de germinação, primeira contagem de germinação, Método Agroflora e emergência de plântulas em casa de vegetação, quanto à indicação dos lotes de melhor e pior qualidade (Tabela 27).

Verificando os resultados do teste de envelhecimento acelerado (com solução salina), utilizando a mesma combinação do teste tradicional, ou seja, $41^{\circ} \mathrm{C} / 72 \mathrm{~h}$, esse apresentou a mesma tendência do procedimento tradicional com relação à separação dos lotes em níveis de potencial fisiológico, com exceção do lote 9 , classificado antes como intermediário e, agora, tendendo à inferioridade.

Constatou-se que essa metodologia alternativa do teste de envelhecimento acelerado pode ser considerada promissora para utilização em programas de controle de qualidade, visto que requer metodologia e equipamento similares ao procedimento tradicional (sem o uso de solução salina), além de reduzir acentuadamente ou impedir o desenvolvimento de microrganismos durante o condicionamento das sementes.

O grau de umidade das sementes após os períodos de condicionamento, dos testes de deterioração controlada e envelhecimento acelerado, encontram-se na Tabela 29.

Com relação aos dados referentes ao grau de umidade após o período de condicionamento em banho-maria, no teste de deterioração controlada, verificou-se, para ambos os híbridos, que as sementes permaneceram, praticamente, com o mesmo grau de umidade em comparação ao início do teste, ou seja, $24 \%$. Nesse sentido, a técnica utilizada para deterioração controlada mostrou-se eficiente na manutenção constante do grau de umidade das sementes durante o decorrer do teste. 
Tabela 29. Dados médios do grau de umidade obtidos após os períodos de deterioração controlada (DC) e de envelhecimento acelerado $\{E A$ (procedimento tradicional e com solução salina)\} de dez lotes de sementes de melão, híbridos AF-646 e AF-682.

\begin{tabular}{|c|c|c|c|c|}
\hline \multirow{2}{*}{ Híbridos } & \multirow{2}{*}{ Lotes } & $\mathrm{DC}$ & EA-tradicional & EA-solução salina \\
\hline & & $24 \% / 24 h$ & \multicolumn{2}{|c|}{$41^{\circ} \mathrm{C} / 72 \mathrm{~h}$} \\
\hline & & $\ldots \ldots . . . \% \quad \% \ldots$ & ……………...... & 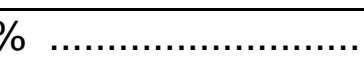 \\
\hline \multirow[t]{5}{*}{ AF-646 } & 1 & 24,4 & 28,4 & 9,2 \\
\hline & 2 & 24,0 & 28,2 & 9,2 \\
\hline & 3 & 24,2 & 29,2 & 9,4 \\
\hline & 4 & 24,0 & 29,7 & 9,2 \\
\hline & 5 & 23,9 & 27,6 & 9,3 \\
\hline \multirow[t]{5}{*}{ AF-682 } & 6 & 24,2 & 27,9 & 9,5 \\
\hline & 7 & 24,4 & 28,3 & 9,1 \\
\hline & 8 & 24,2 & 29,0 & 9,4 \\
\hline & 9 & 24,0 & 29,4 & 9,2 \\
\hline & 10 & 24,0 & 29,0 & 9,2 \\
\hline
\end{tabular}

No caso das sementes envelhecidas artificialmente, sem o uso de solução salina, mostraram elevação acentuada no grau de umidade, atingindo valor médio de $28,7 \%$ para ambos os híbridos. Por outro lado, as sementes expostas à solução saturada do sal $(\mathrm{NaCl})$ apresentaram valores menores e mais uniformes do que os observados para as envelhecidas sem o uso do sal, ficando entre 9,2 e 9,4\% para o híbrido AF-646 e entre 9,1 e 9,5\% para o híbrido AF-682, revelando, com isso a eficiência do método em retardar a absorção de água pelas sementes pequenas no teste de envelhecimento acelerado. 
$\mathrm{Na}$ Tabela 30 encontram-se os dados obtidos para os testes de condutividade elétrica e lixiviação de potássio.

Tabela 30. Dados médios obtidos para os testes de condutividade elétrica (após 8 e 24 horas de embebição) e de lixiviação de potássio (após 2 horas de embebição), de dez lotes de sementes de melão, híbridos AF-646 e AF-682.

\begin{tabular}{|c|c|c|c|c|}
\hline \multirow{2}{*}{ Híbridos } & \multirow{2}{*}{ Lotes } & \multicolumn{2}{|c|}{ Condutividade elétrica } & \multirow{2}{*}{$\frac{\text { Lixiviação de potássio }}{2 \mathrm{~h}}$} \\
\hline & & $8 \mathrm{~h}$ & $24 \mathrm{~h}$ & \\
\hline & \multicolumn{3}{|c|}{$\ldots \ldots . . \mu \mathrm{mho} / \mathrm{cm} / \mathrm{g} \quad \ldots \ldots \ldots . . . .}$. & ........ ppm/g ........ \\
\hline \multirow[t]{6}{*}{ AF-646 } & 1 & $49,9 a^{*}$ & $70,5 \mathrm{a}$ & $893 \mathrm{a}$ \\
\hline & 2 & 57,2 b & $84,8 \mathrm{~b}$ & $874 \mathrm{a}$ \\
\hline & 3 & $75,0 \mathrm{c}$ & $116,9 \mathrm{c}$ & $1283 c$ \\
\hline & 4 & $70,8 \mathrm{c}$ & $113,9 \mathrm{c}$ & $1181 b$ \\
\hline & 5 & $48,2 \mathrm{a}$ & $69,0 \mathrm{a}$ & $882 \mathrm{a}$ \\
\hline & C.V.(\%) & 6,5 & 6,5 & 5,2 \\
\hline \multirow[t]{6}{*}{ AF-682 } & 6 & $55,5 \mathrm{a}$ & $75,8 \mathrm{a}$ & $990 \mathrm{a}$ \\
\hline & 7 & $80,3 \mathrm{~b}$ & $83,6 \mathrm{~b}$ & $1367 b$ \\
\hline & 8 & $54,2 \mathrm{a}$ & $73,9 \mathrm{a}$ & $1001 \mathrm{a}$ \\
\hline & 9 & $95,9 \mathrm{c}$ & $126,4 \mathrm{c}$ & $1593 \mathrm{c}$ \\
\hline & 10 & $53,8 \mathrm{a}$ & $77,9 \mathrm{a}$ & $896 \mathrm{a}$ \\
\hline & C.V.(\%) & 5,4 & 5,4 & 6,2 \\
\hline
\end{tabular}

Analisando os resultados do teste de condutividade elétrica, utilizando a combinação 50 sementes $/ 75 \mathrm{~mL} / 25^{\circ} \mathrm{C}$, verificou-se para ambos os híbridos, que os períodos de embebição (8 e 24 horas) mostraram concordância quanto à 
ordenação dos lotes e a possibilidade de redução no período de condicionamento das sementes de melão, sem que haja prejuízo na confiabilidade dos resultados. Esta possibilidade na redução do período de embebição das sementes de hortaliças foi também verificada por Andrade et al. (1995), com sementes de cenoura; Torres et al. (1998), com maxixe; Dias et al. (1998), com quiabo e Sá (1999), com tomate. Neste teste os lotes 1 e 5 do híbrido AF-646 foram indicados como os mais vigorosos, enquanto os lotes 3 e 4 como de qualidade inferior; o lote 2 apresentou resultado intermediário. Entretanto, da mesma forma como observado na Etapa 1, a condutividade elétrica não forneceu informações compatíveis com os demais testes empregados (Tabela 27), exceto para o lote 5 que manteve a superioridade. Para o híbrido AF-682, os lotes 6, 8 e 10 foram considerados como de melhor potencial fisiológico e o lote 9 como de pior desempenho; o lote 7 apresentou comportamento intermediário. Para este híbrido, os resultados de condutividade elétrica também não foram totalmente coerentes com os obtidos nos testes de germinação, primeira contagem de germinação, Método Agroflora e emergência de plântulas em casa de vegetação (Tabela 27) que, para estes testes, o lote 10 é tido como de pior qualidade.

O teste de condutividade elétrica tem sido reconhecido como eficiente para a avaliação do vigor de sementes de hortaliças, conforme demostraram Andrade et al. (1995), para cenoura; Dias et al. (1996), para couve-flor, cenoura e cebola, e Torres (1998), para cebola. No entanto, o teste também não tem sido considerado eficiente para algumas hortaliças como cebola, melão, tomate e pimentão, nestas espécies a presença da membrana semi-permeável, de origem nucelar, permite a entrada de água mas não a difusão de certos eletrólitos para o exterior. Nesse sentido, Lima (1993), com sementes de cebola, verificou que o teste de condutividade elétrica não mostrou sensibilidade para detectar diferenças entre lotes de maior e menor vigor. O mesmo foi também verificado por Argerich \& Bradford (1989) e Novembre et al. (1995) para sementes de tomate. 
Em outros casos, o insucesso desse teste tem sido atribuído a influência do genótipo, associada à características do tegumento, permitindo a liberação mais, ou menos, acentuada dos lixiviados. Assim, Rech et al. (1999) verificaram que o teste de condutividade elétrica foi eficiente para a avaliação do vigor de sementes de ervilha, porém se apresentou pouco consistente entre cultivares. Já Thornton et al. (1990), trabalhando com brássicas, destacaram que o tegumento das sementes restringiu, em grau variável, a exsudação de eletrólitos durante a embebição, dependendo do cultivar analisado, interferindo, portanto, nos resultados do teste de condutividade elétrica. Segundo McCormac \& Keffe (1990), a testa pode agir como barreira à entrada de água durante a embebição. Estes autores, verificaram que as caraterísticas do tegumento podem afetar os resultados do teste de condutividade e se constituir na principal causa de variações das informações obtidas quando são avaliadas sementes de diferentes cultivares ou até amostras de um mesmo cultivar e, que isso pode ocorrer também para sementes de hortaliças.

Portanto, constatou-se que o teste de condutividade elétrica pode ser considerado como menos adequado para avaliação do vigor das sementes de melão, uma vez que seus resultados se mostraram contraditórios aos obtidos nos outros testes, em maior ou menor intensidade, dependendo do híbrido avaliado. Entretanto, a continuidade da pesquisa provavelmente fornecerá subsídios para o esclarecimento dos motivos que determinam a obtenção de resultados imprevisíveis com esse teste.

Com base nos resultados do teste de lixiviação de potássio, onde se utilizou a combinação 25 sementes $/ 50 \mathrm{~mL} / 30^{\circ} \mathrm{C}$ por 2 horas de embebição, verificou-se, de forma geral, que ambos os híbridos apresentaram comportamento semelhante aos de condutividade elétrica, quanto à ordenação dos lotes, exceto para os lotes 2 e 4 do híbrido AF-646 que apresentaram comportamento diferenciado. Portanto, relacionando os resultados de lixiviação de potássio com os de germinação, primeira contagem de germinação, Método Agroflora e emergência de plântulas em casa de vegetação, verificou-se, para 
ambos os híbridos, resultados contraditórios, quanto á indicação dos lotes de pior qualidade (Tabela 27).

Para ambos os híbridos, verificou-se que o teste de lixiviação de potássio concordou com os demais testes, quanto àindicação do lote de melhor potencial fisiológico, em período de tempo consideravelmente reduzido (2 horas). Apesar da menor precisão das informações geradas, o referido teste pode se constituir em um opção promissora, em razão da sua simplicidade de execução e rapidez, permitindo a tomada de decisões, principalmente em programas de controle de qualidade pós-colheita, desde que o procedimento seja convenientemente estudado e desenvolvido, pois o fato de indicar apenas o melhor lote não atinge os objetivos desejados para um teste de vigor.

Assim, com base nos resultados desta pesquisa, pode-se afirmar que dentre os testes avaliados, o de deterioração controlada e o de envelhecimento acelerado com e sem solução salina possibilitaram a melhor identificação de lotes com diferentes níveis de potencial fisiológico, revelando resultados coerentes com os testes de germinação, primeira contagem de germinação, Método Agroflora e emergência de plântulas em casa de vegetação, demonstrando eficiência para avaliação do vigor de sementes de melão. 


\section{CONCLUSÕES}

A análise dos dados e interpretação dos resultados permitiram concluir que:

- o teste de deterioração controla $\left(24 \% / 45 \%{ }^{\circ} \mathrm{C} / 24 \mathrm{~h}\right)$ e o de envelhecimento acelerado (procedimento tradicional e com solução salina), utilizando a combinação $41^{\circ} \mathrm{C} / 72 \mathrm{~h}$, apresentam sensibilidade suficiente para avaliação do potencial fisiológico de sementes de melão;

- o teste de condutividade elétrica não se constitui em opção eficiente para avaliação do vigor das sementes, enquanto o teste de lixiviação de potássio necessita de estudos adicionais para adequar sua metodologia e viabilizar a sua utilização para sementes de melão, considerando-se, inclusive, os prováveis efeitos do genótipo. 


\section{REFERÊNCIAS BIBLIOGRÁFICAS}

ABDEL SAMAD, L.M.; PEARCE, R.S. Leaching of ions, organic molecules, and enzymes from seeds of peanut (Arachis hypogaea L.) imbibing without testas or with intact testas. Journal of Experimenta Botany, v.29, n.112, p.1471-1478, 1978.

ALSADON, A.; YULE, L.J.; POWELL, A.A. Influence of seed ageing on the germination, vigour and emergence in module trays of tomato and cucumber seeds. Seed Science and Technology, v.23, n.3, p.665-672, 1995.

ANDRADE, R.N.; SANTOS, D.S.B.; SANTOS FILHO, B.G.; MELLO, V.D.C. Correlação entre testes de vigor em sementes de cenoura armazenadas por diferentes períodos. Pesquisa Agropecuária Gaúcha, v.1, n.2, p.153-162, 1995.

ARGERICH, C.A.; BRADFORD, K.J. The effects of priming and ageing on seed vigour in tomato. Journal of Experimental Botany, v.40, n.214, p.599-607, 1989.

ASSOCIATION OF OFFICIAL SEED ANALYSTS. Seed vigor testing handbook. East Lasing, 1983. 93p. (Contribution, 32). 
BARBEDO, A.S.C.; CÂMARA, F.L.A.; NAKAGAWA, J.; BARBEDO, C.J. População de plantas, método de colheita e qualidade de sementes de cenoura cultivar Brasília. Pesquisa Agropecuária Brasileira, v.35, n.8, p.1645-1652, 2000.

BARROS, A.S.R.; MARCOS FILHO, J. Testes para avaliação rápida do vigor de sementes de soja. Revista Brasileira de Sementes, v.19, n.2, p.289-295, 1997.

BENNETT, M.A.; EVANS, A.F.; GRASSBAUGH, E.M. Saturated salt accelerated aging (SSAA) test for assessing and comparing sh2 and se sweet corn seed lots. In: CONGRESS OF ISTA, 26., Angers, 2001. Abstracts appendix. Angers: ISTA. 2001. p.11.

BEWLEY, J.D.; BLACK, M. Seeds: physiology of development and germination. New York: Plenum Press, 1994. 444p.

BHÉRING, M.C.; BARROS, D.I.; DIAS, D.C.F.S. Aplicação do vigor de sementes de melancia pelos testes de envelhecimento acelerado e deterioração controlada. Informativo ABRATES, v.11, n.2, p.204, 2001 a.

BHÉRING, M.C.; BARROS, D.I.; DIAS, D.C.F.S.; NUNES, H.V. Testes para avaliação da qualidade fisiológica de sementes de berinjela. Informativo ABRATES, v.11, n.2, p.203, 2001b.

BHÉRING, M.C.; DIAS, D.C.F.S.; BARROS, D.I.; GOMES, J.M. Comparação entre métodos para avaliação do vigor de sementes de pepino. Informativo ABRATES, v.11, n.2, p.204, 2001b. 
BHÉRING, M.C.; DIAS, D.C.F.S.; GOMES, J.M.; BARROS, D.I. Métodos para avaliação do vigor de sementes de pepino. Revista Brasileira de Sementes, v.22, n.2, p.171-175, 2000.

BRASIL. Ministério da Agricultura e Reforma Agrária. Regras para análise de sementes. Brasília: SNDA; DNDV; CLAV, 1992. 365p.

BUSTAMANTE, L.; SEDDON, M.G.; DON, R.; RENNIE, W.J. Pea seed quality and seedling emergence in the field. Seed Science and Technology, v.12, n.2, p.551-558, 1984.

CARVALHO, N.M.; NAKAGAWA, J. Sementes: ciência, tecnologia e produção. 4 ed. Jaboticabal: Funep, 2000. 588p.

CANO-RÍOS, P.; RAMÍREZ-ROSALES, G.; ORTEGÓN-PÉREZ, J.; ESPARZAMARTÍNEZ J.H.; RODRÍGUEZ-HERRERA, S. Análisis dialélico para vigor de semilla en melón. Agrociencia, v.34, n.3, p.337-342, 2000.

CORTES, P.M.; SPAETH, S.C. Potassium leakage from artificially aged pea (Pisum sativum L.) embryos during imbibition. Journal of Seed Technology, v.8, n.1, p.30-42, 1994.

CUSTÓDIO, C.C.; MARCOS FILHO, J. Potassium leachate test for the evaluation of soybean seed physiological quality. Seed Science and Technology, v. 25, n.3, p.549-564, 1997.

DELOUCHE, J.C.; BASKIN, C.C. Accelerated aging techniques for predicting the relative storability of seed lots. Seed Science and Technology, v.1, n.2, p.427-452, 1973. 
DELOUCHE, J.C.; Standardization of vigor tests. Journal of Seed Technology, v.1, n.2, p.75-85, 1976.

DEMIR, I.; ELLIS, R.H. Development of peper (Capsicum annuum) seed quality. Annals of Applied Biology, v.121, n.2, p.385-399, 1992.

DESWAL, D.P.; SHEORAN, I.S. A simple method for seed leakage measurement: applicable to single seeds of any size. Seed Science and Technology, v.21, n.1, p.179-185, 1993.

DIAS, D.C.F.S.; MARCOS FILHO, J. Testes de vigor baseados na permeabilidade das membranas celulares: I. Condutividade elétrica. Informativo ABRATES, v.5, n.1, p.26-36, 1995.

DIAS, D.C.F.S.; MARCOS FILHO, J.; CARMELLO, Q.A.C. Potassium leakage test for the evaluation of vigour in soybean seeds. Seed Science and Technology, v.25, n.1, p.7-18, 1996.

DIAS, D.C.F.S.; MARCOS FILHO, J.; CARMELLO, Q.A.C. Potassium leakage test for the evaluation of vigour in soybean seeds. Seed Science and Technology, v.25, n.1, p.7-18, 1996.

DIAS, D.C.F.S.; VIEIRA, A.N.; BHÉRING, M.C. Condutividade elétrica e lixiviação de potássio para avaliação do vigor de sementes de hortaliças: feijão-de-vagem e quiabo. Revista Brasileira de Sementes, v.20, n.2, p.408-413, 1998. 
DIAS, D.C.F.S.; VIEIRA, A.N.; BHÉRING, M.C. Estudo dos testes de condutividade elétrica e lixiviação de potássio para avaliação do vigor de sementes de hortaliças: I. Couve flor, cebola, e cenoura. In: SEMINÁRIO PANAMERICANO DE SEMILLAS, 15., Gramado, 1996. Anais. Gramado: CESM; FELAS, 1996. p.28.

DIAS, M.C.L.; BARROS, A.S.R. Relatório do comitê de vigor da ABRATES. Informativo ABRATES, v.3, n.1, p.17-23, 1992.

DOIJOD, S.D. Solute leakage in relation to loss of seed viability in chilli cultivars. Indian Journal of Plant Physiology, v.31, n.3, p.285-287, 1988.

DUKE, S.H.; KAKEFUDA, G. Role of the testa in preventing cellular rupture during imbibition of legume seeds. Plant Physiology, v.67, n.2, p.449-456, 1981.

DURÁN, J.M.; CAMACHO, M.J.; RETAMAL, N. Un metodo rapido para la determinacion de calidad de semillas horticolas. Revista Científica Rural, v.2, n.1, p.1-7, 1997.

FNP CONSULTORIA \& COMÉRCIO. AGRIANUAL 2002: anuário da agricultura brasileira. São Paulo, 2001. 536p.

GIVELBERG, A.; HOROWITZ, M.; POLJAKOFF-MAYBER, A. Solute leakage from Solanum nigrum L. seeds exposed to high temperatures during imbibition. Journal of Experimental Botany, v.35, n.161, p.1754-1763, 1984. 
GORECKI, R.J.; HARMAN, G.E.; MATTICK, L.R. The volatile exudates from germination pea seeds of defferent viability and vigor. Canadian Journal of Botany, v.63, n.6, p.1035-1039, 1985.

GRANQVIST, G.A. Leakage of cations from a carrot seed lot. Acta Horticulturae, n.215, p.219-224, 1987.

GUIMARÃES, J.R.M.; MALAVASI, M.M.; LOPES, H.M. Definição do protocolo do teste de condutividade elétrica para avaliação do vigor de sementes de alface (Lactuca sativa L.). Informativo ABRATES, v.3, n.3, p.138, 1993.

HALMER, P.; BEWLEY, J.D. A physiological perspective on seed vigour testing. Seed Science and Technology, v.12, n.2, p.561-575, 1984.

HALLOIN, J.M. Solute loss deteriorated cottonseed: relationship between deterioration, seed moisture, and solute loss. Crop Science, v.15, n.1, p.1115, 1975.

HAMPTON, J.G. Conductivity test. In: VAN DER VENTER, H.A. (Ed.). Seed vigour testing seminar. Zürich: ISTA,1995. p.10-28.

HAMPTON, J.G.; COOLBEAR, P. Potential versus actual seed performance can vigour testing provide an answer? Seed Science and Technology, v.18, n.2, p.215-228, 1990.

HAMPTON, J.G.; JONHSTONE, K.A.; EUA-UMPON, V. Bulk conductivity test variables for mungbean, soybean and French bean seed lots. Seed Science and Technology, v.20, n.3, p.677-686, 1992. 
HAMPTON, J.G.; TEKRONY, D.M. Handbook of vigor test methods. Zürich: ISTA, 1995. 117p.

HAMPTON, J.G.; LUNGWANGWA, A.L.; HILL, K.A. The bulk conductivity test for lotus seed lots. Seed Science and Technology, v.22, n.1, p.177-180, 1994.

HEPBURN, H.A.; POWELL, A.A.; MATTHEWS, S. Problems associated with the routine aplication of electrical conductivity measurements of individual seeds in the germination testing of peas and soybeans. Seed Science and Technology, v.12, n.2, p.403-413, 1984.

IDIARTE, H.G. Relação do envelhecimento acelerado na qualidade fisiológica de sementes de cebola. Piracicaba, 1995. 84p. Dissertação (Mestrado) Escola Superior de Agricultura "Luiz de Queiroz", Universidade de São Paulo.

INTERNATIONAL SEED TESTING ASSOCIATION. Handbook of vigour test methods. 3.ed. Zürich, 1995.117p.

JIANHUA, Z.; McDONALD, M.B. The saturated salt accelerated aging test for small-seeded crops. Seed Science and Technology, v.25, n.1, p.123-131, 1997.

KRISHNASAMY, V.; RAMARAJPALANIAPPAN, M.S.M.G. Electrical conductivity of seed leachate in tomato and brinjal. South Indian Horticulture, v.37, n.5, p.303-304, 1989. 
KRZYZANOWSKI, F.C.; FRANÇA NETO, J.B.; HENNING, A.A. Relato dos testes de vigor disponíveis para grandes culturas. Informativo ABRATES, v.1, n.2, p.15-50, 1991.

KRZYZANOWSKI, F.C.; FRANÇA NETO, J.B. Situação atual do uso de testes de vigor como rotina em programas de sementes no Brasil. Informativo ABRATES, v.1, n.3, p.42-53, 1991.

KULIK, M.M.; YAKLICH, R.W. Evaluation for vigor tests in soybean seeds relationship of accelerated aging, cold, sand bench and speed of germination tests to field performance. Crop Science, v.22, n.4, p.776-770, 1982.

LARSEN, S.U.; POVLSEN, F.V.; ERIKSEN, E.N.; PEDERSEN, H.C. The influence of seedvigour on field performance and the evaluation of the applicability of the controlled deterioration vigour test in oil seed rape (Brassica napus) and pea (Pisum sativum). Seed Science and Technology, v.26, n.3, p.627-641,1998

LEOPOLD, A.C. Temperature effects on soybean imbibition and leakage. Plant Physiology, v.65, n.4, p.1096-1098, 1980.

LIMA, D. Avaliação da viabilidade e vigor de sementes de cebola (Allium cepa L.). Pelotas, 1993. 61p. Disssertação (M.S.) - Universidade Federal de Pelotas.

LIMA, W.A.A.; DIAS, D.C.F.S.; BACCO, M.G. Teste de envelhecimento acelerado na avaliação do vigor de sementes de quiabo. Informativo ABRATES, v.7, n.1/2, p.179, 1997. 
LOEFFLER, T.M. The bulk conductivity test as an indicator of soybean seed quality. Lexington, 1981. 181p. Dissertation (M.S.) - University of Kentucky.

LOEFFLER, T.M.; TEKRONY, D.M.; EGLI, D.B. The bulk conductivity test as an indicator of soybean seed quality. Journal of Seed Technology, v.12, n.1, p.37-53, 1988.

LOOMIS, E.L.; SMITH, O.E. The effect of artificial aging on the concentration of $\mathrm{Ca}, \mathrm{Mg}, \mathrm{Mn}, \mathrm{K}$, and $\mathrm{Cl}$ in imbibing cabbage seed. Journal of American Society of Horticultural Science, v.105, n.5, p.647-650, 1980.

LOTT, J.N.A.; CAVDEK, V.; CARSON, J. Leakage of $\mathrm{K}, \mathrm{Mg}, \mathrm{Cl}$, $\mathrm{Ca}$ and $\mathrm{Mn}$ from imbibing seeds, grains and isolated seed parts. Seed Science Research, v.1, n.4, p.229-233, 1991.

MARCOS FILHO, J. Qualidade fisiológica e maturação de sementes de soja (Glycine max (L.) Merrill). Piracicaba, 1979. 180p. Tese (Livre-Docência) Escola Superior de Agricultura "Luiz de Queiroz", Universidade de São Paulo.

MARCOS FILHO, J. O valor dos testes de vigor. Seed News, n.6, p.32, jul/ago. 1998.

MARCOS FILHO, J. Teste de envelhecimento acelerado. In: KRZYZANOWSKI, F.C.; VIEIRA, R.D.; FRANÇA NETO, J.B. (Eds.). Vigor de sementes: conceitos e testes. Londrina: ABRATES, 1999b. cap.3, p.1-24. 
MARCOS FILHO, J. Testes de vigor: importância e utilização. In: KRZYZANOWSKI, F.C.; VIEIRA, R.D.; FRANÇA NETO, J.B. (Eds.). Vigor de sementes: conceitos e testes. Londrina: ABRATES, 1999a. cap.1, p.121.

MARCOS FILHO, J.; CICERO, S.M.; SILVA, W.R. Avaliação da qualidade das sementes. Piracicaba: FEALQ, 1987. 230p.

MARCOS FILHO, J.; SILVA, W.R. NOVEMBRE, A.D.C.; CHAMMA, H.M.C.P. Estudo comparativo de métodos para avaliação da qualidade fisiológica de sementes de soja, com ênfase ao teste de condutividade elétrica. Pesquisa Agropecuária Brasileira, v.25, n.12, p.1805-1815, 1990.

MARCOS FILHO, J.; NOVEMBRE, A.D.C.; CHAMMA, H.M.C.P. Testes de envelhecimento acelerado e deterioração controlada para avaliação do vigor de sementes de soja. Scientia Agricola, v.58, n.2, p.421-426, 2001.

MARCOS FILHO, J.; AMORIM, H.V.; SILVAROLA, M.B.; PESCARIN, H.M.C. Relação entre germinação, vigor e permeabilidade das membranas celulares durante a maturação de sementes e soja. In: SEMINÁRIO NACIONAL DE PESQUISA DE SOJA, 2., Brasília, 1981. Anais. Londrina: EMBRAPA, CNPSo, 1982. p.676-683.

MARCOS FILHO, J.; PESCARIN, H.M.C.; KOMATSU, Y.H.; DEMÉTRIO, C.G.B.; FANCELLI, A.L. Testes para avaliação do vigor de sementes de soja e suas relações com a emergência das plântulas em campo. Pesquisa Agropecuária Brasileira, v.19, n.5, p.605-613, 1984. 
MARTINS, L.; SPINOLA, M.C.M.; CALIARI, M.F.; TESSARIOLI NETO, J. Comparação entre métodos para avaliação do vigor de sementes de cenoura (Daucus carota L.). In: SEMINÁRIO PANAMERICANO DE SEMILLAS, 15., Gramado, 1996. Anais. Gramado: CESM; ELAS, 1996. p.20.

MATTHEWS, S. Controlled deterioration: a new vigour testfor crop seeds. In: HEBBLETHWAITE, P.D. (Ed.). Seed production. London: Butterworths, 1980. p 647-660.

MATTHEWS, S.; BRADNOCK, W.T. The detection of seed samples of wrinkleseed peas (Pisum sativum L.) of potentially low planting value. Proceedings of the International Seed Testing Association, v.32, p.553563, 1967.

MATTHEWS, S.; POWELL, A.A. Electrical conductivity test. In: PERRY, D.A. (Ed.). Handbook of vigour test methods. Zürich: ISTA, 1981. p.37-42.

MATTHEWS, S.; POWELL, A.A. Controlled deterioration test. In: PERRY, D.A. (Ed.). Handbook of vigour test methods. Zürich: ISTA, 1987. p.49-56

McCORMAC, A.C.;KEFFE, P.D. Cauliflower seed vigour: imbibition effects. Journal of Experimental Botany, v.41, n.228, p.893-899, 1990.

McDONALD, M.B. Improving our understanding of vegetable and flower seed quality. Seed Technology, v.20, n.2, p.121-124, 1998.

McDONALD, M.B.; WILSON, D.O. An assesment of the standardization and ability of the ASA-610 to rapidly predict potential soybean germination. Journal of Seed Technology, v.4, n.2, p.1-11, 1979. 
McKERSIE, B.D.; STINSON, R.H. Effect of dehydration on leakage and membrane structure in Lotus corniculatus L. seeds. Plant Physiology, v.66, n.2, p.316-320, 1980.

MELLO, S.C.; SPINOLA, M.C.M.; MINAMI, K. Métodos de avaliação da qualidade fisiológica de sementes de brócolos. Scientia Agricola, v.56, n.4, p.1151-1155, 1999.

MENDONÇA, E.A.F.; RAMOS, N.P.; FESSEL, S.A.; SADER, R. Teste de deterioração controlada em sementes de brocoli (Brassica oleraceae L.) var. italica. Revista Brasileira de Sementes, v.22, n.1, p.280-287, 2000.

MENÊZES, J.E.; NASCIMENTO, W.N. Teste de envelhecimento precoce em sementes de ervilha (Pisum sativum L.). Horticultura Brasileira, v.6, n.1, p.63, 1988.

MENEZES, N.L.; SILVEIRA, T.L.D.; STORCK, L. Efeito do nível de umedecimento do substrato sobre a germinação de cucurbitaceas. Ciência Rural, v.23, n.2, p.157-160, 1993.

MULLET, J.H.; WILKINSON, R.I. The relationship between amounts of electrolyte lost on leaching seeds of Pisum sativum and some parameters of plant growth. Seed Science and Technology, v.7, n.3, p.393-398, 1979.

MURPHY, J.B.; NOLAND, T.L. Temperature effects on seed imbibition and leakage mediated by viscosity and membranes. Plant Physiology, v.69, n.2, p.428-431, 1982. 
NAKAGAWA, J. Testes de vigor baseados no desempenho das plântulas. In: KRZYZANOWSKI, F.C.; VIEIRA, R.D.; FRANÇA NETO, J.B. (Ed.). Vigor de sementes: conceitos e testes. Londrina: ABRATES, 1999. cap.2, p.1-24.

NAKAGAWA, J. Testes de vigor baseados na avaliação das plântulas. In: VIEIRA, R.D.; CARVALHO, N.M. (Ed.). Testes de vigor de sementes. Jaboticabal: FUNEP, 1994. p.49-85.

NASCIMENTO, W.M.; BARROS, B.C.G.; PESSOA, H.B.S.V. Teste de envelhecimento acelerado em sementes de tomate. Revista Brasileira de Sementes, v.15, n.2, p.251-253, 1993.

NOVEMBRE, A.D.L.C.; DIAS, D.C.F.S.; CHAMMA, H.M.C.P.; MARCOS FILHO, J. Estudo da metodologia dos testes de envelhecimento acelerado e de condutividade elétrica para sementes de tomate. Informativo ABRATES, v.3, n.3, p.140, 1995.

OLUOCH, M.O.; WELBAUM, G.E. Effect of postharvest washing and posstorage priming on viability and vigour of six-year-old muskmelon (Cucumis melo L.) seeds from eight stages of development. Seed Science and Technology, v.24 n.2, p.195-209, 1996.

OSMAN, O.A.; GEORGE, R.A.T. Controlled deterioration as a vigour test for sweet pepper seed. Acta Horticulturae, n.218, p.109-114, 1988.

PANDEY, D.K. Ageing of French bean seeds at ambient temperature in relation to vigour and viability. Seed Science and Technology, v.17, n.1, p.41-47, 1989. 
PANOBIANCO, M. Avaliação do potencial fisiológico de sementes de tomate. Piracicaba, 2000. 152p. Tese (Doutorado) - Escola Superior de Agricultura "Luiz de Queiroz", Universidade de São Paulo.

PANOBIANCO, M.; MARCOS FILHO, J. Comparação entre métodos para avaliação da qualidade fisiológica de sementes de pimentão. Revista Brasileira de Sementes, v.20, n.2, p.306-310, 1998.

PANOBIANCO, M.; MARCOS FILHO, J. Envelhecimento acelerado e deterioração controlada em sementes de tomate. Scientia Agricola, v.58, n.3, p.525-531, 2001.

PANOBIANCO, M.; VIEIRA, R.D.; KRZYZANOWSKI, F.C.; FRANÇA NETO, J.B. Electrical conductivity of soybean seed and correlation with seed coat lignin content. Seed Science and Technology, v.27, n.3, p.945-949, 1999.

PANOBIANCO, M.;VIEIRA, R.D. Electrical conductivity of soybean soaked seeds: I - Effect of genotype. Pesquisa Agropecuária Brasileira, v.31, n.9, p.621-627, 1996.

PERRY, D.A. Report of vigour test committee 1979-1980. Seed Science and Technology, v.9, n.1, p.115-126, 1981.

PESIS, E.; TIMOTHY, J.N. Viability, vigor, and electrolytic leakage of musmelon seeds subjected to accelerated aging. Hortscience, v.18, n.2, p.242-244, 1983.

PIANA, Z.; TILLMANN, M.A.A.; MINAMI, K. Avaliação da qualidade fisiológica de sementes de cebola e sua relação com a produção de mudas vigorosas. Revista Brasileira de Sementes, v.17, n.2, p.149-153, 1995. 
POWELL, A.A. Cell membranes and seed leachate conductivity in relation to the quality of seed for sowing. Journal of Seed Technology, v.10, n.2, p.81$100,1986$.

POWELL, A.A. The controlled deterioration test. In: VAN DER VENTER, H.A. (Ed.). Seed vigour testing seminar. Copenhagen: The International Seed Testing Association, 1995. p.73-87.

POWELL, A.A.; MATTHEWS, S. The influence of testa condition on the imbibition and vigour of pea seeds. Journal of Experimental Botany, v.30, n.114, p.193-197, 1979.

POWELL, A.A.; MATTHEWS, S. Evaluation of controlled deterioration, a new vigour test for small seeds vegetables. Seed Science and Technology, v.9, n.2, p.633-640, 1981.

POWELL, A.A.; FERGUSON, A.J.; MATTHEWS, S. Identification of vigour differences among combining pea (Pisum sativum) seed lots. Seed Science and Technology, v.25, n.3, p.443-464, 1997.

PRETE, C.E.C. Condutividade elétrica do exsudato de grãos de café (Coffea arabica L.) e sua relação com a qualidade da bebida. Piracicaba, 1992. 125p. Tese (Doutorado) - Escola Superior de Agricultura "Luiz de Queiroz", Universidade de São Paulo.

RAM, C.; KUMARI, P.; SINGH, O.; SARDANA, R.K. Relationship between seed vigour tests and field emergence in chickpea. Seed Science and Technology, v.17, n.1, p.169-173, 1989. 
RECH, E.G.; VILLELA, F.A.; TILLMANN, M.A.A. Avaliação rápida da qualidade fisiológica de sementes de ervilha. Revista Brasileira de Sementes, v.21, n.2, p.1-9, 1999.

RIBEIRO, F.C.; CARVALHO, N.M. The saturated salt accelerated ageing (SSAA) method seems to act too leniently on carrot (Daucus carota L.), lettuce (Lactuca satica L.), and brocoli (Brassica oleraceae, var. Italica, Plenck) seeds germination. In: CONGRESS OF INTERNATIONAL SEED TESTING ASSOCIATION, 26., Angers, 2001. Abstracts. Angers: ISTA. 2001. p.41-42.

RODO, A.B.; MARCOS FILHO, J. Teste de lixiviação de potássio para aplicação rápida do potencial fisiológico de sementes de cebola. Informativo ABRATES, v.11, n.2, p.183, 2001b.

RODO, A.B.; PANOBIANCO, M.; MARCOS FILHO, J. Metodologia alternativa do teste de envelhecimento acelerado para sementes de cenoura. Scientia Agricola, v.57, n.2, p.289-292, 2000.

RODO, A.B.; PERLEBERG, C.S.; TORRES, S.B.; GENTIL, D.F.O.; TESSARIOLI NETO, J. Qualidade fisiológica e tamanho de sementes de cenoura. Scientia Agricola, v.58, n.1, p.201-204, 2001.

RODO, A.B.; TILLMANN, M.A.A.; VILLELA, F.A.; SAMPAIO, N.V. Teste de condutividade elétrica em sementes de tomate. Revista Brasileira de Sementes, v.20, n.1, p.29-38, 1998a. 
ROSSETO, C.A.V.; FERNANDEZ, E.M.; MARCOS FILHO, J. Metodologias de ajuste do grau de umidade e comportamento das sementes de soja no teste de germinação. Revista Brasileira de Sementes, v.17, n.2, p.171-178, 1995.

SÁ, M.E. Condutividade elétrica em sementes de tomate (Lycopersicon lycopersicum L.). Scientia Agricola, v.56, n.1, p.13-19, 1999.

SAMAD, I.M.A.; PEARCE, R.S. Leaching of onions, organic molecules, and enzymes from seeds of peanut (Arachis hypogea L.) imbibing without testas or with intact testas. Journal of Experimental Botany, v.29, n.113, p.1471$1478,1978$.

SCHMIDT, D.H.; TRACY, W.F. Duration of imbibition affects seed leachate conductivity in sweet corn. HortScience, v.24, n.2, p.346-347, 1989.

SHORT, G.E.; LACY, M.L. Carbohydrate exudation from pea seeds: effect of cultivar, seed age, seed color, and temperature. Phytopathology, v.66, n.2, p.182-187, 1976.

SIDDIQUE, M.A.; GOODWIN, P.B. Conductivity measurements on single seeds to predict the germinability of French beans. Seed Science and Technology, v.13, n.3, p.643-652, 1985.

SIMON, E.W.; MATHAVAN, S. The time-course of leakage from imbibing seeds of different species. Seed Science and Technology, v.14, n.1, p.9-13, 1986.

SIMON, E.W.; RAJA HARUN, R.M. Leakage during seed imbibition. Journal of Experimental Botany, v.23, n.77, p.1076-1085, 1972. 
STRYDOM, A.; VAN DE VENTER, H.A. Comparison of seed vigour tests for cabbage (Brassica oleracea L. var. capitata). Seed Science and Technology, v.26, n.3, p.579-585, 1998.

STYER, R.C.; CANTLIFFE, D.J. Changes in seed structure and composition during development and their effects on leakage in two endosperm mutants of sweet corn. Journal of the American Society Horticultural Science, v.108, n.5, p.721-728, 1983.

TAO, J.K. Factors causing variations in the conductivity test for soybean seeds. Journal of Seed Technology, v.3, n.1, p.10-18, 1978.

TAYLOR, A.G.; LEE, S.S.; BERESNIEWICZ, M.M.; PAINE, D.H. Amino acid leakage from aged vegetable seeds. Seed Science and Technology, v.23, n.1, p.113-122, 1995.

TEBALDI, N.D.; SADER, R.; BIRUEL, R.P.; SCALON, N.J.O.; BALLARIS, A.L.; GAVIOLI, E. Determinação do tempo e da temperatura para o teste de envelhecimento acelerado de sementes de brócolos. (Brassica oleracea L.) var. italica Plenk. In: CONGRESO BRASIEIRO DE SEMENTES, 11., Foz do Iguaçu, 1999. Resumos. Curitiba: ABRATES, 1999. p.120.

TEKRONY, D.M.; EGLI, D.B. Relationship between laboratory indices of soybean seed vigor and field emergence. Crop Science, v.17, n.4, p.573$577,1977$.

TEKRONY, D.M. Accelerated aging. In: VAN DE VENTER, H.A. (Ed.). Seed vigour testing seminar. Copenhagen: The international Seed Testing Association. 1995. p.53-72. 
TEKRONY, D.M. Seed vigor testing - 1982. Journal of Seed Technology, v.8, n.1, p.55-60, 1983.

THORNTON, J.M.; POWELL, A.A.; MATTHEWS, S. Investigation of the relationship between seed leachate conductivity and the germination of Brassica seed. Annals of Applied Biology, v.117, n.1, p.129-135, 1990.

TOMES, L.T.; TEKRONY, D.M.; EGLI, D.B. Factors influencing the tray accelerated aging test for soybean seed. Journal of Seed Technology, v.12, n.1, p.24-36, 1988.

TORRES, S.B. Comparação entre diferentes testes de vigor e a correlação com a emergência no campo de sementes de cebola. Revista Brasileira de Sementes, v.20, n.1, p.65-69, 1998.

TORRES, S.B.; CARVALHO, I.M.S. Teste de envelhecimento acelerado em sementes de quiabo [Abelmoschus esculentus (L.) Moench]. Revista Brasileira de Sementes, v.20, n.1, p.209-211, 1998.

TORRES, S.B.; CASEIRO, R.F.; RODO, A.B.; MARCOS FILHO, J. Testes de vigor em sementes de maxixe (Cucumis anguria L.) com ênfase ao teste de condutividade elétrica. Revista Brasileira de Sementes, v.20, n.2, p.480483, 1998.

TORRES, S.B.; MINAMI, K. Qualidade fisiológica de sementes de pimentão. Scientia Agricola, v.57, n.1, p.109-112, 2000.

TORRES, S.B.; SILVA, M.A.S.; CARVALHO, I.M.S.; QUEIRÓZ, M.A. Correlação entre testes de vigor em sementes de maxixe. Pesquisa Agropecuária Brasileira, v.34, n.6, p.1075-1080, 1999. 
TRAWATHA, S.E; STEINER, J.J.; BRADFORD, K.J. Laboratory vigor tests used to predict pepper seedling field emergence performance. Crop Science, v.30, n.2, p.713-717, 1990.

TRIGO, L.F.N.; TRIGO, M.F.O.O. Avaliação da qualidade fisiológica de sementes de melancia, Citrulus lanatus (Thunb) Mtsum et Nakai. Informativo ABRATES, v.5, n.2, p.129, 1995c.

TRIGO, M.F.O.O.; TRIGO, L.F.N. Avaliação do vigor em sementes de pepino (Cucumis sativus L.). Informativo ABRATES, v.5, n.2, p.131, 1995a.

TRIGO, M.F.O.O.; TRIGO, L.F.N. Determinação da qualidade fisiológica de sementes de cenoura. Informativo ABRATES, v.5, n.2, p.134, 1995b.

VIEIRA, R.D. Teste de condutividade elétrica. In: VIEIRA, R.D.; CARVALHO, N.M. (Eds.). Testes de vigor em semente. Jaboticabal: FUNEP, 1994. p.103-132.

VIEIRA, R.D.; KRZYZANOWSKI, F.C. Teste de condutividade elétrica. In: KRZYZANOWSKI, F.C.; VIEIRA, R.D.; FRANÇA NETO, J.B. (Eds.). Vigor de sementes: conceitos e testes. Londrina: ABRATES, 1999. cap.4, p.1-26.

VIEIRA, R.D.; MINOHARA, L.; PANOBIANCO, M.; BERGAMASCHI, M.C.M.; MAURO, A.O. Comportamento de cultivares de soja quanto a qualidade fisiológica de sementes. Pesquisa Agropecuária Brasileira, v.33, n.2, p.123-130, 1998. 
VIEIRA, R.D.; PANOBIANCO, M.; LEMOS, L.B.; FORNASIERI FILHO, D. Efeito de genótipos de feijão e de soja sobre os resultados da condutividade elétrica de sementes. Revista Brasileira de Sementes, v.18, n.2, p.220224, 1996.

VOLK, W.D.; DILLON, P.F.; COPELAND, L.F.; DILLEY, D.R. Dynamics of imbibition in Phaseolus vulgaris L. in relation to initial seed moisture content. Plant Physiology, v.89, n.3, p.805-810, 1989.

WANG, Y.R.; HAMPTON, J.G.; HILL, M.J. Red clover vigour testing - Effects of three test variables. Seed Science and Technology, v.22, n.1, p.99-105, 1994.

WOODSTOCK, L.W. Seed imbibition: a critical period for successful germination. Journal of Seed Technology, v.12, n.1, p.1-15, 1988.

WOODSTOCK, L.W.; FURMAN, K.; LEFFLER, H.R. Relationship between weathering deterioration and germination, respiratory metabolism, and mineral leaching from cottonseeds. Crop Science, v.25, n.3, p.459-466, 1985.

ZHANG, T.; HAMPTON, J.G. The controlled deterioration test induce dormancy in swede (Brassica napus var. naprobrassica) seed. Seed Science and Technology, v.27, n.3, p.1033-1036, 1999.

ZONTA, E.P.; MACHADO, A.A. Sistema de análise estatística para microcomputadores - SANEST. Pelotas: UFPel, 1984. (Registro SEI no 06606-0, Categoria AO). 